UNIVERSIDADE DE SÃO PAULO

FACULDADE DE ECONOMIA, ADMINISTRAÇÃO E CONTABILIDADE DEPARTAMENTO DE ADMINISTRAÇÃO

PROGRAMA DE PÓS-GRADUAÇÃO EM ADMINISTRAÇÃO

\title{
ESTRATÉGIAS DE DIVERSIFICAÇÃO DE CARTEIRAS DE AÇÕES COM DEPENDÊNCIA ASSIMÉTRICA
}

Daniel Reed Bergmann

Orientador: Prof. Dr. José Roberto Ferreira Savoia

Versão Corrigida

(Versão Original disponível na Faculdade de Economia, Administração e Contabilidade)

SÃO PAULO

2013 
Prof. Dr. João Grandino Rodas

Reitor da Universidade de São Paulo

Prof. Dr. Reinaldo Guerreiro

Diretor da Faculdade de Economia, Administração e Contabilidade

Prof. Dr. Adalberto Américo Fischmann

Chefe do Departamento de Administração

Prof. Dr. Lindolfo Galvão de Albuquerque Coordenador do Programa de Pós-Graduação em Administração 
DANIEL REED BERGMANN

\title{
ESTRATÉGIAS DE DIVERSIFICAÇÃO DE CARTEIRAS DE AÇÕES COM DEPENDÊNCIA ASSIMÉTRICA
}

\author{
Tese apresentada ao Programa de Pós- \\ Graduação em Administração da Faculdade de \\ Economia, Administração e Contabilidade da \\ Universidade de São Paulo, para a obtenção do \\ título de Doutor em Ciências.
}

Orientador: Prof. Dr. José Roberto Ferreira Savoia

Versão Original

SÃO PAULO

2013 
FICHA CATALOGRÁFICA

Elaborada pela Seção de Processamento Técnico do SBD/FEA/USP

Bergmann, Daniel Reed

Estratégias de diversificação de carteiras de ações com dependência assimétrica / Daniel Reed Bergmann. - São Paulo, 2013.

$x x x p$.

Tese (Doutorado) - Universidade de São Paulo, 2013.

Orientador: José Roberto Ferreira Savoia.

1. Administração de carteiras 2. Ações 3. Finanças I. Universidade de São Paulo. Faculdade de Economia, Administração e Contabilidade II. Título.

CDD - 332.6 


\section{AGRADECIMENTOS}

Agradeço ao Prof. Dr. José Roberto Ferreira Savoia, meu orientador, pelo forte incentivo, tutoria, paciência e contribuição essencial ao meu desenvolvimento acadêmico e profissional durante o doutorado e, especialmente, pela amizade e confiança nesses últimos 10 anos. Tivemos reuniões semanais durante todo o ano de 2012 que foram fundamentais para o fechamento deste trabalho. Sou muito grato pelas nossas conversas, pela amizade, e pelas oportunidades de pesquisa em artigos e consultorias. Aprendo muito a cada reunião de trabalho.

Agradeço a toda minha família e amigos pela contribuição de apoio e companheirismo durante o doutorado.

Ao Prof. Dr. José Roberto Securato, membro das bancas de qualificação e de defesa, pelas contribuições valiosas que aperfeiçoaram esse trabalho, pelas disciplinas no programa, e pelas oportunidades propiciadas, acadêmicas e profissionais, por intermédio do LABFIN/PROVAR da FIA e da Saint Paul Escola de Negócios. Sua disciplina de Decisões Financeiras em Condições de Risco no curso de Pós-Graduação do Departamento de Administração da FEAUSP promoveu o direcionamento deste trabalho.

Ao Prof. Dr. Emerson Antônio Maccari pelo convite em trabalhar como professorpesquisador na equipe de excelência do Mestrado Profissional em Gestão de Projetos da UNINOVE. A todos os professores do mestrado profissional da UNINOVE pela amizade e parceria em artigos.

Ao Prof. Dr. Wilson Toshiro Nakamura, pela disposição em participar das bancas de qualificação e de defesa, pelas contribuições valiosas que aprimoraram essa tese e, sobretudo, pela amizade nesses últimos 10 anos e parcerias e oportunidades em artigos científicos. Ao Prof. Dr. Adolpho Walter Pimazoni Canton e ao Prof. Dr. Ricardo Ratner Rochman, pelo aceite da minha banca de defesa de doutorado. 
Ao amigo Prof. Dr. Wesley Mendes-da-Silva que sempre me ligava para perguntar sobre o andamento da tese. Nossas conversas acadêmicas e parcerias foram muito valiosas nesses anos. Ao amigo Prof. Mauri Aparecido de Oliveira, que foi fundamental nas parceiras em artigos, amizade e opiniões sobre este trabalho.

Aos amigos da FEA: André Saito, Contani, Marcela Galeno, Marco, Paiva e Ricardo Serra pela amizade e parcerias realizadas.

À todos da FEA, seu corpo docente, seus funcionários e colaboradores, pela atenção dada e contribuição à formação ao longo dos programas de graduação, mestrado e doutorado. 
"Ignorar o inesperado (ainda que fosse possível) seria viver sem oportunidade, sem espontaneidade e sem os ricos momentos dos quais a vida é feita." 


\section{RESUMO}

DeMiguel, Garlappi e Uppal (2009) fizeram a comparação da regra $1 / \mathrm{N}$ ou de Talmud com 14 modelos de otimização que vieram depois do trabalho de Markowitz (1952). As conclusões mostraram que todos os modelos de alocação ótima analisados tiveram um desempenho inferior ao da regra de Talmud. Tu e Zhou (2011) propuseram uma combinação entre Markowitz e Talmud para que tal modelo superasse Talmud. Os resultados obtidos foram satisfatórios. A desconsideração dos eventos extremos (dependência assimétrica ou caudal) durante o processo de construção de carteiras poderá diminuir as habilidades dos gestores de ativos em reduzir o risco através da diversificação. A modelagem de cópulas sobre os retornos dos ativos nos permite calcular uma alternativa para medir a dependência dos ativos em eventos extremos através do índice de dependência caudal inferior. Hatherley e Alcock (2007) relataram que o modelo de Markowitz tende a subestimar as perdas potenciais que venham a ocorrer na presença de eventos extremos de mercado (crashes) para um determinado nível de retorno esperado. Verificamos se as estratégias com dependência caudal superaram Talmud, o modelo de Markowitz e o modelo de Tu e Zhou (2011) através da simulação de 1.000 carteiras com 3, 5, 10 e 20 ativos escolhidos ao acaso do índice DJIA no período de 03/1990 até 12/2012. Concluímos que os modelos de dependência caudal e o de Markowitz tiveram uma desempenho fora da amostra superior ao Talmud e ao modelo de Tu e Zhou (2011) para as carteiras com 3, 5, 10 e 20 ativos. A estratégia com dependência caudal superou Markowitz, em termos de retorno acumulado, em mais de $60 \%$ dos meses considerados em todas as análises. Os resultados apontam que a regra de Talmud deve ser descartada num contexto de construção de carteiras com ações frente à estratégia com dependência caudal.

\section{Palavras-chave:}

Dependência caudal, diversificação de ativos, coeficiente de correlação e desempenho fora da amostra. 


\begin{abstract}
DeMiguel, Garlappi and Uppal (2009) made a comparison of rule 1 / N or Talmud with 14 optimization models that came after the work of Markowitz (1952). The findings showed that all models of optimal allocation analyzed underperformed the Talmud rule. $\mathrm{Tu}$ and Zhou (2011) proposed a combination between Markowitz and Talmud to overcome such a model Talmud. The results obtained were satisfactory. Disregard of extreme events (asymmetric dependence or flow) during the process of portfolio construction can reduce the skills of asset managers to reduce risk through diversification. The modeling of copulas on asset returns allows us to calculate an alternative to measure the dependence of the assets in extreme events through the index lower tail dependence. Hatherley and Alcock (2007) reported that the Markowitz model tends to underestimate the potential losses that may occur in the presence of extreme market events (crashes) for a given level of expected return. We check that the strategies with tail dependence overcame Talmud rule, the Markowitz model and the model of Tu and Zhou (2011) by simulating 1,000 portfolios with 3, 5, 10 and 20 randomly selected assets from DJIA for the period 03/1990 until 12/2012. We conclude that models of tail dependence and Markowitz had more performance than Talmud and the Tu and Zhou (2011) model for portfolios with 3, 5, 10 and 20 assets. A tail dependence model overcome Markowitz, in terms of cumulative return, in over $60 \%$ of months considered in the analysis. The results indicate that the Talmud rule should be discarded in a context of constructing portfolios with individual stocks ahead strategies with tail dependence.
\end{abstract}

\title{
Keywords:
}

Tail dependence, asset diversification, correlation coeficient and performance. 



\section{SUMÁRIO}

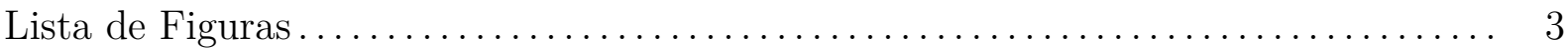

Lista de Tabelas............................................... 5

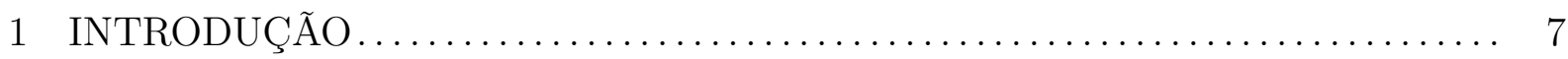

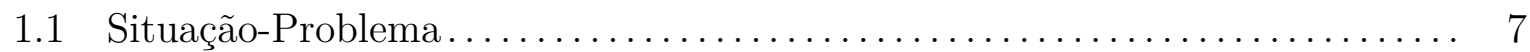

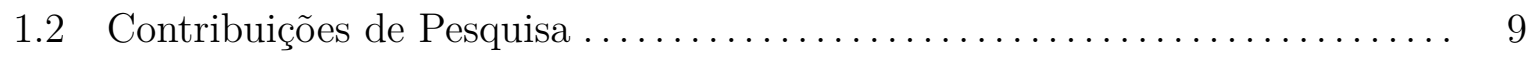

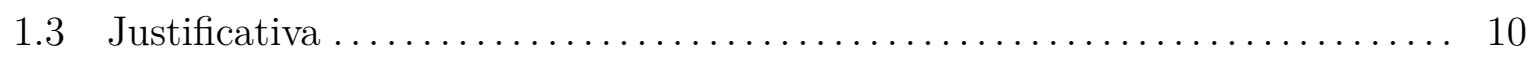

1.4 Objetivos de Pesquisa.................................... 11

1.5 Resumo da Metodologia .................................... 12

1.6 Limitações do Trabalho ......................................... 14

1.7 Estrutura do Trabalho ......................................... 14

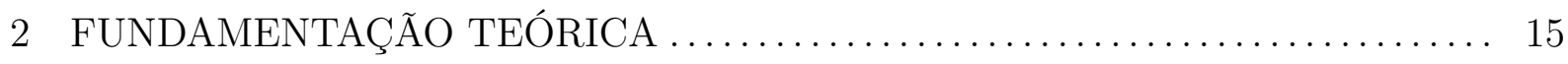

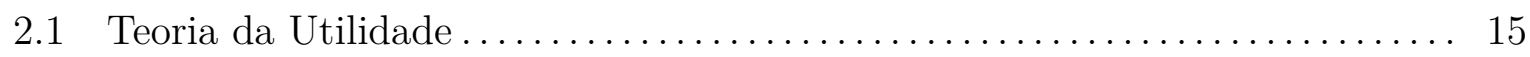

2.1.1 Representação da Utilidade e seus Axiomas.................... 17

2.1.2 Conceito de Risco e Incerteza ........................... 19

2.1.3 Função Utilidade e Equivalente Certo..................... 20

2.1.4 Coeficiente de aversão ao risco . . . . . . . . . . . . . . . . . . . . 22

2.2 Decisões em condições de risco e teoria de Markowitz . ................. 24

2.2.1 Propriedades matemáticas da fronteira eficiente ................ 31

2.2.2 Matriz robusta de covariâncias no modelo de Markowitz ......... 35

2.2.3 Comparação da performance da regra de Talmud com o modelo de Markowitz....................................... 37

2.2.4 Modelo de Tu e Zhou ................................. 40

2.3 Estratégias de diversificação com dependência caudal ou assimétrica....... 43

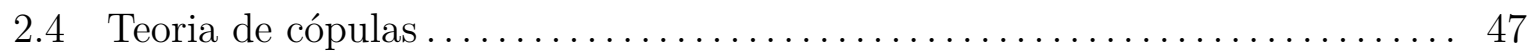

2.4 .1 Função cópula ........................................ 50

2.4 .2 Teorema de Sklar ................................ 50

2.4.2.1 A cópula de Joe-Clayton simetrizada (cópula-SJC) ...... 51

2.4.2.2 A cópula gaussiana.......................... 52

2.4.2.3 Cópulas de valores extremos.................... 53

2.4.2.4 A cópula t-Student.......................... 54

2.4 .3 Medidas de dependência ............................ 55

2.4.4 Coeficiente de correlação linear ...................... 56

2.4.5 Coeficiente de correlação tau de Kendall ................... 58

2.4.6 Coeficiente de correlação de Spearman ........................ 59

2.4 .7 Medidas de dependência de caudas . ....................... 59 


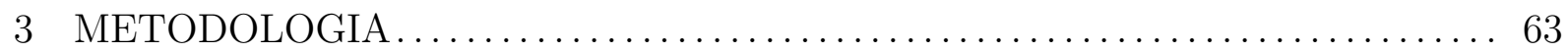

3.1 Hipóteses de Pesquisa .................................... 63

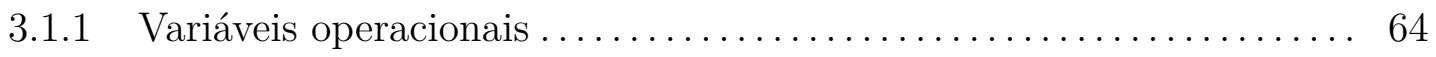

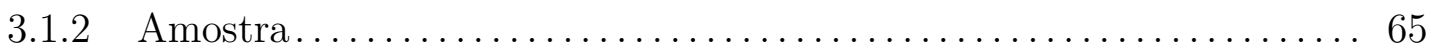

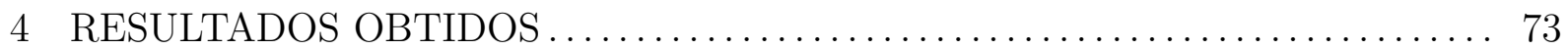

4.1 Resultados obtidos para carteiras formadas com 3 ativos escolhidos

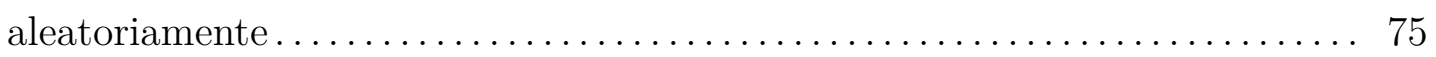

4.2 Resultados obtidos para carteiras formadas com 5 ativos escolhidos

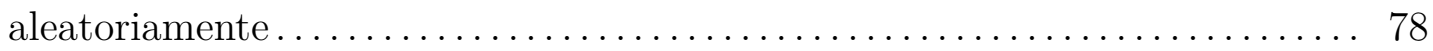

4.3 Resultados obtidos para carteiras formadas com 10 ativos escolhidos

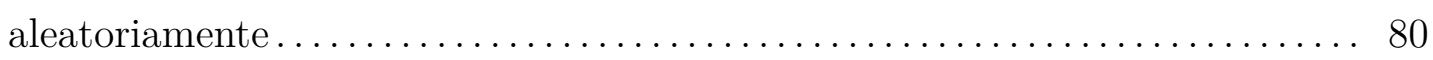

4.3.1 Resultados obtidos para carteiras formadas com 20 ativos escolhidos

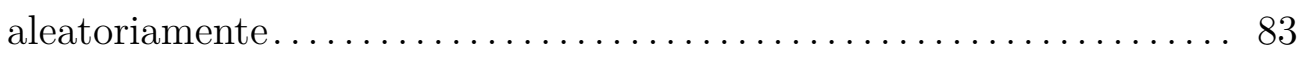

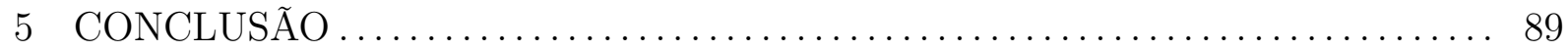




\section{LISTA DE FIGURAS}

2.1 Representação do Risco e da Incerteza numa distribuição de retornos

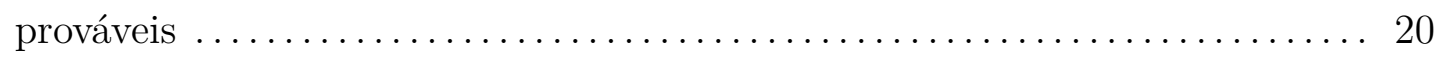

2.2 Representação da função de utilidade côncava e crescente ............... 21

2.3 Representação do equivalente-certo para uma função de utilidade côncava e crescente ............................................ 21

2.4 Exemplo de Curvas de Indiferença conforme os níveis de risco $(\sigma)$ e de

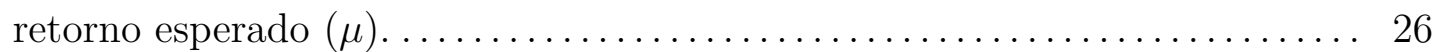

2.5 Fronteira eficiente para três carteiras com os ativos da MSFT, INTC e JNJ

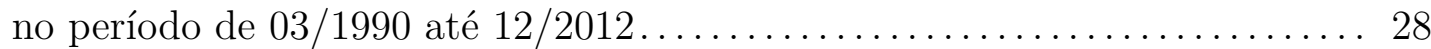

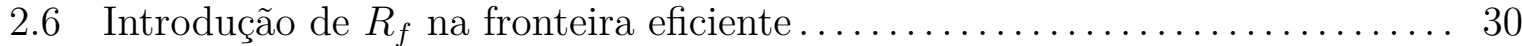

2.7 Exemplo de carteiras na fronteira eficiente sem o ativo livre de risco....... 33

2.8 Fronteira eficiente para as carteiras hipotéticas A, B e C.............. 33

2.9 Fronteiras eficiente do modelo com dependência assimétrica e do MMV clássico. ................................................... 46

2.10 Cópula Gaussiana estimada para os índices de ações da França e da

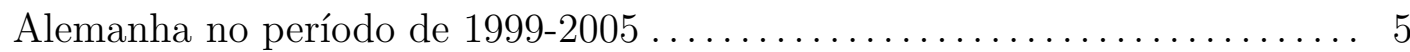

2.11 Cópula-t estimada para os índices de ações da França e da Alemanha no

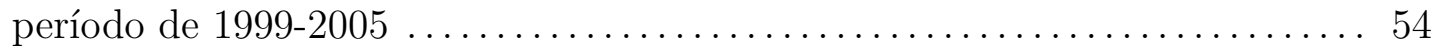

2.12 Dendograma dos 32 pares de países conforme os índices de dependência caudal inferior $\lambda_{L}$ dos pares dos países.

3.1 Evolução dos preços de fechamento das ações BAC, CSCO, CVX e DD no

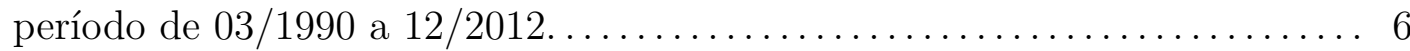

4.1 Média dos retornos acumulados para 1.000 carteiras com 3 ações do DJIA escolhidas aleatoriamente nos 152 meses. . . . . . . . . . . . . . . . . . . 76

4.2 Média dos retornos acumulados para 1.000 carteiras com 5 ações do DJIA escolhidas aleatoriamente nos 152 meses. . . . . . . . . . . . . . . . . . . . . . 79

4.3 Média dos retornos acumulados para 1.000 carteiras com 10 ações do DJIA escolhidas aleatoriamente nos 152 meses........................ 82

4.4 Média dos retornos acumulados para 1.000 carteiras com 20 ações do DJIA escolhidas aleatoriamente nos 152 meses. . . . . . . . . . . . . . . . . . . . . . 85

4.5 Comparação entre o CER do Talmud e o CER da Dependência Caudal para carteiras com 3, 5, 10 e 20 ativos 
4.6 Comparação entre o CER do Tu e Zhou e o CER da Dependência Caudal para carteiras com $3,5,10$ e 20 ativos ...................... 87

4.7 Comparação entre o CER do Tu e Zhou e o CER da regra de Talmud para carteiras com 3, 5, 10 e 20 ativos ........................... 87 


\section{LISTA DE TABELAS}

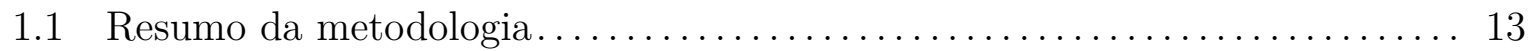

2.1 Paradoxo de Allais............................................ 19

2.2 Comportamento do decisor conforme o coeficente absoluto de aversão ao

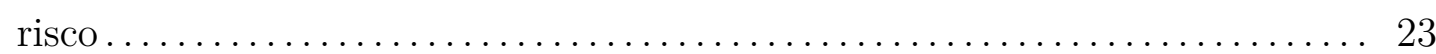

2.3 Comportamento do decisor conforme o coeficiente relativo de aversão ao risco 24

2.4 Coeficientes de correlação de Pearson entre os log-retornos diários dos índices de ações dos países da America Latina no período de 1994-2006. . . 61

2.5 Coeficientes de índices de dependência caudal $\lambda_{U}$ e $\lambda_{L}$ entre os log-retornos diários dos índices de ações dos países da América Latina no período de

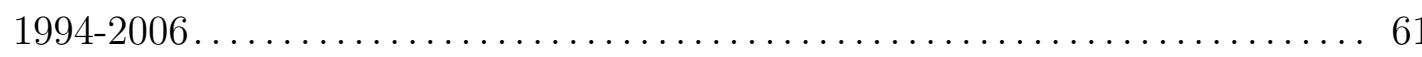

4.1 Estatísticas das 30 ações que compõem o DJIA e para o S\&P 500 no período

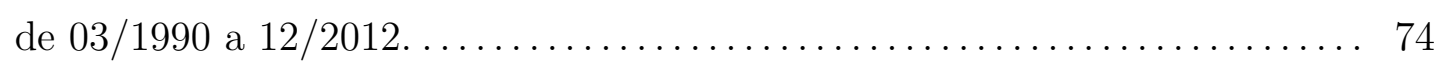

4.2 Resultados médios para 1.000 carteiras de 3 ações escolhidas ao acaso do

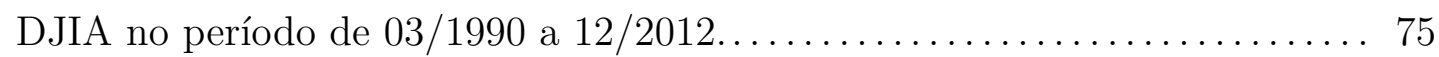

4.3 Comparação entre o CER médio das estratégias com dependência caudal e o CER médio das outras estratégias ao nível de 5\% para as 1.000 carteiras com 3 ações do DJIA escolhidas ao acaso........................ 77

4.4 Resultados encontrados para 1.000 carteiras com 5 ações escolhidas ao acaso do DJIA no período de $03 / 1990$ a $12 / 2012 \ldots \ldots \ldots \ldots \ldots \ldots \ldots \ldots \ldots \ldots . \ldots$

4.5 Comparação entre o CER médio das estratégias com dependência caudal e o CER médio das outras estratégias ao nível de 5\% para as 1.000 carteiras com 5 ações do DJIA escolhidas ao acaso......................... 80

4.6 Resultados encontrados para 1.000 carteiras com 10 ações escolhidas ao acaso do DJIA no período de 03/1990 a 12/2012 .................. 81

4.7 Comparação entre o CER médio das estratégias com dependência caudal e o CER médio das outras estratégias ao nível de 5\% para as 1.000 carteiras com 10 ações do DJIA escolhidas ao acaso.................... 83

4.8 Resultados encontrados para 1.000 carteiras com 20 ações escolhidas ao acaso do DJIA no período de $03 / 1990$ a $12 / 2012 \ldots \ldots \ldots \ldots \ldots \ldots \ldots \ldots . \ldots 4$

4.9 Comparação entre o CER médio das estratégias com dependência caudal e o CER médio das outras estratégias ao nível de 5\% para as 1.000 carteiras com 20 ações do DJIA escolhidas ao acaso....................... 85 


\section{Capítulo 1}

\section{INTRODUÇÃO}

\subsection{Situação-Problema}

O problema da seleção de carteiras é clássico na literatura de finanças pelo trabalho seminal Harry Markowitz de 1952. Mais recentemente, as considerações sob normalidade foram substituídas por modelos mais robustos que incorporam distribuições assimétricas e caudas longas da distribuição dos retornos dos ativos (ALCOCK e HATHERLEY, 2009; HATHERLEY e ALCOCK, 2007).

O relacionamento entre duas ações numa carteira através do coeficiente de correlação linear $(\rho)$ foi a abordagem utilizada pelo modelo de média-variância de Markowitz (MMV) em 1952. Campbell, Koedijk e Kofman (2002, p. 87) declaram que a correlação linear é uma medida apropriada de dependência se os retornos dos ativos seguirem uma distribuição elíptica bivariada como, por exemplo, a distribuição normal ou a tStudent. Pagan (1996) e Rachev, Menn e Fabozzi (2005) mostraram empiricamente que os retornos de ativos frequentemente apresentam caudas gordas, assimetria, fazendo com que o coeficiente de correlação linear não seja uma medida apropriada para avaliar o relacionamento do ativos e, consequentemente, que tenha uma utilização no MMV.

Logo, a matriz de covariâncias utilizada no MMV deve ser ajustada para medir adequadamente o relacionamento existente entre os ativos. Dessa forma, utilizaremos o método de shrinkage proposto por Ledoit e Wolf (2004) no MMV, cuja denominação será dada por MMV robusto. O método de shrinkage adapta as características empíricas dos retornos de ações a fim de que a matriz de covariâncias possa ser utilizada apropriadamente no MMV.

Conforme Tu e Zhou (2011), embora mais da metade de um século tenha se passado desde o artigo seminal de Markowitz (1952), o MMV é ainda o mais utilizado na alocação de ativos e gestão de carteiras apesar de que muitos outros modelos alternativos já tivessem sido desenvolvidos no campo acadêmico [Brandt (2009), Meucci ( 2005) e Litterman (2003)]. As duas principais razões é que o MMV apresenta soluções matemáticas rápidas e eficientes para a maioria dos problemas de alocação de carteiras de ações e a demanda por hedge intertemporal é relativamente pequena nos investimentos de longo prazo. 
Michaud (2008), Duchin e Levy (2009) compararam o desempenho do modelo clássico de Markowitz (1952) com uma regra ingênua, conhecida por regra de Talmud ou regra $1 / N$, que aloca os investimentos em proporções iguais aos $N$ ativos considerados. Já DeMiguel, Garlappi e Uppal (2009) fizeram a comparação da regra 1/N com a maioria das técnicas de otimização que vieram depois do trabalho de Markowitz (1952). Conforme Neto, Leal e Almeida (2011), as conclusões foram devastadoras para todos os modelos de alocação ótima de carteiras de ativos.

Já Tu e Zhou (2011) propuseram que as carteiras de ações fossem formadas por uma combinação linear entre a regra de Talmud com outra estratégia de diversificação como, por exemplo, o MMV. Os resultados mostraram que a combinação linear entre estratégias formaram carteiras de ações mais eficientes àquelas da regra de Talmud. Com tal resultado, os autores afirmaram que o MMV apresenta utilidade para os investidores desde que combinado com a regra de Talmud.

Silvapulle e Granger (2001), Long e Solnik (2001), Ramchand e Susmel (1998), Ang e Bekaert (2002) e Patton (2004) mostraram que os retornos de ações tendem a estar mais correlacionados nos mercados em declínio (bear markets) do que nos mercados em alta (bull markets). Assim, Patton (2006) e Silvapulle e Granger (2001) declararam que é apropriado a inclusão da dependência dos ativos em períodos de alta volatilidade na avaliação do risco da carteira, pois o aumento da correlação entre os ativos em períodos de bear markets tende a diminuir significativamente os benefícios da diversificação. Sabemos que a matriz simétrica das correlações utilizada nos tradicionais modelos de otimização de carteiras como, por exemplo, no MMV, torna-se incompatível com a estrutura empírica das correlações observadas dos ativos em tempos de alta volatilidade. Hatherly e Alcock (2007) incorporaram a dependência assimétrica no modelo MMV por meio dos índices de dependência caudal da teoria de cópula. Esta metodologia sobressai-se a outras abordagens estatísticas no sentido de capturar mais eficientemente a dependência assimétrica dos ativos (MENDES, LEAL e CARVALHAL-DA-SILVA, 2007; PATTON, 2006; CHERUBINI, LUCIANO e VECCHIATO, 2004; ANÉ E KHAROUBI, 2003; BREYMANN, DIAS e EMBRECHTS, 2003).

Estes autores mostraram que a incorporação da dependência assimétrica dos ativos revela que as perdas potencias podem ser maiores com o uso de modelos clássicos na medida em que a fronteira eficiente que considera a dependência assimétrica apresenta um considerável deslocamento para a direita em comparação a fronteira eficiente do modelo de Markowitz. Carteiras determinadas por Markowitz tendem a possuir riscos subestimados pela desconsideração dos eventos extremos de mercado. 
Pelo exposto, torna-se fundamental avaliar se a existência da dependência assimétrica dos ativos pode proporcionar carteiras de ações com maior desempenho em comparação ao modelo $1 / \mathrm{N}$ (regra de Talmud)?

Nesta tese, utilizaremos o retorno em equivalente certo ou, simplesmente, utilidade (CER - certainty-equivalent return) como medida de avaliação do desempenho das carteiras de ações. Vale ressaltar que não se pode comparar o desempenho de ativos quando o índice de Sharpe for negativo. Dessa maneira, a utilidade se mostra adequada para avaliar o desempenho das carteiras de ações mesmo quando seu valor for negativo o que indica uma perda de dinheiro conforme o risco assumido pelo investidor. Como a utilidade aparece em quase todos os problemas de tomada de decisões financeiras no ambiente de incerteza, os resultados obtidos poderão ser aplicados em muitas áreas. As aplicações possivéis seriam em derivativos e na determinação da estrutura ótima de capital (TU e ZHOU, p. 214, 2011).

\subsection{Contribuições de Pesquisa}

As principais contribuições originais desta pesquisa são:

- Melhoria na composição de carteiras de ações sob a existência da dependência assimétrica por meio da cópula de Joe-Clayton Simetrizada. Este fato é de extrema relevância, pois os períodos de alta volatilidade devem ser considerados na formação de carteiras diversificadas (LEAL e MENDES, 2010; ALCOCK e HATHERLEY, 2009; CAMPBELL et al., 2008; HATHERLY e ALCOCK, 2007; LONGIN e SOLNIK, 2001).

- Proposta para avaliar se as estratégias com dependência assimétrica possuem performance superior a regra de Talmud em carteiras formadas com ações do DJIA (Dow Jones Industrial Average) escolhidas ao acaso. Os estudos de Tu e Zhou (2011), DeMiguel, Gallarpi e Uppal (2009) e Disatnik e Benninga (2007) estudaram o comportamento de carteiras de ações que foram construídas com base em outras carteiras de ações sob certos critérios como, por exemplo, book-to-market ratio. Provavelmente, a regra de Talmud se mostrou superior aos modelos de otimização pela diminuição acentuada do risco idiossincrático neste processo e não somente pelo erro de estimação dos modelos. 


\section{$1.3 \quad$ Justificativa}

O problema da seleção de carteiras é clássico na literatura de finanças sendo objeto desde a década de 1960 por Harry Markowitz. Trata-se de um problema de otimização quadrática que envolve a maximização do retorno da carteira e a minimização do risco. Os parâmetros de entrada para o modelo de otimização são: (i) a matriz de covariâncias clássica e (ii) o vetor de médias, que promovem resultados apropriados quando os retornos seguirem uma distribuição normal multivariada. A principal desvantagem da matriz de covariâncias é que ela considera o mesmo peso para todos os valores da amostra em questão. Poon, Rockinger e Tawn (2004) e Patton (2004) afirmaram que uma única observação extrema ou outlier pode ocasionar um aumento significativo no coeficiente $\rho$ com uma consequente subestimação do risco da carteira. Por tal fato, as considerações sob normalidade foram substituídas por modelos mais robustos que incorporam a dependência assimétrica e as caudas gordas da distribuição dos retornos dos ativos (LEAL e MENDES, 2010; ALCOCK e HATHERLEY, 2009; HATHERLEY e ALCOCK, 2007; LEDOIT e WOLF, 2004; PATTON, 2004).

Embretchs, McNeil e Straumann (2001) e Longin e Solnik (2001) identificaram que o relacionamento entre os ativos em dias usuais de mercado pode ser bem diferente do que em períodos extremos. Durante as crises econômico-financeiras, os mercados se tornam muito mais integrados devido ao contágio, e a correlação linear $\rho$ é insuficiente para capturar integralmente como os ativos se relacionam. Patton (2004) e Silvapulle e Granger (2001) afirmaram que a dependência em períodos de alta volatilidade entre os ativos deve ser considerada na avaliação do retorno ajustado ao risco, pois o aumento da correlação entre os ativos em períodos de bear markets tende a diminuir significativamente os benefícios da diversificação.

Na presença de fatores extremos, o coeficiente $\rho$ tende a crescer em módulo, tornando espúrios os resultados de uma diversificação baseadas apenas neste coeficiente. Nestas circunstâncias, a superioridade do índice caudal como fator de diversificação torna-se evidente produzindo melhores resultados no estudo em tela.

Tu e Zhou (2011), DeMiguel, Garlappi e Uppal (2009) e Disatnik e Benninga (2007) não consideraram os efeitos deletérios dos eventos extremos na diversificação dos ativos. Leal e Mendes (2010), Alcock e Hatherley (2009) e Hatherley e Alcock (2007) construiram fronteiras eficientes sob o efeito da dependência assimétrica numa abordagem ex-post. O modelo clássico de Markowitz tende a subestimar as perdas potenciais que venham a ocorrer na presença de eventos extremos de mercado (crashes), pois a fronteira eficiente da estratégia com dependência assimétrica se deslocou para a direita em relação a do 
modelo clássico. Portanto, a escolha de uma metodologia (teoria de cópulas) que permita mensurar como os ativos se relacionam em momentos extremos pretende produzir carteiras com maior utilidade do que a regra de Talmud e o próprio MMV numa abordagem ex-ante.

A originalidade deste trabalho está centrada nos seguintes aspectos:

- Comparação do desempenho de carteiras formadas pela regra de Talmud e por estratégias de dependência caudal;

- Utilização de carteiras de ações escolhidas ao acaso;

- Comparação eficiente dos indicadores de desempenho a partir de testes de hipóteses apropriados.

\subsection{Objetivos de Pesquisa}

O objetivo principal desta tese é verificar se as carteiras de ações formadas pelas estratégias com dependência assimétrica apresentam maior desempenho do que quando são formadas pela regra de Talmud. Leal e Mendes (2010) e Patton (2004) afirmam que os valores extremos das variáveis tendem a se localizar nos cantos da sua distribuição o que proprociona uma superestimação do coeficiente de correlação $\rho$, pois há um desvio da condição de distribuição gaussiana. Em outras palavras, o grau de associação entre os retornos dos ativos pode ser realmente muito menor em condições normais de mercado do que o demonstrado pelo coeficiente de correlação $\rho$ quando da presença de eventos extremos. A escolha de métodos que possam aferir a dependência em momentos extremos são trabalhados nesta tese na tentativa de obter carteiras com maior utilidade (retorno ajustado ao risco). Em relação aos objetivos específicos, pretende-se: (i) Determinar a dependência assimétrica dos retornos das ações por meio do índice caudal inferior da cópula de Joe-Clayton Simetrizada (BERGMANN et al., 2011; PATTON, 2006). A medida $\lambda$ servirá de instrumento para a determinação da dependência assimétrica dos ativos conforme preconizado na teoria de cópulas. Dessa forma, o índice $\lambda_{U}$ mede como dois ativos se relacionam em períodos de alta (booms) e o índice $\lambda_{L}$ mede como dois ativos se relacionam em períodos de grande declínio (crashes). Conforme Patton (2006), a cópula de Joe-Clayton Simetrizada é a mais adequada para medir o relacionamento dos ativos financeiros em condições de alta volatilidade, pois permite que $\lambda_{L}$ possa ser maior do que $\lambda_{U}$, ou seja, duas ações podem ser mais dependentes em crashes do que em booms, que é um fato clássico na literatura financeira (PATTON, 2004; ANG E BEKAERT, 2002; SILVAPULLE E GRANGER, 2001; LONG E SOLNIK, 2001; RAMCHAND E SUSMEL, 1998) e (ii) Verificar se as carteiras de ações formadas pelas estratégias com dependência 
assimétrica apresentam maior desempenho ex-ante do que quando são formadas pelo MMV robusto e ao modelo de Tu e Zhou.

\subsection{Resumo da Metodologia}

Abaixo se encontra os principais procedimentos metodológicos a serem adotados nesta tese conforme o problema de pesquisa e os objetivos declarados. Os estudos de Tu e Zhou (2011), DeMiguel, Garlappi e Uppal (2009), Alcock e Hatherley (2009), Hatherley e Alcock (2007) e Ledoit e Wolf (2004) trabalharam com retornos mensais e janela de estimação com 60 ou 120 meses para a determinação do vetor de médias e matriz de covariâncias. Formaremos 1.000 carteiras de ações para 3, 5, 10 e 20 ativos escolhidos ao acaso do índice DJIA no período de 03/1990 até 12/2012. O intuito é verificar se a regra de Talmud apresenta uma performance crescente quando a quantidade de ativos aumenta devido ao erro de estimação das médias, da matriz de covariâncias e da matriz $\lambda_{L}$. A janela de estimação conterá 120 observações mensais a fim de determinar os parâmetros já destacados. 


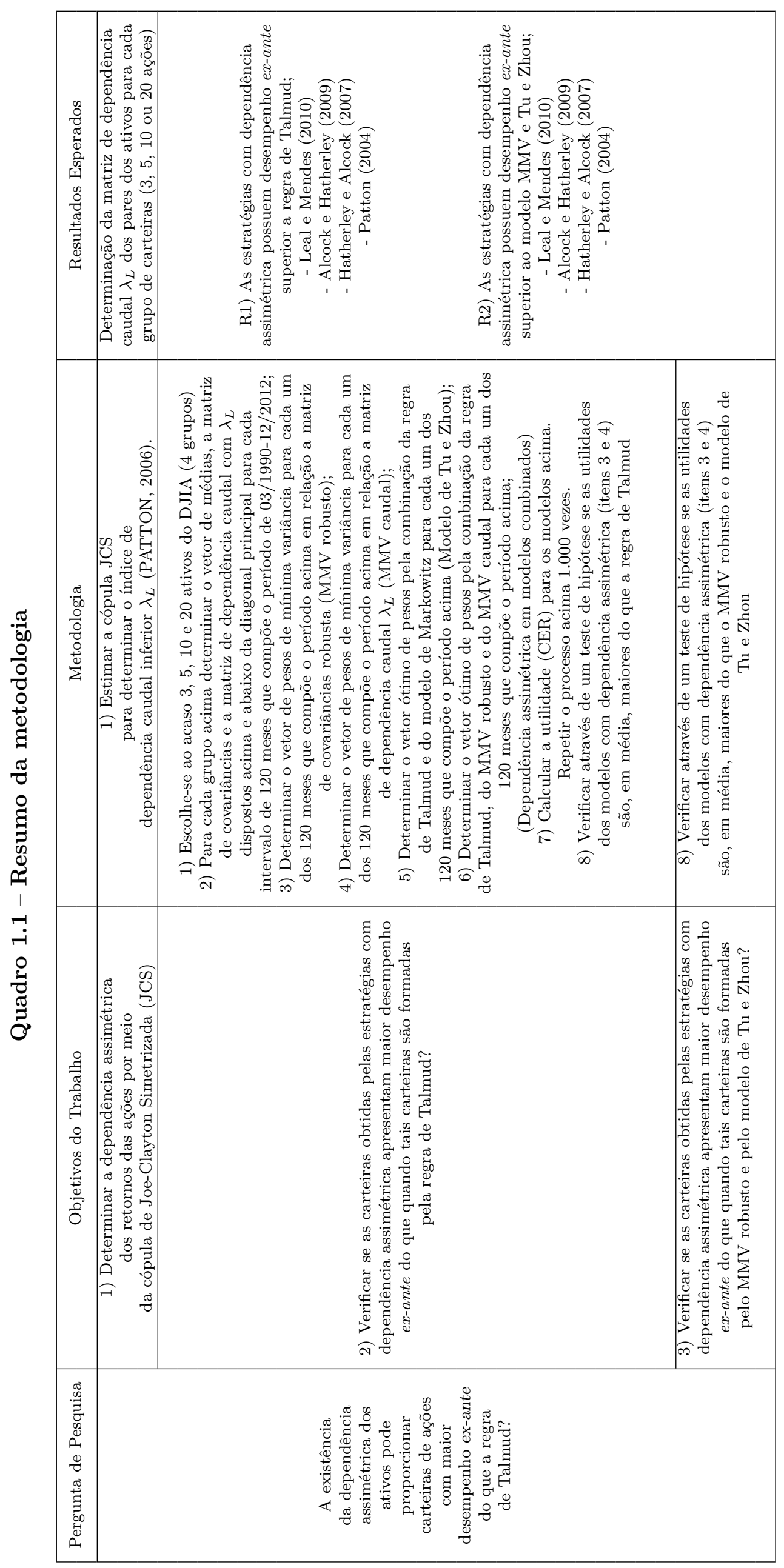




\subsection{Limitações do Trabalho}

As principais limitações deste estudo seriam:

1. Outros modelos de otimização, como aqueles contemplados em DeMiguel, Garlappi e Uppal (2009), podem apresentar desempenho superior aos modelos que contemplam dependência assimétrica. Este estudo só considerou o MMV e suas extensões, pois é o mais usado na prática e apresenta características computacionais vantajosas;

2. Trata-se de um estudo realizado por simulações de Monte Carlo e, assim, não se desenvolveu uma formulação matemática que demonstre a superioridade dos modelos com dependência assimétrica frente a regra de Talmud;

\subsection{Estrutura do Trabalho}

A estrutura da presente tese é composta de cinco capítulos. Inicia-se com esta Introdução, na qual são expostos o contexto envolvendo o problema de pesquisa, e é explicitada a questão de investigação, bem como, os objetivos, justificativa, principais contribuições e aspectos metodológicos. O Capítulo 2 explora a fundamentação teórica envolvida neste trabalho. Primeiramente, a teoria da utilidade é contemplada para que os conceitos de risco, incerteza, função utilidade, coeficiente de aversão ao risco e, finalmente, o conceito de retorno em equivalente-certo sejam desenvolvidos de forma apropriada. Na sequência, a teoria de Markowitz é desenvolvida no contexto de explorar seus principais aspectos e deficiências, as propriedades matemáticas da fronteira eficiente e a importância da utilização da matriz robusta de covariâncias no problema de otimização. Posteriormente, são apresentadas evidências empíricas de que os modelos de otimização, inclusive o MMV, não produzem carteiras mais eficientes do que a regra de Talmud. Já Tu e Zhou (2011) contemplam estratégias combinadas de diversificação a fim de superar tais evidências devastadoras aos modelos de otimização. A dependência em períodos de alta volatilidade entre os ativos deve ser considerada na formação de carteiras eficientes, pois o aumento da correlação entre os ativos em períodos de bear markets tende a diminuir significativamente os benefícios da diversificação. Assim, explora-se as estratégias de diversificação com dependência assimétrica por meio da teoria de cópulas. A seguir, no Capítulo 3, são descritos os aspectos metodológicos, envolvendo a montagem das bases de dados, a definição das variáveis do estudo e das hipóteses de pesquisa. Os testes empíricos e seus resultados são apresentados no Capítulo 4. Por fim, no Capítulo 5, as considerações finais, as conclusões e as limitações da pesquisa. 


\section{Capítulo 2}

\section{FUNDAMENTAÇÃO TEÓRICA}

\subsection{Teoria da Utilidade}

A hipótese central da teoria da utilidade é a de que agentes tomam suas decisões de investimento objetivando maximizar sua utilidade esperada. Bernoulli (1954) descreve o seguinte exemplo: "De alguma forma, uma pessoa muito pobre obtém um bilhete de loteria que premia, com probabilidades iguais, 20.000 moedas de ouro ou nada".

A pergunta que pode ser feita imediatamente é se esta pessoa avaliará em 10.000 moedas de ouro suas chances de ganhar esta loteria. Será que ela não a venderia por 9.000 moedas de ouro? E se fosse feita a uma pessoa rica uma proposta de comprar o bilhete por 9.000 moedas de ouro? Será que ela recusaria? Talvez não. Fica evidente, portanto, que estas duas pessoas usam regras de decisão completamente diferentes, mesmo a loteria pagando a ambos o mesmo valor monetário. Elas decidem não com base no valor, mas na utilidade que este valor proporciona. Assim, não resta dúvida de que a utilidade do ganho de 1.000 moedas de ouro é muito maior para o homem pobre que para o homem rico.

Esta regra fundamental ficou conhecida como Hipótese ou Princípio de Bernoulli, conforme Borch (1968) e Park e Sharp-Bette (1990, p. 357). De maneira geral, as preferências de um agente econômico possuem uma representação da utilidade esperada se existir uma função $u$ tal que o consumo aleatório $X$ for preferível ao consumo aleatório $Y$ se, e somente se,

$$
E[u(X)]>E[u(Y)]
$$

tal que $E[\cdot]$ é o operador esperança idiossincrático do agente econômico.

Segundo Castro Júnior (2008), o tratamento da utilidade como uma quantidade medida numerciamente foi um tema polêmico até Von Neumann e Morgenstern (1947) tratarem as preferências com o auxílio de probabilidades objetivas quanto às suas ocorrências na natureza. Na década de 1940, a teoria da utilidade esperada já era bicentenária. Às vezes, alguém fazia referência à teoria de Bernoulli, sugerindo que a maximização da utilidade esperada seria um meio adequado de representar as preferências dos indivíduos em condições de incerteza. Porém, a sugestão se encerrava em uma fraqueza: não havia razão para supor que as escolhas dos indivíduos seriam suportadas pela teoria da utilidade 
esperada. Por que especificamente a utilidade esperada seria a medida relevante para representar a tomada de decisões? Por que não utilizar a variância, a amplitude, a curtose ou outras características de uma função de preferências?

Von Neumann e Morgenstern (1947) mostraram que a maximização da utilidade esperada é logicamente equivalente à hipótese de que o comportamento de escolha satisfaz algumas restrições sob a forma de axiomas. Assim, se estes axiomas são satisfeitos, então é possível construir uma função de utilidade esperada que represente as preferências de um indivíduo. A relevância deste resultado é que se estes axiomas são plausíveis, então a hipótese da utilidade esperada também será. E, portanto, pode ser aplicada para modelar o comportamento dos tomadores de decisão.

O primeiro passo da representação é definir um conjunto de resultados possíveis ou conjunto de prêmios de uma situação de escolha. As relações de preferência, bem como sua representação, serão tratadas a seguir:

Definição 1: Seja $X$ um conjunto de alternativas de consumo, o qual chamaremos de plano de consumo. Uma relação binária, descrita como um sub-conjunto de $X \times X$, representado por $P$, é uma coleção de pares de planos de consumo $(x, y)$. Se $(x, y) \in P$, é possível escrever $x \succeq y$ e dizer que $x$ é preferível a $y$. Se $(x, y) \notin P$, então escreve-se $x \nsucceq y$, e diz-se que $x$ não é preferível a $y$.

Definição 2: Tanto $x \succeq y$ quanto $y \succeq x$ podem ser simultaneamente verdadeiros, de forma que é possivel dizer que $x$ é indiferente a $y$, representado simbolicamente por $x \sim y$.

Definição 3: Finalmente, se $x \succeq y$, mas $y \nsucceq x$, diz-se que $x$ é estritamente preferível a y e sua representação é $x \succ y$.

Definição 4: Uma relação binária é dita transitiva se $x \succeq y$ e $y \succeq v$ implicar que $x \succeq v$; ou seja, se $x$ é preferível a y e y é preferível a $v$, então $x$ é preferível $a v$.

Definição 5: Uma relação binária é dita completa se, para quaisquer dois planos de consumo $x$ e $y$, for sabido que $x \succeq y$ ou que $y \succeq x$; ou seja, quaisquer dois planos de consumo sempre podem ser comparados.

Definição 6: Uma relação de preferência é uma relação binária que é ao mesmo tempo transitiva e completa. Entre dois planos de consumo $x$ e $y$, ela é representada por $x \succeq y$. É possível ainda definir uma relação de indiferença e uma relação de preferência estrita entre os planos de consumo $x$ e $y$, representadas, respectivamente, por $x \sim y$ e $x \succ y$. 


\subsubsection{Representação da Utilidade e seus Axiomas}

É possível dizer que uma função $u: X \rightarrow \mathcal{R}$ representa uma preferência $\succeq$ se, para todo $x$ e $y \in X, x \succeq y$ se, e somente se, $u(x) \geq u(y)$. Se a função $u$ representa a relação de preferência $\succeq$, podemos nos referir a ela como função de utilidade e dizer que $\succeq$ possui uma representação sob a forma de utilidade.

Em termos econômicos, é muito mais vantajoso usar o conceito de utilidade que simplesmente o de preferência. Isto porque é mais conveniente expressar a decisão sob a forma de uma maximização de uma função numérica a uma relação de preferências. Caso seja possível garantir a existência de funções de utilidade para toda relação de preferência sem perda de generalidade, conseguir-se-iam resolver situações como: alternativa $a$ é preferível à alternativa $b$ mais que a alternativa $c$ é preferível à alternativa $d$.

Fica, portanto, a pergunta que precisa ser considerada: sob quais circunstâncias uma relação de preferência pode ser representada por uma função de utilidade? Há seis axiomas necessários e suficientes para que uma relação binária de preferência definida sobre um espaço de probabilidades $\mathcal{P}$ possa ter uma representação sob a forma de utilidade esperada. Conforme Bekman e Costa Neto (2002, p. 56), os axiomas são:

Axioma 1 Axioma da Ordenabilidade

$\succ$ é uma relação de preferência sobre $\mathcal{P}$, e dados os prêmios $p$ e $r$, para todo $p, r \in \mathcal{P}$ ou $p \succ r$, ou $p \sim r$, ou $p \prec r$.

Axioma 2 Axioma da Transitividade

Para todo $p, q, r \in \mathcal{P}$, se $p \succ q$ e $q \succ r$, então $p \succ r$.

Axioma 3 Axioma da Continuidade

Para todo $p, q, r \in \mathcal{P}$, se $p \succ q \succ r$, então existe $\alpha \in(0,1)$ tal que $q \sim \alpha p+(1-\alpha) r$.

Este axioma ilustra que, dadas três loterias cuja relação de preferência estrita seja da forma $p \succ q \succ r$, podemos combinar a preferível entre as loterias com a não-preferível $(p, r)$ por meio de um $\alpha \in(0,1)$ de tal forma que a composição de $p$ e $r$ torna-se indiferente à loteria intermediária $q$.

Axioma 4 Axioma da Substitutibilidade 
Para todo $p, q, r \in \mathcal{P}$, se $p \sim q$, então $\alpha p+(1-\alpha) r \sim \alpha q+(1-\alpha) r$ para todo $\alpha \in(0,1)$.

Este axioma também é bastante conhecido como o axioma da independência ou, ainda, como o axioma do cancelamento. Ele pode ser ilustrado com o seguinte exemplo:

Exemplo Sejam duas loterias disponíveis $L_{1}$ e $L_{2}$, que consistem no lançamento de uma moeda com chance $\alpha$ de dar cara. Os prêmios das loterias são definidos a seguir: $L_{1}$ : se der cara, ganha-se $p$, caso contrário, $r . L_{2}$ : se der cara, ganha-se $q$, caso contrário, $r$. Suponha que o apostador prefere $p$ a $q$. Ele pensa: "Se der coroa, ganharei $r$ com certeza, portanto, escolherei $L_{1}$, pois no caso do resultado ser cara, posso receber $p$, que é a minha preferência."

Axioma 5 Axioma da Redutibilidade

Para todo $p, r \in \mathcal{P}$, e $\alpha, \beta \in(0,1),[\alpha p+(1-\alpha) r] \beta+(1-\beta) r \sim \alpha \beta p+(1-\alpha \beta) r$.

Axioma 6 Axioma da Monoticidade

Para todo $p, r \in \mathcal{P}$, e $\alpha, \beta \in(0,1)$, se $p \succ r$, então $\alpha p+(1-\alpha) r \succ \beta p+(1-\beta) r$ se, e somente se, $\alpha>\beta$.

Dentre os seis axiomas apresentados, o da substitutibilidade é frequentemente violado em alguns experimentos. O mais importante deles foi construído por Allais e Hagen (1979), razão pela qual passou a ser conhecido por Paradoxo de Allais.

Considere dois pares de loterias, conforme descritas na Tabela 2.1. Evidências empíricas mostram que a maioria dos decisores, quando confrontados com a Decisão 1, preferem a Loteria A, que lhes dá 100 milhões com certeza ao invés da Loteria B que contém a chance, mesmo que muito pequena, de sair sem ganho algum. Por outro lado, a maioria dos decisores, quando confrontados com a Decisão 2, preferem a Loteria D. Isto faz com que estes decisores cometam uma violação do axioma da substitutibilidade.

Para verificar a violação, faça a diferença entre as utilidades das loterias $A$ e $B$ e entre as loterias $C$ e $D$ :

$$
\begin{aligned}
u(A)-u(B) & =u(\$ 100)-0,1 u(\$ 500)-0,89 u(\$ 100)-0,01 u(\$ 0) \\
= & 0,11 u(\$ 100)-0,1 u(\$ 500)-0,01 u(\$ 0) \\
u(C)-u(D) & =0,11 u(\$ 100)+0,89 u(\$ 0)-0,1 u(\$ 500)-0.9 u(\$ 0)
\end{aligned}
$$


Tabela 2.1 - Paradoxo de Allais

\begin{tabular}{|l|c|l|}
\hline \multirow{2}{*}{ Decisão 1 } & A & Ganhar $\$ 100$ milhões com probabilidade 1 \\
\cline { 2 - 3 } & B & $\begin{array}{l}\text { Ganhar } \$ 500 \text { milhões com probabilidade 0,10 } \\
\text { Ganhar } \$ 100 \text { milhões com probabilidade 0,89 } \\
\text { Ganhar } \$ 0 \text { com probabilidade 0,01 }\end{array}$ \\
\hline \multirow{2}{*}{ Decisão 2 } & C & $\begin{array}{l}\text { Ganhar } \$ 100 \text { milhões com probabilidade 0,11 } \\
\text { Ganhar } \$ 0 \text { com probabilidade 0,89 }\end{array}$ \\
\cline { 2 - 3 } & \multirow{2}{*}{ D } & $\begin{array}{l}\text { Ganhar } \$ 500 \text { milhões com probabilidades } 0,10 \\
\text { Ganhar } \$ 0 \text { com probabilidade } 0,90\end{array}$ \\
\hline
\end{tabular}

$$
=0,11 u(\$ 100)-0,1 u(\$ 500)-0,01 u(\$ 0)
$$

Como as diferenças entre as utilidades dos pares de loterias que compreendem cada decisão são exatamente iguais, não faz sentido algum, além de ser uma violação do axioma da substitutibilidade, escolher as Loterias A e D. Para manter a consistência da sua regra de decisão, ou escolhem-se as Loterias A e C ou as Loterias B e D.

Machina (1982) demonstrou que análises com base na utilidade esperada são robustas a violações do axioma de substitutibilidade, como as encontradas em Allais e Hagen (1979). Mostrou-se que os principais resultados permanecem inalterados quando é assumido que as preferências são suaves, ou seja, que sua função é diferenciável.

\subsubsection{Conceito de Risco e Incerteza}

Existem alguns conceitos com os quais convivemos, quase sempre, de forma natural. $\mathrm{O}$ risco, a certeza e a incerteza são conceitos deste tipo, visto que levamos nossas vidas voltadas para o futuro. Assim, estamos habituados às condições de risco e incerteza. Naturalmente, esta questão torna-se mais importante no mundo dos negócios, onde a avaliação dos riscos é fundamental para a tomada de decisão. Na área financeira, o risco e a incerteza estão presentes em um grande número de decisões do executivo que, em seu conjunto, podem levá-lo ao fracasso ou ao sucesso e, com ele, a própria empresa.

Conforme Ingersoll (1987), risco é o grau de incerteza a respeito de um evento. Para entendermos melhor esta definição, observemos que ela estabelece um conceito relativo que é o grau de incerteza de um evento. Lembremos que um "evento certo", ou seja, que com certeza ocorrerá, é tratado no estudo do cálculo de probabilidades como correspondendo à probabilidade de 100\%; nestas condições, sempre que estivermos diante de eventos que apresentem certo grau de incerteza, podemos estabelecer uma correspondente probabilidade de ocorrência do evento. O risco pode ser definido como a probabilidade de ocorrência do evento gerador da perda econômica. Assim, o risco pode estar em um valor mobiliário, em uma carteira de ativos ou mesmo em uma empresa. Com 
a finalidade de definirmos o risco como uma probabilidade, vamos estabelecer algumas premissas em relação ao problema a ser analisado. Sabemos que o processo decisório tem como principal finalidade chegar a um objetivo prefixado. Consideremos os eventos que podem ocorrer quando nos propomos a atingir nossos objetivos e admitamos que sejam dois tipos:

- Sucessos: são os eventos que nos permitem atingir os objetivos, ou seja, alcançar um determinado benchmark;

- Fracassos: são os eventos que não nos permitem atingir os objetivos, ou seja, alcançar um determinado benchmark

A Figura 2.1 abaixo, adaptada de Castro Junior (2008), busca esclarecer a distinção entre incerteza e risco. A região hachurada à esquerda do valor de referência (benchmark) é a parte utilizada para o cálculo de uma medida de risco, enquanto que toda a distribuição de probabilidades representa a incerteza. Desta forma, toda distribuição de probabilidades que contém em seu domínio valores abaixo do benchmark possui risco.

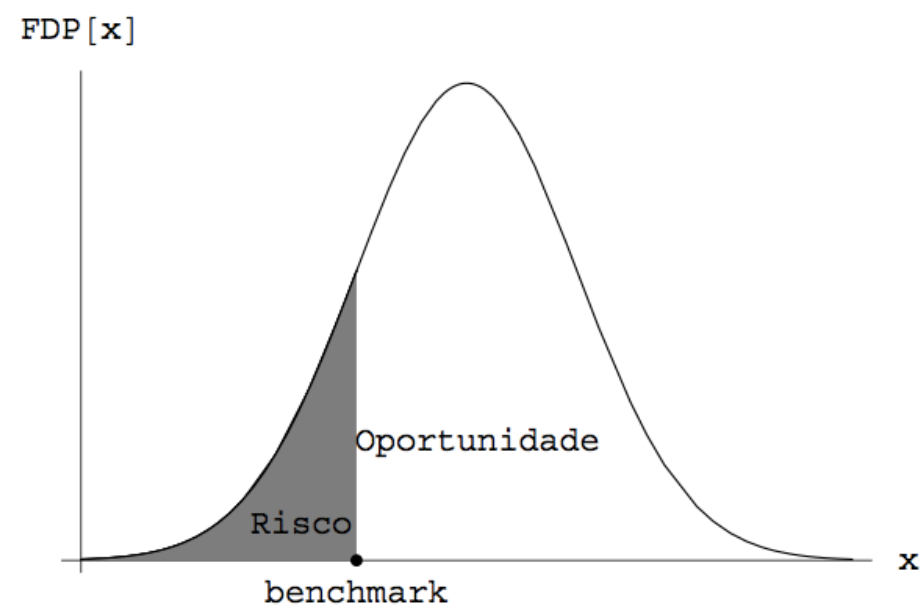

Figura 2.1 - Representação do Risco e da Incerteza numa distribuição de retornos prováveis

\subsubsection{Função Utilidade e Equivalente Certo}

Dado que a utilidade é a variável cuja magnitude relativa indica a direção da preferência, possibilitando assim que se compreendam as escolhas feitas pelo tomador de decisão, a função de utilidade é a função que descreve esse comportamento, ou melhor, a função que indica o grau de satisfação do indivíduo para determinada situação de risco. 


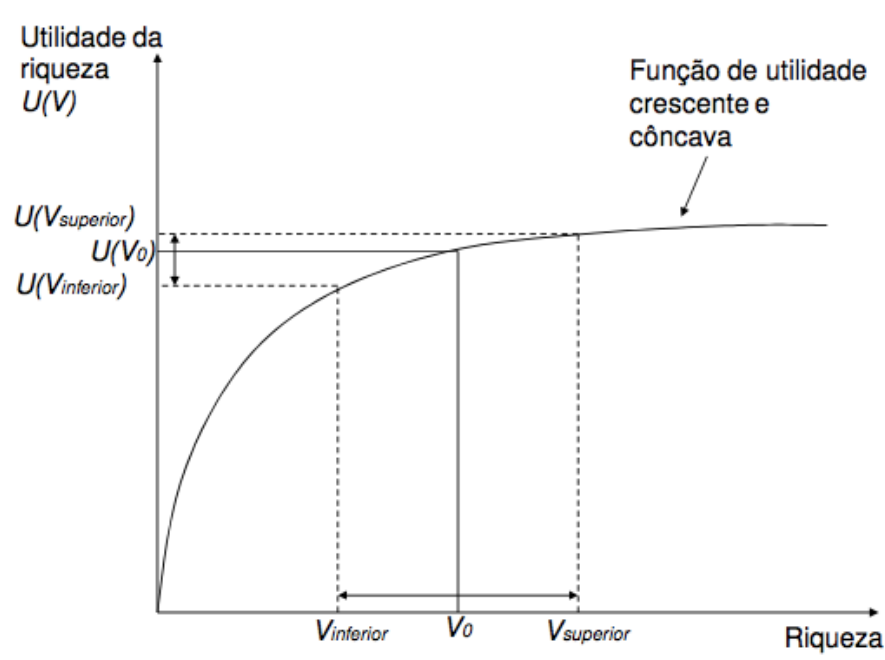

Figura 2.2 - Representação da função de utilidade côncava e crescente

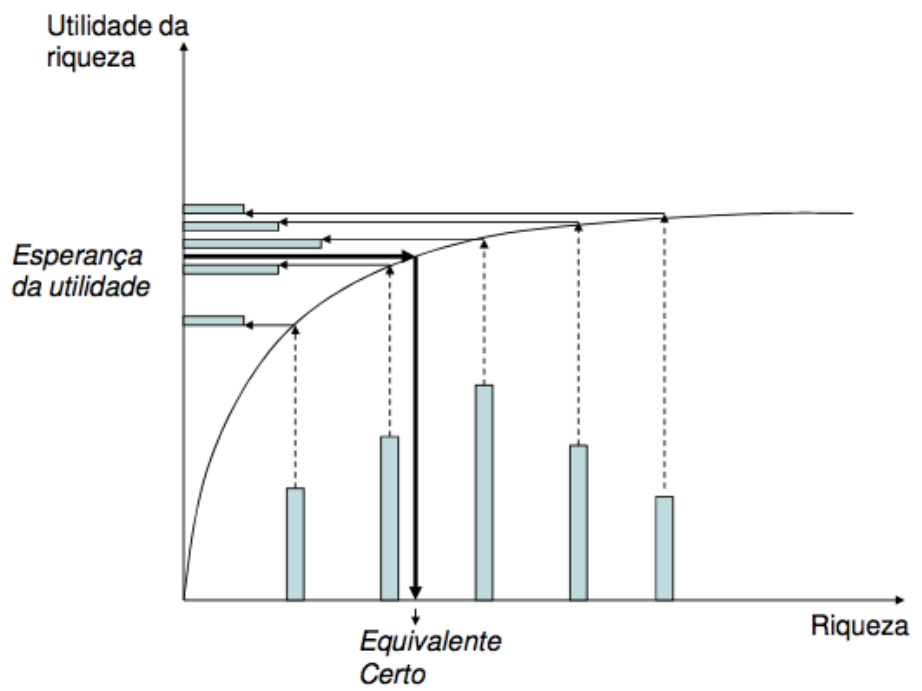

Figura 2.3 - Representação do equivalente-certo para uma função de utilidade côncava e crescente

Como mostra a Figura (2.2), para uma variação de riqueza de mesma amplitude sobre a riqueza média $V_{0}$, obtemos variações de utilidade com amplitudes diferentes. Um acréscimo na riqueza sobre a riqueza média gera um aumento em sua utilidade menor que uma redução sobre a riqueza média de mesma amplitude. Esta característica captura a "aversão ao risco" do investidor.

A maneira com a qual a distribuição de risco da riqueza é avaliada é por meio do equivalente certo (EC ou CEQ). Na Figura, a distribuição da riqueza é dada pelas linhas tracejadas originadas no eixo da riqueza. Assim, cada uma delas corresponde a um nível de riqueza. Cada linha tracejada possui uma probabilidade de êxito, indicada pelas barras verticais, que traz um correspondente valor no eixo vertical mostrando a distribuição 
da utilidade da riqueza. Apesar das linhas tracejadas originadas no eixo horizontal estarem dispostas de maneira simétrica, os correspondentes valores do eixo vertical são assimétricos, com variações menores conforme aumento da riqueza, demonstrando que o investidor dá mais ênfase às perdas do que aos ganhos.

Calculando o valor esperado da utilidade que corresponde ao valor médio no eixo vertical, obtemos, no eixo horizontal, a equivalente certo da riqueza, indicada na Figura (2.3) pela seta em negrito. Importante notar que está abaixo do nível médio da riqueza (linha tracejada central no eixo da riqueza) com risco, e essa diferença é definida como "prêmio pelo risco".

$$
\text { Prêmio pelo risco }=\text { riqueza média }-C E Q
$$

Esse prêmio nada mais é do que uma compensação ao investidor avesso ao risco para que se sinta convencido a assumir ou investir em ativos com determinado nível de risco.

Calcula-se o retorno do equivalente certo (CEQ) como a taxa livre de risco na qual um investidor estaria disposto a investir ao invés de adotar uma estratégia particular com ativos de risco. Formalmente, calcula-se o CEQ de uma estratégia $k$ pela equação abaixo:

$$
\widehat{C E Q}_{k}=\hat{\mu}_{k}-\frac{\gamma}{2} \hat{\sigma}_{k}^{2}
$$

Quanto maior o $\widehat{C E Q}_{k}$, maior será a satisfação em investidor na estratégia de risco $k$. Se uma determinada estratégia de risco $k_{1}$ possuir $\widehat{C E Q}_{k_{1}}$ maior do que o $\widehat{C E Q}_{k_{2}}$ de uma outra estratégia de risco $k_{2}$, a estratégia de risco $k_{1}$ é preferível a estratégia de risco $k_{2}$. $\widehat{C E Q}_{k}$ é adimensional, pois os retornos das ações, que é uma divisão de preços, não possui unidade.

\subsubsection{Coeficiente de aversão ao risco}

Bekman e Costa Neto (2002, p. 69) mencionam que este coeficiente indica qual é o comportamento do decisor, com referência a valores monetários, frente a situações de risco. O coeficiente pode assumir valor positivo, negativo ou nulo.

Um coeficiente positivo indica um agente decisório avesso ao risco. Já o coeficiente negativo, um indivíduo propenso ao risco, e o coeficiente nulo, que pode ser obtido a partir de uma função de utilidade linear, indiferença ao risco. Bekman e Costa Neto (2002) afirmam que o coeficiente de aversão ao risco $a(x)$ é uma grandeza muito útil no estudo dos modelos de utilidade, sendo dado pela seguinte expressão matemática:

$$
a(x)=-\frac{u^{\prime \prime}(x)}{u^{\prime}(x)}
$$


Sendo que $u^{\prime \prime}(x)$ e $u^{\prime}(x)$ correspondem as derivadas de segunda e primeira ordem da função de utilidade $u(x)$. Bekman e Costa Neto (2002) mostra que há ainda o coeficiente absoluto de aversão ao risco $[a(W)]$ e o coeficiente relativo de aversão ao risco $(\gamma)$.

Uma propriedade importante associada ao coeficiente absoluto de aversão ao risco é a de como as preferências do decisor mudam conforme as variações de sua riqueza. Por exemplo: se a riqueza do decisor aumentar, ele investirá mais ou menos em ativos com risco? Ou manterá a mesma quantidade investida? Ou seja, suponha que a riqueza do decisor é $W$ e que ele mantém $W / 2$ investido em um ativo com risco. Agora suponha que sua riqueza aumente para $2 W$. O que ocorrerá com a quantidade investida no ativo com risco? Será mantida em $W / 2$ ? Aumentará? Ou diminuirá?

A resposta a esta pergunta é inerente ao conceito do coeficiente absoluto de aversão ao risco. Se a quantidade, em dinheiro, investida no ativo com risco for mantida, diz-se que ele possui coeficiente absoluto de aversão ao risco constante. Do contrário, se a quantidade, em dinheiro, investida no ativo com risco diminuir, ele possui coeficiente absoluto de aversão ao risco crescente.

A primeira derivada do coeficiente absoluto de aversão ao risco com relação à riqueza é a chave para as distinções entre os comportamentos, permitindo atribuir a eles subclassificações conforme a Tabela abaixo.

Tabela 2.2 - Comportamento do decisor conforme o coeficente absoluto de aversão ao risco

\begin{tabular}{|c|l|c|}
\hline Coeficiente Absoluto & Definição & Propriedade \\
\hline Aversão ao Risco Decrescente & $\begin{array}{l}\text { A medida em que a riqueza } \\
\text { cresce, investe mais dinheiro } \\
\text { em ativos com risco }\end{array}$ & $\frac{d}{d W} a(W)<0$ \\
\hline Aversão ao Risco Constante & $\begin{array}{l}\text { A medida em que a riqueza } \\
\text { cresce, investe a mesma } \\
\text { quantidade de dinheiro em } \\
\text { ativos com risco }\end{array}$ & $\frac{d}{d W} a(W)=0$ \\
\hline Aversão ao Risco Crescente & $\begin{array}{l}\text { A medida em que a riqueza } \\
\text { cresce, investe menos } \\
\text { dinheiro em ativos com risco }\end{array}$ & $\frac{d}{d W} a(W)>0$ \\
\hline
\end{tabular}

Uma pergunta que ainda resta ser discutida é: como a variação de riqueza influencia no percentual dela investido em ativos com risco? Por exemplo: quando a riqueza de um indivíduo é $W$, ele investe $50 \%$ de seu capital no ativo com risco. Quanto será que ele investiria, em termos percentuais de seu capital, no ativo com risco, se sua riqueza 
aumentasse para $2 W ?$

A resposta a estas perguntas repousa no conceito de coeficiente relativo de aversão ao risco $(\gamma)$. O coeficiente relativo refere-se a quanto varia o percentual de riqueza investido no ativo com risco, para variações na riqueza do decisor. Em termos matemáticos, o coeficiente relativo de aversão ao risco é definido como:

$$
\gamma=-W a(W)
$$

Em termos econômicos, pode ser visto como o negativo da elasticidade da utilidade marginal da riqueza $W$. A utilidade marginal é definida por $d u(W) / d W$.

Uma vantagem do coeficiente relativo sobre o absoluto de aversão ao risco é que o primeiro independe da unidade monetária de riqueza. Se este decisor mantivesse os mesmos $50 \%$ de sua riqueza investida no ativo com risco, seu comportamento seria o de quem possui o coeficiente relativo de aversão ao risco constante. Se ele aumentasse o percentual investido no ativo com risco, o coeficiente relativo de aversão ao risco seria decrescente. E, por último, se o percentual investido no ativo com risco diminuísse, ele possuiria coeficiente relativo de aversão ao risco crescente. A Tabela abaixo resume estas possibilidades do $\gamma$.

Tabela 2.3 - Comportamento do decisor conforme o coeficiente relativo de aversão ao risco

\begin{tabular}{|c|c|c|}
\hline Coeficiente Relativo & Definição & Propriedade \\
\hline Aversão ao Risco Decrescente & $\begin{array}{c}\text { À medida em que a riqueza } \\
\text { cresce, investe mais dinheiro } \\
\text { em ativos com risco }\end{array}$ & $\frac{d}{d W} \gamma(W)<0$ \\
\hline Aversão ao Risco Constante & $\begin{array}{c}\text { À medida em que a riqueza } \\
\text { cresce, investe a mesma } \\
\text { quantidade de dinheiro em } \\
\text { ativos com risco }\end{array}$ & $\frac{d}{d W} \gamma(W)=0$ \\
\hline Aversão ao Risco Crescente & $\begin{array}{c}\text { À medida em que a riqueza } \\
\text { cresce, investe menos } \\
\text { dinheiro em ativos com risco }\end{array}$ & \\
\hline \multicolumn{2}{|c|}{} \\
\hline
\end{tabular}

\subsection{Decisões em condições de risco e teoria de Markowitz}

A teoria proposta por Markowitz (1952) contribuiu para formar a base da teoria de carteiras moderna, pois viabilizou a consideração do risco na análise e seleção de 
investimentos. Esta teoria foi traduzida em um modelo que possibilita ao investidor identificar a melhor alternativa de investimento em condições de risco sob a consideração de suas preferências individuais.

Dado o comportamento incerto dos preços dos ativos com risco, os retornos dos ativos são tratados como variáveis aleatórias (v.a.), descritas por seus momentos. Os dois primeiros momentos de uma v.a. são a média e a variância que, do ponto de vista dos investimentos em ativos financeiros, correspondem à expressão do seu retorno esperado, $\mu$ ou $E[R]$, e risco $\sigma^{2}$, respectivamente. Assim, o retorno esperado pode ser calculado da seguinte maneira:

$$
E\left(R_{i}\right)=\bar{R}_{i}=\sum_{j=1}^{M} P_{i j} R_{i j}
$$

sendo que:

$E\left[R_{i}\right]$ é o retorno esperado do ativo $i$;

$P_{i j}$ é a probabilidade do retorno do ativo $i$ para o cenário $j$;

$R_{i j}$ é o retorno realizado do ativo $i$ para o cenário $j$;

Na avaliação de investimentos, é necessário utilizar também uma medida de risco, ou seja, de incerteza, que mensure quanto os resultados diferem do retorno médio. Esta medida é denominada variância, indicada por $\sigma^{2}$ :

$$
\sigma^{2}\left(R_{i}\right)=\sigma_{i}^{2}=\sum_{j=1}^{M}\left(P_{i j}\left(R_{i j}-E\left(R_{i}\right)\right)^{2}\right)
$$

Cabe lembrar que o desvio padrão, que é a raiz quadrada da variância, indicado por $s_{i}$, também pode ser utilizado como parâmetro de estimativa de risco. Parte-se do pressuposto de que a frequência de ocorrência dos retornos ex-post possa ser utilizada para a elaboração das distribuições de retorno ex-ante. Um agente racional que considera o risco de uma oportunidade de investimento atua subjetivamente, de acordo com a sua experiência pessoal. Esta subjetividade não prejudica a análise já que a distribuição de probabilidade que o investidor considera na tomada de decisão reflete exatamente a distribuição de probabilidade determinada objetivamente através da observação de informações históricas. Portanto, o uso da variância ou do desvio padrão ex-post como medida de risco na avaliação de expectativas de retorno não compromete o modelo.

A teoria de carteiras também assume que o investidor conhece as distribuições de probabilidades dos investimentos, considerando a média e a variância dessas distribuições 
no processo de tomada de decisão (SHARPE, 1964, p. 24). Por exemplo, um investidor escolhe entre diferentes carteiras, considerando: (i) se duas carteiras apresentarem o mesmo risco e diferentes retornos esperados, aquela com o maior retorno esperado será a escolhida; (ii) se duas carteiras apresentarem o mesmo retorno esperado e diferentes níveis riscos, aquela com menor risco será a escolhida. Assim, outra premissa da teoria de carteiras é que o investidor prefere maior retorno e menos risco. Esta premissa de que as pessoas procuram sempre minimizar o risco é chamada de aversão ao risco e a literatura aponta que grande parte dos investidores tem aversão ao risco na tomada de decisão.

É interessante distinguir a análise individual de ativos da teoria de carteiras. Segundo Sharpe (1964), a análise de um ativo individual é uma "arte" que requer previsões da situação futura dos ativos na economia. Essas previsões devem levar em consideração a incerteza e o retorno esperado do ativo. Particularmente, a distribuição de probabilidade resultante da análise individual dos ativos deve servir de parâmetro de entrada para a análise de carteiras.

As preferências individuais quanto a risco e retorno são representadas graficamente através de curvas de indiferença, cujos pontos compreendem um mesmo nível de satisfação de um dado indivíduo. As curvas são desenhadas em um plano $(\mu, \sigma)$ de retornos de ativos com risco.

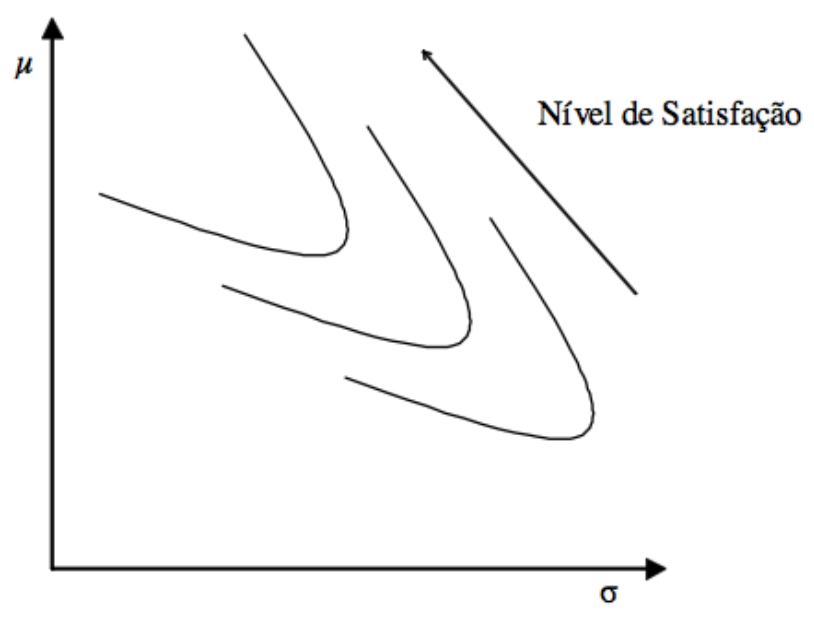

Figura 2.4 - Exemplo de Curvas de Indiferença conforme os níveis de risco $(\sigma)$ e de retorno esperado $(\mu)$.

As várias curvas de indiferença de um dado indivíduo não se interceptam, cada uma delas representando um nível de satisfação. O conjunto de curvas de indiferença de um dado indivíduo forma o chamado mapa de indiferença, sendo que, quanto mais a noroeste estiver a curva de indiferença, mais satisfeitos estarão os investidores. 
Deve-se ter em mente as suposições de insaciedade, isto é, os indivíduos sempre desejam mais riqueza do que menos, sem limites sob determinado nível de aversão ao risco, na qual explica o fato das curvas de indiferença serem convexas e positivamente inclinadas, significando que os investidores avessos ao risco aumentam a sua exigência de retorno quanto mais alto o risco envolvido do investimento considerado.

Já os indivíduos com maior propensão ao risco apresentam curvas de indiferença com formato côncavo e com declividade negativa ao plano $(\mu, \sigma)$. Quanto aos investidores neutros em relação ao risco, suas preferências são representadas por linhas horizontais no plano $(\mu, \sigma)$, significando que, para qualquer nível de risco ficam satisfeitos em receber o mesmo retorno esperado. Ou seja, não importando quanto de risco esteja sendo assumido, o investidor neutro ao risco buscará sempre as alternativas de investimento com maior retorno esperado.

Diante da escolha da melhor carteira dentre as várias alternativas que podem ser consideradas, um investidor escolherá sua carteira ótima no conjunto de carteiras que oferecer: a) mínimo risco a cada nível de retorno esperado, e/ou b) máximo retorno esperado a cada nível de risco.

Denomina-se de conjunto eficiente aquele que satisfaz as condições acima simultaneamente. O conjunto eficiente faz parte do chamado conjunto viável (ou conjunto de oportunidades), que é composto por todas as carteiras que podem ser formadas a partir de um grupo de $N$ ativos. Posteriormente, verificaremos que o conjunto viável sempre será uma região hiperbólica. Este conjunto viável também poderá ser chamado de fronteira eficiente (ou fronteira média-variância). As melhores carteiras em termos de retorno esperado e de desvio padrão estão situados na borda superior do conjunto viável, que corresponde as carteiras com máximo retorno dado um nível de risco, e as carteiras com menor risco dado um nível de retorno. A Figura 2.5 representa um exemplo hipotético de fronteira eficiente gerada no software MATLAB R2009a para os ativos MSFT (Microsoft), INTC (Intel) e JNJ (Johnson \& Johnson) no perído de 03/1990 até 12/2012. A linha azul representa a fronteira eficiente. 


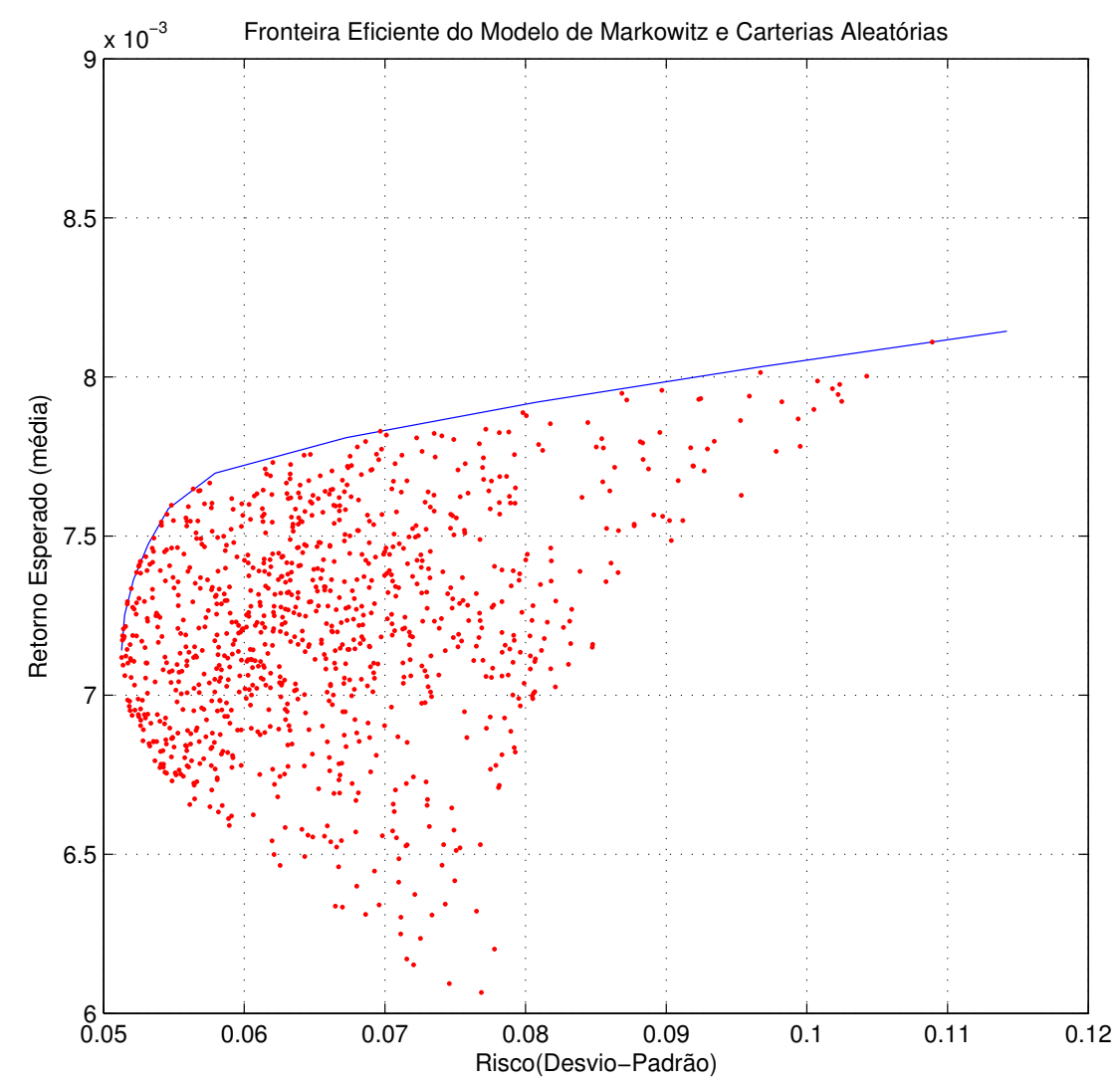

Figura 2.5 - Fronteira eficiente para três carteiras com os ativos da MSFT, INTC e JNJ no período de $03 / 1990$ até $12 / 2012$

A seleção da carteira ótima, para um dado investidor, será dada pelo ponto de tangência entre uma das curvas de seu mapa de indiferença com o conjunto eficiente.

A concavidade do conjunto eficiente é explicada pelo fato de que o desvio padrão de uma carteira geralmente será menor que a média ponderada dos desvios padrão dos ativos na carteira, o que veio a ser chamado de efeito de diversificação.

A fim de explicar melhor o chamado efeito diversificação, convém definir o chamado modelo de mercado, que pressupõe a existência de uma relação linear entre o retorno de um índice de mercado $R_{m}$ (e.g. S\&P 500) e o retorno de uma dada carteira $R_{i}$. Tal relação pode ser expressada da seguinte forma:

$$
R_{i}=\alpha_{i m}+\beta_{i m} R_{m}+\epsilon_{i m}
$$

sendo que $\epsilon_{i m} \sim N\left(0, \alpha_{\epsilon_{i m}}^{2}\right)$. 
A inclinação do modelo de mercado mede a sensibilidade dos retornos da carteira aos retornos da carteira de mercado, e é conhecido como $\beta_{i m}$. O beta de uma carteira pode ser estimado por:

$$
\beta_{i m}=\frac{\operatorname{Cov}\left[R_{i}, R_{m}\right]}{\operatorname{Var}\left[R_{m}\right]}
$$

Aplicando o operador variância nos dois membros de 2.7, obtemos a seguinte equação:

$$
\operatorname{Var}\left[R_{i}\right]=\beta_{i m}^{2} \operatorname{Var}\left[R_{m}\right]+\operatorname{Var}\left[\epsilon_{i m}\right]
$$

Ou seja, o risco total de uma carteira, medido por $\operatorname{Var}\left[R_{i}\right]$, pode ser decomposto em duas partes, uma que corresponde ao risco de mercado (ou sistemático), dado por $\beta_{i m}^{2} \operatorname{Var}\left[R_{m}\right]$, e outra que diz respeito ao risco idiossincrático (ou não-sistemático), dado por $\operatorname{Var}\left[\epsilon_{i m}\right]$.

O risco de uma carteira $R_{p}$ que contenha $N$ ativos pode ser igualmente definido pelos seus componentes de risco sistemático e de risco idiossincrático:

$$
\begin{gathered}
R_{p}=\sum_{i=1}^{N} w_{i} R_{i} \\
R_{p}=\sum_{i=1}^{N} w_{i}\left(\alpha_{i m}+\beta_{i m} R_{m}+\epsilon_{i m}\right) \\
R_{p}=\sum_{i=1}^{N} w_{i} \alpha_{i m}+\sum_{i=1}^{N} w_{i}\left(\beta_{i m} R_{m}\right)+\sum_{i=1}^{N} w_{i} \epsilon_{i m} \\
R_{p}=\alpha_{p m}+\beta_{p m} R_{m}+\epsilon_{p m}
\end{gathered}
$$

Portanto,

$$
\operatorname{Var}\left[R_{p}\right]=\beta_{p m}^{2} \operatorname{Var}\left[R_{m}\right]+\operatorname{Var}\left[\epsilon_{p m}\right]
$$

Conforme 2.14, através do processo de diversificação, pode-se reduzir o risco total da carteira $p$ através da redução de seu componente de risco idiossincrático $\operatorname{Var}\left[\epsilon_{p m}\right]$.

Esta redução do risco idiossincrático de uma carteira diversificada pode ser facilmente obtida, supondo que todos os ativos de uma carteira têm a mesma participação:

$$
\epsilon_{p m}=\sum_{i=1}^{N}\left[\frac{1}{N}\right] \epsilon_{i m}
$$


Aplicando o operador $\operatorname{Var}[$.$] em 2.15, temos:$

$$
\operatorname{Var}\left[\epsilon_{p m}\right]=\left[\frac{1}{N}\right]^{2} \sum_{i=1}^{N} \operatorname{Var}\left[\epsilon_{i m}\right]
$$

Conforme 2.16, quanto maior o número de ativos, menor tende a ser o valor de $\operatorname{Var}\left[\epsilon_{p m}\right]$, o que economicamente é explicado pela compensação entre os riscos exclusivos dos ativos sujeitos a diferentes efeitos diante da ocorrência dos mesmos eventos econômicos (LUENBERGER, 1998, p. 151).

A identificação das carteiras ótimas, ou seja, as que fazem parte do conjunto eficiente, pode ser feita através da aplicação do método de programação quadrática, tal como proposto por Markowitz (1959) no livro Portfolio Selection, em seu capítulo VIII e apêndice A.

A abordagem de Markowitz, definindo a existência do conjunto eficiente, pode ser expandida mediante a introdução da possibilidade de se negociar um ativo livre de risco, isto é, aquele cujos retornos têm desvio padrão igual a zero. Além disso, a covariância entre um ativo livre de risco com qualquer outro ativo de risco é também igual a zero. A possibilidade de se poder investir (comprar) um ativo livre de risco $R_{f}$ expande as oportunidades de conjunto viável, mudando a localização de uma parte substancial do conjunto eficiente de Markowitz, conforme se pode notar logo a seguir.

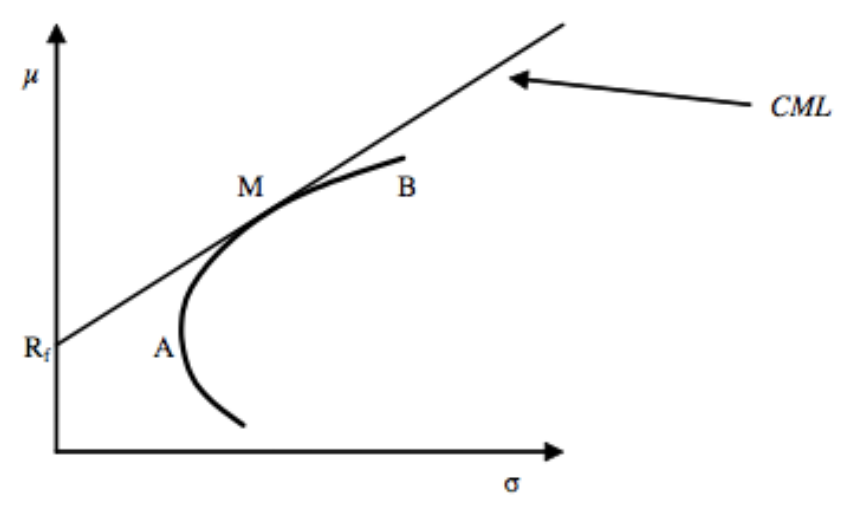

Figura 2.6 - Introdução de $R_{f}$ na fronteira eficiente

A reta exposta na Figura 2.6 mostra todas as possibilidades de um investidor formar suas carteiras com ativos de risco e ativos livres de risco. Ressalta-se que com a adição do ativo livre de risco as carteiras ótimas não se situam mais na fronteira eficiente, mas sim na reta $C M L$ (Capital Market Line). A carteira $M$ é ótima, pois situa na tangente entre a reta CML e a fronteira eficiente. À medida que a aversão ao risco aumenta (ou diminui), 
as carteiras percorrem sobre a reta $C M L$ para a esquerda (ou para a direita). Como exemplo, o ponto B não é uma carteira ótima, pois é possível elaborar uma carteira (com ativos de risco e ativo livre de risco) que possua o mesmo retorno esperado com menor nível de risco. Analogamente, este fato também ocorre com o ponto A.

\subsubsection{Propriedades matemáticas da fronteira eficiente}

As propriedades matemáticas serão mostradas conforme Campbell, Lo e MacKinlay (1997, p. 184-188) e Cochrane (2001, p. 84-86). Primeiramente, iniciaremos com a seguinte notação matemática: Tomemos $N$ ativos com risco com vetor de médias $\underset{(N \times 1)}{\boldsymbol{\mu}}$ e matriz de covariâncias $\underset{(N \times N)}{\Omega}$. Assume-se que os retornos esperados de pelos menos dois ativos diferem e a matriz de covariâncias é de posto completo ${ }^{1}$ Define-se $\boldsymbol{w}_{a}$ como um vetor de pesos para uma carteira arbitrária a com pesos somando 1. A carteira a tem retorno médio $\mu_{a}=\boldsymbol{w}_{a}^{\boldsymbol{T}} \boldsymbol{\mu}$ e variância $\sigma_{a}^{2}=\boldsymbol{w}_{\boldsymbol{a}}^{\boldsymbol{T}} \boldsymbol{\Omega} \boldsymbol{w}_{\boldsymbol{a}}$. A covariância entre duas carteiras $a$ e $b$ é dada por $\boldsymbol{w}_{\boldsymbol{a}}^{\boldsymbol{T}} \boldsymbol{\Omega} \boldsymbol{w}_{\boldsymbol{b}}$. Primeiramente, não consideraremos o ativo livre de risco.

Definição: Carteira $p$ é de variância mínima dentre todas com retorno médio $\mu_{p}$ se o vetor de pesos da carteira $\boldsymbol{w}_{\boldsymbol{p}}$ é a solução para o seguinte problema matemático:

$$
\min \mathbf{w}^{\mathbf{T}} \Omega \mathbf{w}
$$

sujeito a

$$
\begin{gathered}
\boldsymbol{w}^{\boldsymbol{T}} \boldsymbol{\mu}=\mu_{p} \\
\boldsymbol{w}^{\boldsymbol{T}} \boldsymbol{\iota}=1
\end{gathered}
$$

sendo que $w_{i} \geq 0, i=1,2, \ldots, N$ e $\underset{(1 \times N)}{\boldsymbol{\iota}}=[1, \ldots, 1]$.

Para resolver o problema, forma-se o Lagrangiano $\mathcal{L}$ :

$$
\mathcal{L}=\boldsymbol{w}^{T} \boldsymbol{\Omega} \boldsymbol{w}+\delta_{1}\left(\mu_{p}-\boldsymbol{w}^{T} \boldsymbol{\mu}\right)+\delta_{2}\left(1-\boldsymbol{w}^{\boldsymbol{T}} \boldsymbol{\imath}\right)
$$

Calculando a derivada de $\mathcal{L}$ relação a $\boldsymbol{w}$ e igualando a zero, obtemos:

$$
2 \Omega w-\delta_{1} \mu-\delta_{2} \imath
$$

Substituindo 2.18 e 2.19 em 2.21:

$$
\boldsymbol{w}_{p}^{*}=\boldsymbol{g}+\boldsymbol{h} \mu_{p}
$$

\footnotetext{
${ }^{1}$ Posto ou rank de uma matriz é o número de linhas ou colunas linearmente independentes. Ou seja, os valores de uma linha da matriz não podem ser determinados através de uma combinação linear dos valores de outra linha da matriz.
} 
e

$$
\sigma_{p}^{2 *}=\frac{C \mu_{p}^{2}-2 A \mu_{p}+B}{D}
$$

sendo que

$$
\begin{aligned}
& \underset{N \times 1}{\boldsymbol{g}}=\frac{1}{D}\left[B\left(\boldsymbol{\Omega}^{-\mathbf{1}} \boldsymbol{\imath}\right)-A\left(\boldsymbol{\Omega}^{-\mathbf{1}} \boldsymbol{\mu}\right)\right] \\
& \underset{N \times 1}{\boldsymbol{h}}=\frac{1}{D}\left[C\left(\boldsymbol{\Omega}^{-\mathbf{1}} \boldsymbol{\mu}\right)-A\left(\boldsymbol{\Omega}^{-\mathbf{1}} \boldsymbol{\imath}\right)\right]
\end{aligned}
$$

com $A=\boldsymbol{\imath}^{\boldsymbol{T}} \boldsymbol{\Omega}^{-\mathbf{1}} \boldsymbol{\mu}, B=\boldsymbol{\mu}^{\boldsymbol{T}} \boldsymbol{\Omega}^{-\mathbf{1}} \boldsymbol{\mu}, C=\boldsymbol{\imath}^{\boldsymbol{T}} \boldsymbol{\Omega}^{-\mathbf{1}} \boldsymbol{\imath}$, e $D=B C-A^{2}$. Os principais resultados advindos da 2.22 serão mencionados a seguir:

- Como mostrado em $2.23, \sigma_{p}^{2 *}$ é uma função quadrática de $\mu_{p}$. Como a raiz quadrada de uma parábola é uma hipérbole, o espaço formado pela média e pelo desvio padrão dos ativos de uma carteira de fronteira será uma região hiperbólica.

- Qualquer carteira que seja uma combinação linear de pelo menos duas carteiras de mínima variância (ou carteira de fronteira) é igualmente de mínima variância (ou de fronteira). Este resultado vem do fato que $\boldsymbol{w}_{\boldsymbol{p}}^{*}$ é uma função linear de $\mu_{p}$. Dessa forma, se $\mu_{3}=\lambda \mu_{1}+(1-\lambda) \mu_{2}$, então $w_{3}=\lambda w_{1}+(1-\lambda) w_{2}$ (COCHRANE, 2001, p.85).

- Sejam $p$ e $r$ duas carteiras de fronteira. A covariância da carteira $p$ com a carteira $r$ é dada por:

$$
\operatorname{Cov}\left(R_{p}, R_{r}\right)=\frac{C}{D}\left(\mu_{p}-\frac{A}{C}\right)\left(\mu_{r}-\frac{A}{C}\right)+\frac{1}{C}
$$

- Definindo a carteira $g$ como a carteira de fronteira global, temos:

$$
\begin{gathered}
\boldsymbol{w}_{g}=\frac{1}{C} \boldsymbol{\Omega}^{-\mathbf{1}} \boldsymbol{\imath} \\
\mu_{g}=\frac{A}{C} \\
\sigma_{g}^{2}=\frac{1}{C}
\end{gathered}
$$

Para cada carteira de fronteira $p$, exceto a carteira de fronteira global $g$, existe uma única carteira de fronteira que tem covariância zero com $p$, que é denominado de carteira com beta zero em relação a $p$. A covariância da carteira $g$ com qualquer outro ativo ou carteira de ativos $a$ é:

$$
\operatorname{Cov}\left(R_{g}, R_{a}\right)=\frac{1}{C}
$$


As carteiras de fronteira que possuem retorno esperado maior ou igual ao retorno esperado da carteira global $g$ são ditas carteiras eficientes. Pela Figura 2.7, a carteira de fronteira global é a $g$; a carteira $p$ pode ser considerado eficiente e a carteira op pode ser considerado uma carteira zero beta em relação ao $p$. Graficamente, temos:

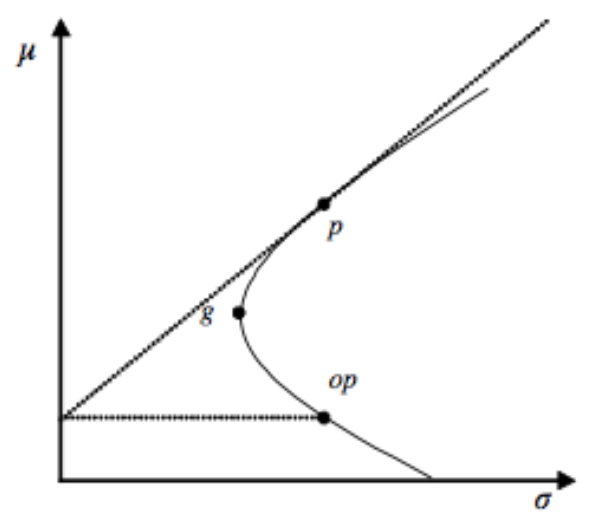

Figura 2.7 - Exemplo de carteiras na fronteira eficiente sem o ativo livre de risco

Exemplo: Sejam três carteiras hipotéticas $A, B$ e $C$ com retornos esperados distintos $\boldsymbol{\mu}=\left[\begin{array}{lll}0.1 & 0.2 & 0.15\end{array}\right]$ e matriz de covariâncias $\boldsymbol{\Omega}=\left[\begin{array}{ccc}0.0100 & -0.0061 & 0.0042 \\ -0.0061 & 0.0400 & -0.0252 \\ 0.0042 & -0.0252 & 0.0255\end{array}\right]$. Utilizaremos a função frontcon ${ }^{2}$ do software MATLAB R2009a a fim de gerar 500 carteiras eficientes. Dessa forma, temos:

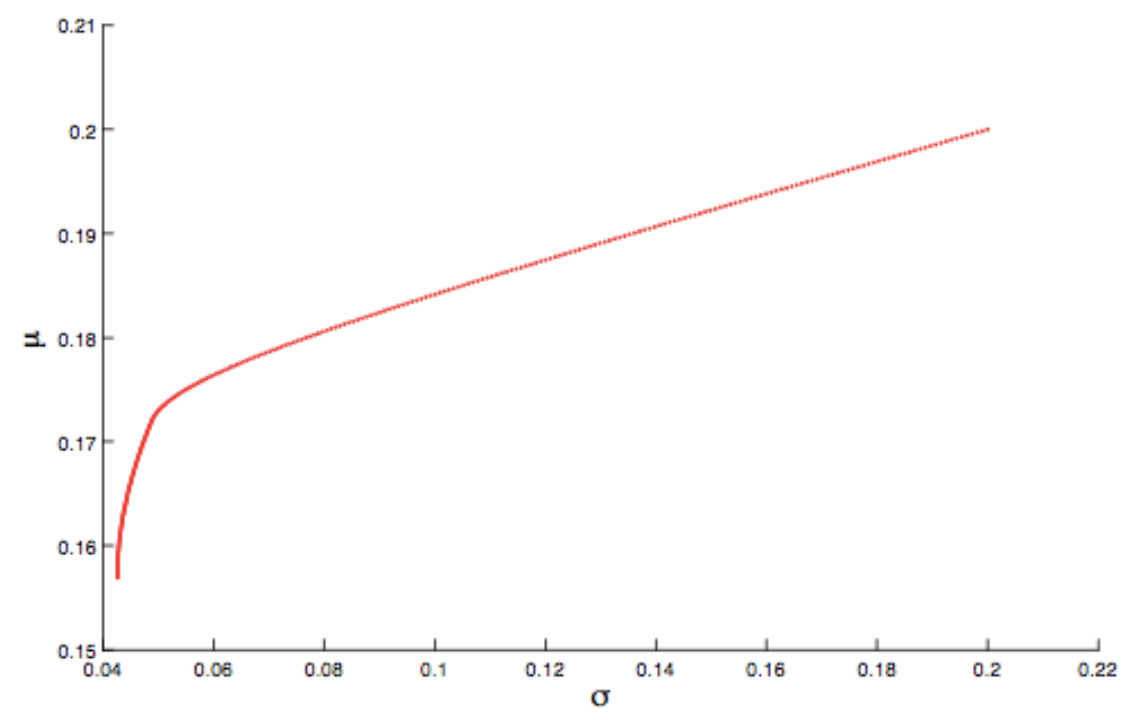

Figura 2.8 - Fronteira eficiente para as carteiras hipotéticas A, B e C.

A seguir, iremos considerar a possibilidade de formar carteiras compostas de $N$ ativos

\footnotetext{
${ }^{2}$ Os parâmetros da função do software MATLAB são o vetor de médias $\boldsymbol{\mu}$, a matriz $\boldsymbol{\Omega}$ e a quantidade de carteiras eficientes a serem geradas
} 
com risco e um ativo livre de risco. Introduzindo um ativo livre de risco no modelo de construção de carteiras, os pesos dos ativos com risco na carteira deixam de estar restritos a totalizar um, uma vez que $\left(\mathbf{1}-\boldsymbol{w}^{T} \boldsymbol{\imath}\right)$ pode ser investido no ativo livre de risco.

Considerando um ativo livre de risco com retorno $R_{f}$, a carteira de fronteira com retorno esperado $\mu_{p}$ será a solução para a otimização restrita:

$$
\min _{\{w\}} w^{T} \Omega w
$$

sujeito a $\boldsymbol{w}^{T} \boldsymbol{\mu}+\left(\mathbf{1}-\boldsymbol{w}^{T} \boldsymbol{\imath}\right) R_{f}=\mu_{p}$.

Para resolver este problema, formamos o lagrangiano $\mathcal{L}$, derivamos com respeito a $w$ e igualamos a zero. Dessa forma, obtemos:

$$
2 \Omega \boldsymbol{w}-\delta\left(\boldsymbol{\mu}-R_{f} \boldsymbol{\imath}\right)=\mathbf{0}
$$

e então,

$$
\boldsymbol{w}_{\boldsymbol{p}}^{*}=\frac{\left(\mu_{p}-R_{f}\right)}{\left(\boldsymbol{\mu}-R_{f} \boldsymbol{\imath}\right)^{T} \boldsymbol{\Omega}^{-\mathbf{1}}\left(\boldsymbol{\mu}-R_{f} \boldsymbol{\imath}\right)} \boldsymbol{\Omega}^{-\mathbf{1}}\left(\boldsymbol{\mu}-R_{f} \boldsymbol{\imath}\right)
$$

Podemos expressar $\boldsymbol{w}_{\boldsymbol{p}}^{*}$ como um escalar que depende da média de $p$, denotada por $c_{p}$, multiplicada por um vetor de pesos da carteira, que não depende de $p$.

$$
\boldsymbol{w}_{p}^{*}=c_{p} \overline{\boldsymbol{w}}
$$

sendo que

$$
\begin{gathered}
c_{p}=\frac{\left(\mu_{p}-R_{f}\right)}{\left(\boldsymbol{\mu}-R_{f} \boldsymbol{\imath}\right)^{T} \boldsymbol{\Omega}^{-1}\left(\boldsymbol{\mu}-R_{f} \boldsymbol{\imath}\right)} \\
\overline{\boldsymbol{w}}=\boldsymbol{\Omega}^{-1}\left(\boldsymbol{\mu}-R_{f} \boldsymbol{\imath}\right)
\end{gathered}
$$

Dessa forma, com um ativo livre de risco $R_{f}$, todas as carteiras na fronteira são uma combinação de uma dada carteira de ativos com risco, com pesos proporcionais a $\overline{\boldsymbol{w}}$, com o ativo sem risco. Esta carteira de ativos com risco é chamada de carteira de tangência $q$ (é a carteira que pertence a fronteira eficiente tangenciando a reta CML) com vetor de pesos $\boldsymbol{w}_{q}^{*}$ igual a:

$$
\boldsymbol{w}_{q}^{*}=\frac{1}{\boldsymbol{\imath}^{\boldsymbol{T}} \boldsymbol{\Omega}^{-1}\left(\boldsymbol{\mu}-R_{f} \boldsymbol{\imath}\right)} \boldsymbol{\Omega}^{-\mathbf{1}}\left(\boldsymbol{\mu}-R_{f} \boldsymbol{\imath}\right)
$$


A equação 2.37 representa os pesos calculados para uma carteira com $N$ ativos que se encontra na fronteira eficiente e também tangencia a $C M L$. A seguir avalairemos a importância em se considerar uma matriz robusta de covariâncias para o cálculo do $\boldsymbol{w}_{\boldsymbol{q}}^{*}$.

DeMiguel, Garlappi e Uppal (2009) compararam diferentes estratégias de diversificação sob um investidor cujas preferências possam ser totalmente descritas pela média $\mu_{t}$ e pela variância $\Sigma_{t}$ de uma determinada carteira, $x_{t}$. Para cada tempo $t$, o tomador de decisão seleciona $x_{t}$ a fim de maximizar a utilidade esperada conforme a expressão abaixo:

$$
\max _{x_{t}} x_{t}^{T} \mu_{t}-\frac{\gamma}{2} x_{t}^{T} \Sigma_{t} x_{t}
$$

sendo que $\gamma$ pode ser interpretado como a aversão ao risco do investidor. A solução da otimização acima é $x_{t}=(1 / \gamma) \Sigma_{t}^{-1} \mu$. O vetor dos pesos da carteira investidos em $N$ ativos com risco no tempo $t$ é:

$$
w_{t}=\frac{\Sigma_{t}^{-1} \mu_{t}}{1_{N} \Sigma_{t}^{-1} \mu_{t}}
$$

Assim, precisamos somente da matriz de covariâncias e do vetor de médias estimados para determinar os pesos ótimos pela equação 2.39. Conforme Ledoit e Wolf (2004) não podemos usar as correlações de Pearson no MMV, pois os retornos de ações não são normais. Logo, há a necessidade de ajuste em $\Sigma_{t}^{-1}$ para considerar que os retornos de ações não são normais e possuem caudas gordas.

\subsubsection{Matriz robusta de covariâncias no modelo de Markowitz}

Disatnik e Benninga (2007) e Ledoit e Wolf (2004) apontam que um dos principais problemas de implementação do MMV advém do erro ocasionado pela estimação da matriz de covariâncias dos retornos dos ativos $\Omega$. Neste caso, há tanto um erro de estimação como um de especificação. O erro de estimação ocorre quando o tamanho da amostra não é suficiente para estimar os parâmetros necessários. Já o erro de especificação ocorre quando algum tipo de estrutura formal, não condizente com a realidade dos dados ${ }^{3}$, é imposto sobre os parâmetros estimados (trata-se do conhecido problema de viés). Michaud (1999) declara que o processo de inversão da matriz de covariâncias dos retornos dos ativos no MMV proporciona um erro de estimação significativo mesmo quando o tamanho da amostra for bem superior a quantidade de parâmetros estimados.

\footnotetext{
${ }^{3} \mathrm{O}$ modelo MMV supõe que os retornos dos ativos seguem uma distribuição normal de probabilidades.
} 
Morettin (2011) afirmam que a correlação linear é uma medida apropriada de dependência caso os retornos dos ativos seguirem uma distribuição normal bivariada. Entretanto, Rachev, Menn e Fabozzi (2005) mostraram que os retornos dos ativos frequentemente apresentam caudas gordas e assimetria, fazendo com que o coeficiente de correlação linear não seja uma medida adequada para se avaliar a dependência entre os ativos no modelo MMV. Analogamente, Fajardo e Farias (2003) e Prause (1999) evidenciaram empiricamente que os retornos diários e semanais de ações no Brasil, na Alemanha e nos EUA não podem ser representados por uma distribuição normal de probabilidades. Diante do exposto, um erro de especificação na matriz de covariâncias dos retornos pode ser considerável por infringir o pressuposto da normalidade.

Conforme Chan, Karceski e Lakonishok (1999), Bengtsson e Holst (2002), Jagannathan e Ma (2003), Ledoit e Wolf (2003), Ledoit e Wolf (2004) e Neto, Leal e Almeida (2011), a matriz de covariâncias dos retornos dos ativos deve ser estimada por um procedimento estatístico robusto conhecido por shrinkage. Este é um processo que visa uma diminuição significativa dos erros encontrados na matriz de covariâncias.

Primeiramente, sabe-se que a matriz de covariâncias amostrais $S$ é não viesada, pois seu valor esperado é igual ao da verdadeira matriz de covariâncias $\Omega$. Assim, a matriz robusta $\Sigma$ encontrada pelo método de shrinkage é dada pela seguinte combinação linear convexa:

$$
\Sigma=\delta F+(1-\delta) S
$$

sendo que $F$ é um estimador altamente estruturado e $\delta$ define a proporção ótima entre as matrizes $S$ e $F$.

Ledoit e Wolf (2004) empregam o modelo de correlação constante para sua versão de shrinkage em que a matriz de covariância amostral é combinada proporcionalmente com outra matriz de covariâncias que emprega a correlação média de todas as correlações existentes entre os ativos.

A diagonal principal da matriz Fserá formada pelas variâncias dos ativos: $f_{i i}=s_{i i}^{2}$ e os outros elementos serão formados por: $f_{i j}=\bar{r} \sqrt{s_{i i}^{2} s_{j j}^{2}}$, com $s_{i i}^{2}$ sendo a variância do ativo $i$ e $\bar{r}=\frac{2}{(N-1) N} \sum_{i=1}^{N-1} \sum_{j=i+1}^{N} r_{i j}$ representando a correlação média entre todos ativos.

Seja uma carteira hipotética de três ativos com variâncias iguais a $s_{11}^{2}=1, s_{22}^{2}=0.5$ e $s_{33}^{2}=1.3$. As correlações são iguais a $r_{12}=0.33, r_{13}=0.22$ e $r_{23}=0.40$. A correlação média será dada por $\bar{r}=0.3167$ e, assim, podemos construir a matriz $F$ da seguinte forma: $f_{11}=1, f_{22}=0.5 * 0.5=0.25, f_{33}=1.3 * 1.3=1.69, f_{12}=0.3167 * \sqrt{1 * 0.5}=0.2240, f_{23}=$ 
$0.3167 * \sqrt{0.5 * 1.3}=0.2553, f_{13}=0.3167 * \sqrt{1 * 1.3}=0.3611$. A matriz estruturada $F$, que contempla a correlação média de todos os ativos, será igual a $\left[\begin{array}{ccc}1 & 0.2240 & 0.3611 \\ 0.2240 & 0.5 & 0.2553 \\ 0.3611 & 0.2553 & 1.3\end{array}\right]$. Já a matriz de covariâncias amostrais $S$ será igual a $\left[\begin{array}{ccc}1 & 0.2333 & 0.2508 \\ 0.2333 & 0.5 & 0.3225 \\ 0.2508 & 0.3225 & 1.3\end{array}\right]$ e, portanto, para um $\delta=0.5$ previamente fixado, a matriz robusta de covariâncias $\Sigma$ resultará em $\left[\begin{array}{ccc}1 & 0.2287 & 0.3060 \\ 0.2287 & 0.5 & 0,2889 \\ 0.3060 & 0,2889 & 1.3\end{array}\right]$. Esta deve ser a matriz utilizada nos problemas de alocação de carteiras, pois não há necessidade de que os retornos sigam uma distribuição normal bivariada.

Os resultados obtidos por Ledoit e Wolf (2004) mostraram que a matriz robusta $\Sigma$ utilizada no MMV fornece carteiras com desempenho superior ao da matriz de covariâncias amostrais $S$. Disatnik e Benninga (2007) concluem que os resultados obtidos com métodos mais simples de shrinkage não se distinguem de métodos mais complexos. Analogamente, Ledoit e Wolf (2004) concluem que seu método apresenta vantagens significativas sobre outros métodos mais complexos de shrinkage e também sobre o MMV clássico. Portanto, o método de shrinkage acima é suficiente para produzir resultados apropriados no MMV.

\subsubsection{Comparação da performance da regra de Talmud com o modelo de Markowitz}

DeMiguel, Garlappi e Uppal (2009) fizeram a comparação da regra $1 / N$ com a maioria das técnicas de otimização que vieram depois do trabalho de Markowitz (1952). Conforme Neto, Leal e Almeida (2011), as conclusões foram devastadoras para todos os modelos de alocação ótima de carteiras de ativos. Já Tu e Zhou (2011) propuseram que as carteiras de ações fossem formadas por uma combinação linear entre a regra de Talmud com outra estratégia de diversificação como, por exemplo, o MMV. Os resultados mostraram que a combinação linear entre estratégias formaram carteiras de ações mais eficientes àquelas da regra de Talmud. Com tal resultado, os autores afirmaram que o MMV apresenta utilidade para os investidores desde que combinado com a regra de Talmud.

Há duas razões básicas para se utilizar a regra de Talmud como benchmark, que são: i) é de fácil implementação, pois não há necessidade de estimar os momentos dos retornos das ações e ii) apesar do aparecimento de sofisticados modelos de otimização nos últimos 50 
anos, os investidores continuam utilizando regras muito simples para alocar suas carteiras ${ }^{4}$.

Vale ressaltar que os trabalhos anteriormente citados se utilizaram de carteiras formadas por outras carteiras de ações sob certos critérios como, por exemplo, o índice Book-toMarket. Assim, é importante que sejam realizadas comparações entre os modelos de alocação de ativos com base em carteiras de ações a fim de considerar a presença do risco idiossincrático dos ativos individuais. DeMiguel, Garlappi e Uppal (2009) afirmam que os resultados proporcionados por carteiras de ações podem divergir daqueles advindos de carteiras formadas por outras carteiras de ações.

DeMiguel, Garlappi e Uppal (2009) provaram matematicamente a seguinte proposição que comprova sob certas condições a superioridade da regra de Talmud

Proposição: Seja $S_{*}^{2}=\mu \Sigma^{-1} \mu$ o índice de Sharpe ao quadrado da carteira tangente (média-variância) de ativos com risco e $S_{e w}^{2}=\left(1_{N}^{T} \mu\right)^{2} / 1_{N}^{T} \Sigma 1_{N}$ o índice de Sharpe ao quadrado da carteira $1 / N$. Então:

1. Se $\mu$ é desconhecido e $\Sigma$ é conhecido, a estratégia média-variância tem uma menor perda esperada do que a estratégia $1 / N$ se: $S_{*}^{2}-S_{e w}^{2}-\frac{N}{M}>0$, sendo que $M$ é a quantidade em meses ou semanas para estimar $\mu$ e $N$ é a quantidade de ativos da carteira

2. Se $\mu$ é conhecido e $\Sigma$ é desconhecido, a estratégia média-variância tem uma menor perda esperada do que a estratégia $1 / N$ se: $k S_{*}^{2}-S_{e w}^{2}>0$, sendo que $k=\left(\frac{M}{M-N-2}\right)\left(2-\frac{M(M-2)}{(M-N-1)(M-N-4)}\right)<1$.

3. Se $\mu$ e $\Sigma$ são desconhecidos, a estratégia de média-variância tem uma menor perda esperada do que a estratégia $1 / N$ se: $k S_{*}^{2}-S_{e w}^{2}-h>0$, sendo que $h=\frac{N M(M-2)}{(M-N-1)(M-N-2)(M-N-4)}>0$

Pela proposição 1, se $\mu$ é desconhecido e $\Sigma$ é conhecido, então a estratégia média-variância supera a estratégia $1 / N$ se a janela dde estimação dos parâmetros de risco e retorno, $M$, é muito alto e se o número de ativos disponíveis, $N$, for suficientemente pequeno. $\mathrm{Na}$ proposição 2 e 3, verifica-se que $k$ é crescente em $M$ e descrescente em $N$ e, portanto, a estratégia média-variância tende a superar a estratégia $1 / N$ quando $M$ aumenta e $N$ diminui. Se a carteira for formada por um grande número de ativos através de uma longa janela de estimação, o MMV tende a superar a regra de Talmud. No Brasil, Oliveira e

\footnotetext{
${ }^{4}$ Por exemplo, Benartzi e Thaler (2001) documentam que investidores alocam sua riqueza em ativos sob a regra de Talmud.
} 
Paula (2008) realizaram um estudo de otimização de carteiras e concluíram que 12 ações, em média, já são adequadas para proporcionar uma diversificação eficiente. Assim, com 10 ou 20 ativos numa carteira e uma janela de estimação de 120 meses, o modelo de Talmud tende a superar o MMV.

Os resultados encontrados por Tu e Zhou (2011) e DeMiguel, Garlappi e Uppal (2009) utilizaram a abordagem conhecida como "rolling-sample". Especificamente, dado um conjunto de retornos de ativos com $T$ meses, escolhe-se uma janela de estimação com tamanho de $M=60$ ou $M=120$ meses $^{5}$. Para cada mês $t$, inicia-se a partir de $t=M+1$. Utilizamos os $M$ meses anteriores a fim de estimar os parâmetros necessários para implementar a estratégia de diversificação. Estes parâmetros estimados são usados para determinar os pesos relativos das carteiras de ações. Por fim, utiliza-se desses pesos para calcular o retorno ex-ante no mês $t+1$. Este processo é realizado continuamente por adicionar o retorno do próximo período $t$ a partir dos pesos relativos obtidos pelos $M$ meses anteriores. O resultado desta abordagem é a obtenção de uma série com $T-M$ retornos mensais fora da amostra para cada estratégia de diversificação estudada. A partir da série de retornos mensais fora da amostra (out-of-sample) para cada estratégia se calculou duas quantidades para avaliar a performance ex-ante. A primeira, foi o cálculo do índice de Sharpe fora da amostra da estratégia $k$, definida como a média amostral dos retornos em excesso (sobre o ativo livre de risco), $\hat{\mu}_{k}$, dividido por seu desvio-padrão amostral, $\hat{\sigma_{k}}$. Para testar se dois índices de Sharpe são estatisticamente iguais para um determinado nível de significância, foi calculado o valor-p da diferença pela abordagem de Jobson e Korkie (1981) corrigido por Memmel (2003). Este teste supõe que os retornos sejam IID $^{6}$ e normais o que contradiz com os fatos estilizados dos retornos de ações. Para tanto, nesta tese, utilizaremos o teste robusto de Ledoit e Wolf (2008) que considera que os retornos de ação não são normais, têm caudas gordas e são fracamente dependentes ao longo do tempo. A utilidade foi calculada para também comparar os desempenhos ex-ante das carteiras dos ativos conforme a equação 2.3. Vale ressaltar que somente utilidades negativas é que possuem significado econômico-financeiro. Já índices de Sharpe negativos devem ser desconsiderados por sua própria construção matemática.

Os resultados por simulação mostraram que para $N=25$ ativos, a janela de estimação requerida para a estratégia média-variância superar a estratégia $1 / N$ é mais do que 200 meses; com 50 ativos, isto aumenta para cerca de 600 meses; e, para 100 ativos, fica em torno de 1200 meses. Vale lembrar que os resultados obtidos pelos autores consideraram os índices de Sharpe fora da amostra com carteiras formadas a partir de outras carteiras

\footnotetext{
${ }^{5}$ DeMiguel, Garlappi e Uppal (2009) afirmam que os resultados com $M=60$ não são muito diferentes daqueles obtidos com $M=120$.

${ }^{6}$ Os retornos são IID ou independentes e identicamente distribuídos.
} 
de ações sob certos critérios financeiros como, por exemplo, book-to-market, size etc.

\subsubsection{Modelo de Tu e Zhou}

Tu e Zhou (2011) propuseram uma combinação ótima da regra ingênua $1 / N$ com qualquer uma das quatro estratégias de alocação ótima de ativos: Markowitz (1952), Jorion (1986), Mackinlay e Pastor (2000) ou Kan e Zhou (2007). Os resultados encontrados mostraram que as carteiras formadas pelas estratégias combinadas foram mais eficientes do que aquelas formadas pela simples regra de alocação 1/N. Consequentemente, Tu e Zhou (2011, p. 204) afirmam que o MMV apresentada utilidade prática desde que combinado com a regra $1 / N$.

Tu e Zhou (2011, p. 205) argumentam que a regra de Talmud é viesada e possui variância nula. Ao contrário, uma regra ótima de diversificação é geralmente não viesada e com uma variância que pode sofre um aumento no caso de pequenas amostras. Considera-se que duas estratégias de diversificação podem ser combinadas da seguinte forma:

$$
\hat{w}_{c}=(1-\delta) w_{e}+\delta \bar{w}
$$

onde $w_{e}=1_{N} / N$ é a regra de Talmud, $\bar{w}$ é uma estratégia ótima de alocação de ativos e $\delta$ um fator entre 0 e 1 . Assume-se que os retornos dos $N$ ativos de risco são independentes e identicamente distribuídos ao longo do tempo e possuem uma distribuição normal multivariada com média $\mu$ e matriz de covariâncias $\Sigma$. Tu e Zhou (2011) demonstraram que a utilidade esperada de $\hat{w}_{c}$ é:

$$
U\left(\hat{w}_{c}\right)=r_{f T+1}+\mu^{\prime} \hat{w}_{c}-\frac{\gamma}{2} \hat{w}_{c}^{\prime} \sum \hat{w}_{c}
$$

sendo que $\gamma$ é o coeficiente relativo de aversão ao risco, $r_{f T+1}$ é o retorno do ativo livre de risco, $\mu$ é o vetor de médias e $\sum$ é a matriz de covariâncias dos retornos. A equação acima nada mais é do que a maximiação da utilidade esperada já mostrada em 2.3.

O objetivo é encontrar uma combinação ótima para o coeficiente $\delta$ tal que a seguinte função de perda esperada $L\left(w^{*}, \hat{w}_{c}\right)$ seja minimizada:

$$
L\left(w^{*}, \hat{w}_{c}\right)=U\left(w^{*}\right)-E\left[U\left(\hat{w}_{c}\right)\right]
$$

sendo que $U\left(w^{*}\right)$ é a utilidade esperada da verdadeira estratégia ótima de diversificação $w^{*}=\sum^{-1} \mu / \gamma$, que é o resultado exato quando se conhece $\mu$. Esta função de perda esperada é um critério padrão em teoria da decisão para avaliar diferentes estratégias de diversificação (STAMBAUGH, 1997; FROST e SAVARINO, 1986). A regra de Talmud é selecionada como o ponto de partida de nossas combinações devido a sua simplicidade e 
pelo fato de obter bons resultados quando a amostra de retornos é pequena. Entretanto, a regra de Talmud não faz nenhum uso das informações amostrais e, assim, nunca converge para a verdadeira estratégia ótima. Em contrapartida, a combinação de uma estratégia ótima com a regra $1 / N, \tilde{w}_{c}$, sempre converge para a verdadeira estratégia ótima e é projetada para ter um desempenho maior do que o da regra $1 / N$ e de $\bar{w}$. No caso do MMV, demonstra-se que:

$$
\bar{w}=\frac{1}{\gamma} \tilde{\Sigma}^{-1} \hat{\mu}
$$

sendo que $\tilde{\Sigma}=(T /(T-N-2)) \hat{\Sigma}$. Este ajuste na matriz de covariâncias amostrais faz com que $\bar{w}$ seja não viesado no modelo MMV. Vale lembrar que $\hat{\Sigma}$ será estimada pelo método de shrinkage em 2.40. A equação 2.43 será dada por:

$$
L\left(w^{*}, \hat{w}_{c}\right)=\frac{\gamma}{2}\left[(1-\delta)^{2} \pi_{1}+\delta^{2} \pi_{2}\right]
$$

sendo que:

$$
\pi_{1}=\left(w_{e}-w^{*}\right)^{\prime} \Sigma\left(w_{e}-w^{*}\right)
$$

e

$$
\pi_{2}=E\left[\left(\bar{w}-w^{*}\right)^{\prime} \Sigma\left(\bar{w}-w^{*}\right)\right] .
$$

Não há o operador esperança $E[$.$] em \pi_{1}$, pois os pesos da regra de Talmud são determinísticos. Deve-se notar que $\pi_{1}$ mede o impacto do viés dos pesos determinados pela regra de Talmud na medida em que todos os pesos são sempre iguais para cada ativo independentemente dos riscos e da correlação entre eles. Já $\pi_{2}$ mede o impacto da variância existente entre os pesos dos ativos no MMV na medida em que os pesos determinados para cada ativo serão influnciados pelos riscos envolvidos e pelo relacionamento existente entre eles. O coeficiente de combinação $\delta$ determinará a escolha ótima entre o viés da regra de Talmud e a variância do MMV que resultará na menor função de perda esperada em utilidade. A escolha ótima é demonstrada por Tu e Zhou (2011):

$$
\delta^{*}=\frac{\pi_{1}}{\pi_{1}+\pi_{2}}
$$

Seja $f(\delta)$ a função que compõe $(2.45),(1-\delta)^{2} \pi_{1}+\delta^{2} \pi_{2}=\pi_{1}-2 \delta \pi_{1}+\delta^{2}\left(\pi_{1}+\pi_{2}\right)$, o ponto ótimo $\delta^{*}$ é determinado igualando a primeira derivada de $f(\delta)$ a zero. Portanto, temos que: $\delta^{*}=\frac{\pi_{1}}{\pi_{1}+\pi_{2}}$. Verifica-se que $f^{\prime \prime}\left(\delta^{*}\right)>0$ e, assim, $\delta^{*}$ é ponto de mínimo para a função $f(\delta)$. Esta função $f(\delta)$ pode ser encontrada em (2.45)

Se $\pi_{1}=\pi_{2}$ em 2.48 , então $\delta^{*}$ será igual a $1 / 2$. Isso implica que o viés proporcionado pela regra de Talmud e a variância proporcionada pelo MMV teriam o mesmo impacto na perda esperada de uma carteira. 
Tu e Zhou (2011, p.206) mostraram que se $\pi_{1}>0$, então há uma escolha ótima $\delta^{*}$ entre 0 e 1, tal que:

$$
L\left(w^{*}, \hat{w}_{c}\right)<\min \left[L\left(w^{*}, w_{e}\right), L\left(w^{*}, \bar{w}\right)\right]
$$

isto é, a combinação ótima $\hat{w}_{c}$ domina estritamente tanto a regra de Talmud como o MMV. A expressão acima declara que a perda esperada proporcionada pela estratégia combinada é estritamente inferior a qualquer uma das perdas esperadas que viessem a ocorrer nos investimentos realizados unicamente na regra de Talmud ou no MMV.

Para estimar 2.48, necessita-se estimar $\pi_{1}$ e $\pi_{2}$ pelas seguintes equações:

$$
\hat{\pi}_{1}=\left(w_{e}-\hat{\Sigma}^{-1} \hat{\mu} / \gamma\right)^{\prime} \hat{\Sigma}\left(w_{e}-\hat{\Sigma}^{-1} \hat{\mu} / \gamma\right)
$$

Vale lembrar que $\hat{\Sigma}$ será a matriz de coavariâncias robusta proposta por Ledoit e Wolf (2004) para o MMV robusto e a matriz dos índices de dependência assimétrica para o MMV caudal. Desenvolvendo 2.50, temos:

$$
\hat{\pi}_{1}=w_{e}^{\prime} \hat{\Sigma} w_{e}-\frac{2}{\gamma} w_{e}^{\prime} \hat{\mu}+\frac{1}{\gamma^{2}} \tilde{\theta}^{2}
$$

Para $\pi_{2}$, temos:

$$
\pi_{2}=E\left[\left(\bar{w}-\Sigma^{-1} \mu / \gamma\right)^{\prime} \Sigma\left(\bar{w}-\Sigma^{-1} \mu / \gamma\right)\right]
$$

Tu e Zhou (2011, p. 214), mostraram que:

$$
\hat{\pi}_{2}=\frac{1}{\gamma^{2}}\left(c_{1}-1\right) \tilde{\theta}^{2}+\frac{c_{1}}{\gamma^{2}} \frac{N}{T}
$$

onde $\tilde{\theta}^{2}$ é um estimador de $\theta^{2}=\mu^{\prime} \Sigma^{-1} \mu$ encontrado em Kan e Zhou (2007), $c_{1}=$ $(T-2)(T-N-2) /((T-N-1)(T-N-4))$ com $N$ igual ao número de ativos e $T$ sendo o tamanho da amostra e $\gamma$ é coeficiente de aversão ao risco do investidor. Conforme Tu e Zhou (2011, p. 208), é interessante que pesquisadores combinem mais de duas estratégias ótimas de diversificação, pois os resultados podem ser ainda mais satisfatórios. Nesse sentido, esta tese se propõe a combinar três estratégias de diversificação a fim de levar em conta a dependência assimétrica dos ativos em modelos combinados. 
Os resultados encontrados pelos autores indicam que as regras combinadas são substancialmente melhores do que as respectivas regras isoladas para praticamente todos os cenários em análise. Algumas regras de otimização, inclusive o MMV, superam a regra de Talmud de forma significativa, mesmo quando o tamanho da janela de estimação dos parâmetros foi pequena $(\mathrm{T}=120)$. Os resultados evidenciam que quanto maior for a janela de estimação $T$, melhor será o desempenho fora da amostra dos modelos de otimização combinados e isolados. Os modelos combinados apresentam um desempenho acima da regra de Talmud independentemente da quantidade de ativos da carteira $N$. Assim, os modelos combinados formados a partir de carteiras de ações com base em outras carterias se mostraram superiores as suas contrapartes isoladas e a regra de Talmud.

\subsection{Estratégias de diversificação com dependência caudal ou assimétrica}

O coeficiente de correlação de Pearson é estimado adequadamente se os retornos seguirem uma distribuição normal multivariada. Como os retornos não são normais, os resultados proporcionados pelo MMV clássico podem ser inapropriados (NETO, LEAL e ALMEIDA, 2011; LEDOIT e WOLF, 2004). O principal problema da matriz de correlação amostral é que ela nos fornece pesos iguais em todos os pontos da amostra, resultando em estimativas que são muito sensíveis a observações extremas. Leal e Mendes (2010) mostraram que o coeficiente $\rho$ tende a suprestimar o relacionamento dos ativos em dias usuais pelo fato de que os próprios retornos não são normais. Quando há a presença de eventos extremos o coeficiente $\rho$ também superestima como os ativos se relacionam entre si em dias usuais de mercado. Logo, há a necessidade de se utilizar outra medida de dependência que considere os dois pontos apontados acima: (i) os retornos não são normais e (ii) presença de eventos extremos de mercado.

Longin e Solnik (2001) usaram a Teoria de Valores Extremos (TVE) para modelar a dependência caudal inferior entre retornos mensais de índices de cinco países no período de 1959 a 1996. A partir de um número de classes de ativos, a TVE envolve especificar uma equação para as caudas das distribuições marginais além de um limite preestabelecido (threshold) ou percentil, $\theta$, bem como a estrutura de dependência destas observações extremas. Eles concluem que a normalidade multivariada é uma apropriada descrição da distribuição conjunta dos retornos acima de um percentil padrão, $\theta$, mas não é uma descrição apropriada abaixo deste limite. Adicionalmente, os resultados aparecem estar mais associados com a tendência do mercado do que com sua volatilidade. Isto é, a correlação aumenta em bear markets, mas não durante bull markets. Diante deste resultado, precisamos de uma medida que seja capaz de medir eficientemente a dependência caudal inferior, ou seja, com os ativos se relacionam em bear markets. 
A desconsideração da dependência caudal inferior durante o processo de construção de carteiras poderá diminuir a habilidades dos gestores de fundos de ativos em reduzir o risco através da diversificação. A modelagem de cópulas sobre os retornos dos ativos nos permite calcular uma alternativa para medir a dependência não-linear dos ativos através do índice de dependência caudal, $\lambda$. Este coeficiente de dependência caudal, $\lambda$, mede como duas variáveis aleatórias se relacionam nos quantis extremos da distribuição de probabilidades. Esta nova medida de interdependência pode ser calculada para ganhos conjuntos, pelo índice de dependência caudal superior $\lambda_{U}$, e para perdas conjuntas, pelo índice de dependência caudal inferior $\lambda_{L}$. Longin e Solnik (2001) relataram que há um efeito expressivo de aumento da correlação dos ativos somente quando os mercados estão em declínio e, portanto, utilizaremos somente a medida $\lambda_{L}$ nos modelos de alocação de carteiras de ações. Por tal resultado, não haveria mudanças significativas em se utilizar $\lambda_{U}$ ao invés do coeficiente de correlação $\rho$.

Recentemente, cópulas foram redescobertas como uma ferramenta útil na modelagem financeira em aplicações diversas como mostrado em Cherubini, Luciano e Vechiatto (2004). Schmidt (2002) investigou o conceito de dependência caudal e mostrou sua utilidade na modelagem de risco de crédito. Ané e Kharoubi (2003) modelaram a estrutura de dependência entre os retornos de ações usando cópulas. Breymann, Dias e Embrechts (2003) usaram cópulas para avaliar o comportamento caudal em dados de alta frequencia, discutindo o problema dos agrupamentos dos extremos nos dados bivariados.

O índice de dependência caudal é um número entre zero e um, e será zero quando as variáveis forem assintoticamente independentes nos momentos extremos. Entretanto, dependência caudal não significa independência. Mendes, Leal e Carvalhal-da-Silva (2007) evidenciaram que dois ativos podem possuir um coeficiente de correlação $\rho$ igual a zero (ou mesmo negativo) e um $\lambda_{L}$ positivo (digamos, $\lambda_{L}=0.12$ ) ao mesmo tempo. Assim, $\rho=0.00$ não garante que não haverá co-movimentos dos ativos em períodos de alta volatilidade. Por outro lado, duas carteiras podem possuir $\rho=0.90$ e $\lambda_{L}=0.00$ (seria o caso da cópula gaussiana), o que exibe forte correlação durante os dias usuais e total disassociação nos eventos extremos de mercado. Além disso, dois ativos podem possuir diferentes índices $\lambda_{L}$ e $\lambda_{U}$, significando que os ganhos extremos são diferentes das perdas extremas. Mendes, Leal e Carvalhal-da-Silva (2007) evidenciaram que os ativos financeiros tipicamente possuem $\lambda_{U}<\lambda_{L}$, que é um tipo de assimetria comumente reportado na literatura acadêmica (PATTON, 2004; LONGIN e SOLNIK, 2001).

Mendes e Kolev (2008) investigaram empiricamente qual seria o tipo e o grau de interdependência entre os mais importantes mercados emergentes em períodos de crises econômicas. Um dos resultados importantes deste trabalho é que a dependência nos 
eventos extremos é potencializada pela presença de uma maior volatilidade condicional dos ativos nos períodos de crises financeiras. Para mostrar tal fato, os autores filtraram os dados a fim de amenizar a presença dos clusters de volatilidade e, consequentemente, a dependência caudal se mostrou bem mais fraca na amostra filtrada do que na amostra original. Assim, podemos afirmar que os clusters de volatilidade, que é um fato estilizado dos ativos financeiros, interferem sobremaneira na dependência caudal dos retornos dos ativos.

O trabalho seminal de Patton (2004) identifica que o conhecimento da dependência assimétrica produz ganhos econômicos que são estatisticamente significativos quando não há vendas a descoberto. Campbell, Koedijk e Kofman (2002) foram os pioneiros em construir uma fronteira eficiente com base no relacionamento dos ativos nos eventos extremos de mercado a partir da conhecida correlação quantílica. O retorno quantílico é simplesmente uma função do desvio-padrão da distribuição normal e, assim, $q_{c}=\zeta_{c} \sigma$. Sendo que $\zeta_{c}$ é o $(1-c) \%$ é o quantil da distribuição normal padrão. Dessa forma, trocando $\sigma$ pela expressão do risco de uma carteira em 2.6, temos: $q_{\text {port }, c}^{2}=\zeta_{c}^{2}\left[w_{x}^{2} \sigma_{x}^{2}+w_{y}^{2} \sigma_{y}^{2}+2 w_{x} w_{y} \sigma_{x y}\right]$. Trocando, os desvios-padrão individuais por suas estimativas quantílicas, temos uma medida de correlação quantílica sob a suposição de normalidade dos ativos conforme:

$$
\rho_{Q}=\frac{q_{\text {port }, c}^{2}-w_{x}^{2} q_{x, Q}^{2}-w_{y}^{2} q_{y, Q}^{2}}{2 w_{x} w_{y} q_{x, Q} q_{y, Q}}
$$

Hatherley e Alcock (2007) utilizaram também a teoria de cópulas para estimar a dependência dos ativos em momentos extremos. A cópula de Clayton e as distribuições marginais normais foram utilizadas para modelar os retornos dos ativos ${ }^{7}$

Hatherley e Alcock (2007), Patton (2004) e Campbell, Koedijk, Kofman (2001) mostraram, para um certo conjunto de ações, que a fronteira eficiente se deslocou significativamente para a direita em comparação ao modelo MMV clássico. A fronteira eficiente gerada por Hatherley e Alcock (2007) está evidenciada logo a seguir:

\footnotetext{
${ }^{7}$ Conforme Bergmann et al. (2011) e Patton (2006) esta cópula não é a mais apropriada para se ajustar a série de retornos dos ativos. Para tanto, nesta tese, utiliza-se a cópula de Joe Clayton Simetrizada proposta por Patton (2006) e a distribuição de Pareto estavél para modelar as marginais conforme Rachev (2004).
} 


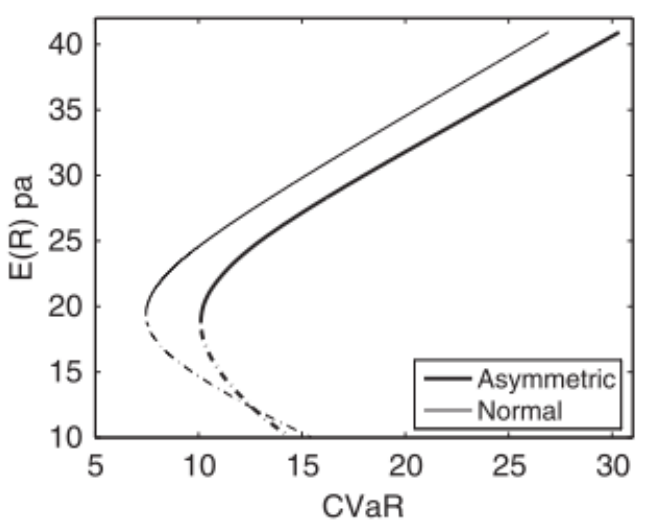

(a) Efficient fromtiers

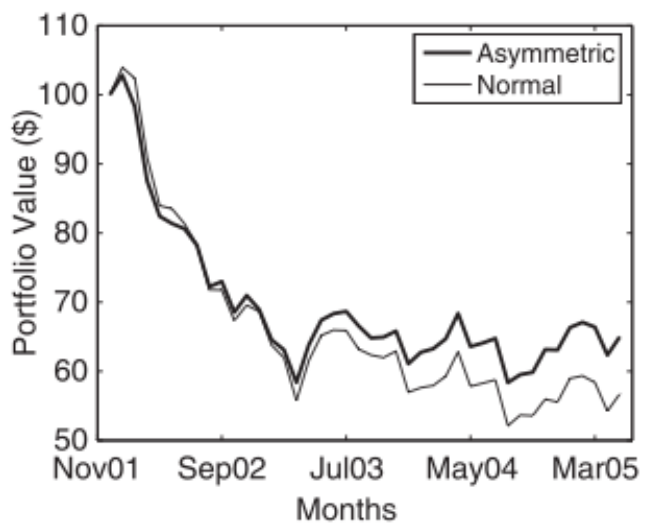

(b) Paper portfolios

\section{Figura 2.9 - Fronteiras eficiente do modelo com dependência assimétrica e do MMV clássico. \\ FONTE: Elaborado por Hatherley e Alcock (2007) com base no ASX 200}

(Australian Stock Exchange)

Pela Figura acima, conclui-se que o MMV tende a subestimar as perdas potenciais que venham a ocorrer na presença de eventos extremos de mercado (crashes) para um determinado nível de retorno esperado, pois a fronteira eficiente da estratégia com dependência assimétrica se deslocou para a direita em relação a do modelo clássico. Verificou-se, ainda, que o retorno acumulado das carteiras que foram construídas com dependência assimétrica foi superior aquele obtido pelo uso do modelo clássico no período de 2001-2005. Diante deste fato, o modelo de Markowitz pode produzir retornos acumulados inferiores ao modelo com dependência assimétrica para um dado nível de risco preestabelecido. Estes resultados se utilizaram de uma abordagem ex-post.

A dependência assimétrica dos ativos será considerada em 2.41, pois $\hat{\Sigma}$ é incapaz de capturar os relacionamentos entre os ativos em períodos de alta volatilidade. A dependência assimétrica tende a promover benefícios na diversificação das carteiras, pois ações que, aparentemente, estão pouco (muito) relacionadas pelo coeficiente $\rho$ clássico podem estar muito (pouco) relacionadas em períodos de alta volatilidade (ALCOCK e HATHERLEY, 2009; SUN et al., 2008; HU, 2006). Mendes, Leal e Carvalhalda-Silva (2007) mostraram que duas carteiras que possuem um $\rho=0.90$ podem ser assintoticamente independentes em períodos de alta volatilidade. Assim, a diversificação destes ativos em períodos de alta volatilidade é muito maior do que quando se utiliza apenas o coeficiente $\rho$.

Em 2.41, $\bar{w}$, que representa o vetor de pesos das estratégias combinadas, será determinado da seguinte forma:

$$
\bar{w}_{\text {Talmud }-M M V}=\delta w_{e}+\left\{\frac{(1-\delta)}{2} \bar{w}_{M M V}\right\}
$$




$$
\bar{w}_{\text {Talmud-MMVCaudal }}=\gamma w_{e}+\left\{\frac{(1-\gamma)}{2} \bar{w}_{M M V \text { Caudal }}\right\}
$$

sendo que $\delta$ e $\gamma$ são determinados por 2.48 no intervalo de $[0,100 \%], \bar{w}_{\text {Talmud-MMV }}$ representa os pesos obtidos pelo MMV e $\bar{w}_{\text {Talmud-MMVCaudal }}$ representa os pesos obtidos quando a dependência assimétrica é considerada na formação de carteiras. Neste caso, a matriz de covariâncias será composta pelos índices de dependência caudal inferior $\lambda_{L}$ da cópula de Joe-Clayton Simetrizada (PATTON, 2006).

Exemplo: Suponha uma carteira composta com duas ações hipotéticas A e B. Os valores de $\delta$ e $\gamma$ obtidos por 2.48 da regra de Talmud são iguais a 0.6 e 0.5 , respectivamente. Os pesos finais da combinação das três estratégias de diversificação combinadas (regra de Talmud, MMV e MMV caudal) serão iguais a: $37.5 \%$, 25\% e 37.5\% respectivamente. Caso haja $10 \%$ de investimentos na regra de Talmud, por exemplo, haverá, necessariamente, $6.67 \%$ no MMV e $10 \%$ no MMV caudal a fim de que se respeite os valores obtidos $\delta=0.6$ e $\gamma=0.5$. Logo, os pesos finais para compor a combinação dos modelos com soma 1 só pode ser dado por $37.5 \%, 25 \%$ e $37.5 \%$.

\subsection{Teoria de cópulas}

A teoria básica de cópulas surgiu nas décadas de 1940 e 1950, com o trabalho de Sklar (1959). Entretanto, sua utilização em finanças ainda é recente, com um grande número de trabalhos aparecendo na década de 2000. Dentre suas aplicações, destacamse a gestão de riscos - Martellini e Meyfredi (2007), Goorah (2007) e Clemente e Romano (2004), a precificação de opções - Cherubini, Luciano e Vecchiato (2004) e Assis e Laurini (2008), e a precificação de derivativos de crédito - Hull e White (2004). Segundo Nelsen (2006), o estudo de cópulas e sua aplicação em estatística, probabilidade e processos estocásticos ainda são recentes, e existe muito campo para seu desenvolvimento. Apesar de seu teorema central ter sido publicado por Abe Sklar (1959), a teoria de cópulas se desenvolveu principalmente nos últimos vinte anos. O autor cita as principais conferências dedicadas ao tema: "Symposium on Distributions with Given Marginals (Fréchet Classes)", em Roma, 1990; "Distributions with Fixed Marginals, Doubly Stochastic Measures, and Markov Operators", em Seattle, 1993; "Distributions with Given Marginals and Moment Problems", em Praga, 1996; "Distributions with Given Marginals and Statistical Modelling", em Barcelona, 2000; e "Dependence Modelling: Statistical Theory and Applications in Finance and Insurance", em Quebec, 2004.

Conforme Santos e Pereira (2011), a teoria de cópulas é uma metodologia de modelagem 
de distribuições multivariadas. Como alicerce principal, admite que toda distribuição multivariada pode ser decomposta em uma estrutura para as distribuições marginais e uma estrutura de dependência, representada pelas funções cópulas que, por sua vez, "ligam" as distribuições marginais numa estrutura única. A metodologia sobressai-se a outras abordagens alternativas, e.g. valores extremos, por modelar toda a distribuição conjunta das variáveis, fornecendo além de medidas de locação e dispersão, e.g. média e variância, outras medidas de dependência como dependências de cauda e correlações de postos. Com efeito, toda distribuição multivariada possui informações sobre as distribuições marginais e sobre as relações de dependência entre as variáveis. A modelagem da distribuição multivariada por cópulas permite isolar dessa estrutura de dependência a estrutura das distribuições marginais, permitindo, como apontado por McNeil et al. (2005), uma modelagem das distribuições multivariadas do "específico para o geral".

Conforme Genest, Rémillard e Beaudoin (2009), correlação é um conceito amplo nas áreas de finanças e seguros e é usada como uma medida de dependência linear entre variáveis aleatórias. Todavia, este termo é frequentemente utilizado de forma incorreta para significar qualquer noção de dependência. A correlação é uma medida muito particular de dependência quando comparada com outras métricas. No mundo das distribuições elípticas como, por exemplo, distribuição normal multivariada ou distribuição t multivariada, esta é uma medida aceitável. Como as teorias financeiras e a análise de gerenciamento de risco se utilizam da estrutura de dependência dos ativos, torna-se importante a introdução de uma medida alternativa que supere tal limitação.

Conforme Morettin e Toloi (2004, p. 10) e Cont (2001, p. 224), os principais fatos estilizados dos retornos financeiros são:

- Os retornos são, em geral, não auto-correlacionados serialmente, mas dependentes ao longo do tempo;

- Decaimento lento da função de auto-correlação dos quadrados dos retornos;

- A distribuição de probabilidades dos retornos apresenta caudas mais pesadas do que uma normal;

- As séries dos log-retornos apresentam clusters de volatilidade ao longo do tempo;

Assim, a Teoria de Cópulas vem sendo utilizada, na maioria das vezes, em Finanças e Econometria para tratar de duas grandes questões relacionadas aos fatos estilizados declarados acima:

- A não-normalidade dos retornos dos ativos financeiros (existência de assimetria e/ou de "caudas pesadas" nas distribuições de probabilidade); 
- A existência de dependência não-linear entre os retornos dos ativos financeiros;

Apesar do conceito de cópulas ter surgido há um longo tempo com Sklar (1959), suas aplicações em finanças e economia começaram a ser publicadas a partir do ano de 1999. Conforme Genest, Gendron e Bordeau-Brien (2009, p. 3), $41 \%$ das publicações relacionadas ao tema de cópulas se relacionam ao estudo na área de finanças. Este autor agrupou os estudos em quatro áreas, que são:

1. Gerenciamento de risco: desenvolvimentos nesta área foram estimulados pelo Acordo de Basiléia II e pelas contribuições acadêmicas de Embrechts, McNeil e Strausmann (1999) e Li (2000);

2. Gestão de carteiras: os trabalhos tratam da dependência entre os mercados financeiros internacionais (PATTON, 2006; BERGMANN et al., 2011);

3. Precificação de derivativos: os trabalhos nesta área procuram tratar de opções exóticas, swaps de crédito etc. Detalhes podem ser encontrados em Cherubini, Vecchiato e Luciano (2004)

4. Mensuração de risco: os temas deste grupo se referem ao VaR (Value-at-Risk), contágio entre os mercados financeiros e expected shortfall. O trabalho de Rodriguez (2007) propõe uma aplicação no tema de contágio, por exemplo.

De maneira simplificada, uma cópula é uma função que modela a relação de dependência entre duas ou mais variáveis aleatórias. Utilizando-se da relação de dependência entre as variáveis aleatórias $X$ e $Y$, a cópula acopla suas distribuições de probabilidade individuais ou margens, construindo uma distribuição conjunta de probabilidade. A grande vantagem da cópula é que ela constrói a distribuição conjunta das variáveis $X$ e $Y$ sem impor que as margens destas variáveis sejam normais, por exemplo.

De acordo com Sun, Rachev e Fabozzi (2006) o co-movimento dos mercados de ações internacionais é frequentemente utilizado como barômetro da globalização econômica e da integração financeira. A análise de tais co-movimentos é importante para diversificação do risco e formação de portfólios internacionais. A origem do co-movimento em um mercado de ações internacional está no efeito da volatilidade-em-correlação encontrado em Andersen et al. (2001), em retornos de ações individuais, e por Solnik, Boucrelie e Le (1996) em índices de retornos internacionais. De fato, o efeito da volatilidadeem-correlação pode ser explicado pela dependência das caudas dos respectivos ativos, o qual exibe eventos extremos simultâneos. O co-movimento, volatilidade-em-correlação, e a dependência de caudas das distribuições são relacionadas quando da análise da estrutura de dependência dos mercados de ações internacionais. Encontra-se também que as correlações entre retornos consecutivos decaem lentamente, isto é, a dependência de longo prazo dos retornos é evidenciada. 


\subsubsection{Função cópula}

Basicamente, uma cópula pode ser definida como uma função que acopla distribuições marginais univariadas formando distribuições multivariadas. Para tanto, faz-se necessário apenas definir a função de dependência entre as variáveis. Cópulas nos permitiram criar distribuições multivariadas que possuam marginais com distribuições diferentes. Isto é de grande valia neste trabalho uma vez que algumas séries financeiras podem apresentar assimetria e curtose nos mais diversos graus (PAGAN, 1996).

Uma função cópula possui informações, a respeito da distribuição conjunta, que não pertencem às distribuições marginais. $\mathrm{O}$ isolamento das informações contidas nas distribuições marginais é obtido pela transformação integral de probabilidade, também conhecida como transformação quantílica.

Seja $F_{i}$ a função de distribuição de uma variável aleatória $Y_{i}$, a função quantílica de $F_{i}$ é definida para todo $u \in(0,1)$ pela sua inversa generalizada ${ }^{8}$, como segue:

$$
F_{i}^{\leftarrow}=\inf \left\{y_{i} \in \mathbb{R}: F_{i}\left(y_{i}\right) \geq u\right\}
$$

Assim, a transformação integral de probabilidade assegura que $Y_{i}$ se distribui de forma $F_{i}$. Definindo as variáveis aleatórias $U_{1}$ e $U_{2}$ como $U_{i}=F_{i}\left(Y_{i}\right)$, então $U_{i}$ distribui-se uniformemente no intervalo unitário $(0,1)$. Vale ressaltar que a recíproca também é válida, isto é, se $U_{i} \sim U(0,1)$, então para $Y_{i} \equiv F_{i}^{\leftarrow}\left(U_{i}\right)$, temos que $F_{i} \sim Y_{i}$.

\subsubsection{Teorema de Sklar}

O teorema principal que é base na teoria de cópulas foi desenvolvido por Sklar (1959), e define a relação entre cópulas e funções de distribuição de variáveis aleatórias. O resultado acima implica na possibilidade de expressar uma distribuição multivariada através de suas marginais. Como uma cópula pode capturar diversas estruturas de dependência entre séries mesmo quando as distribuições marginais não são da mesma família, a utilização desse tipo de função na modelagem torna-se extremamente útil quando estamos num mundo multivariado onde as variáveis têm alguma forma de dependência entre si. É possível obter a distribuição conjunta de um vetor de variáveis a partir da função cópula e das transformações das variáveis em suas respectivas distribuições marginais uniformes, como segue:

\footnotetext{
${ }^{8} \mathrm{~A}$ inversa generalizada $F^{\leftarrow}$, quando $F$ é estritamente crescente e contínua. A função inversa pode, portanto, ser considerada como um caso específico da inversa generalizada.
} 


$$
\begin{gathered}
F\left(y_{1}, y_{2}\right)=P\left(Y_{1} \leq y_{1}, Y_{2} \leq y_{2}\right) \\
F\left(y_{1}, y_{2}\right)=P\left(U_{1} \leq F_{1}\left(y_{1}\right), U_{2} \leq F_{2}\left(y_{2}\right)\right) \\
F\left(y_{1}, y_{2}\right)=C\left(F_{1}\left(y_{1}\right), F_{2}\left(y_{2}\right)\right)
\end{gathered}
$$

Pelo teorema de Sklar e pela definição de função de densidade de probabilidade, temos:

$$
f\left(y_{1}, y_{2}\right)=\frac{\partial C\left(u_{1}, u_{2}\right)}{\partial y_{1} \partial y_{2}} f_{1}\left(y_{1}\right) f_{2}\left(y_{2}\right)
$$

onde $c($.$) é a função densidade da cópula.$

Assim, a função cópula contém informações, sobre a distribuição conjunta, que não estão presentes nas distribuições marginais. Ao converter-se, por meio da transformação quantílica, as variáveis $Y_{1}$ e $Y_{2}$ em variáveis uniformes, a informação das distribuições marginais será filtrada, posto que $U_{1}$ e $U_{2}$ serão uniformes $(0,1)$ independente de $F_{1}$ e $F_{2}$. Segundo Patton (2002), por essa razão a função cópula também é conhecida como função de dependência. No nosso caso, as cópulas servirão como uma forma de representar a estrutura de dependência entre os mercados e os seus fatores de risco, enquanto preservam a especificação da distribuição marginal de cada um dos mercados envolvidos. Segundo Cherubini, Luciano e Vecchiato (2004, p. 41), a representação dos co-movimentos em um mundo no qual as distribuições dos retornos não são normais origina alguns problemas inesperados para alguns estudiosos ou praticantes de finanças. Uma limitação da utilização de cópulas no contexto de avaliação dos co-movimentos dos mercados financeiros é extrapolar os resultados para o longo prazo.

Borovkova (2011) encontrou que a cópula de Joe-Clayton Simetrizada e a t-cópula tiveram o melhor ajuste aos retornos dos ativos do leste asiático. Ning (2010) também encontrou estes resultados para o mercado de índices dos EUA, Reino Unido, França, Alemanha e Japão. Patton (2006) declara que a cópula de Joe-Clayton Simetrizada é extremamente flexível, pois permite captar que os ativos estariam muito mais correlacionados em momentos de baixa do que em alta de mercado, ou seja, $\lambda_{L}>\lambda_{U}$. Dessa forma, esta classe de cópula será utilizada devido aos resultados de ajustamento aos ativos de mercado nos diversos mercados apontados acima.

\subsubsection{A cópula de Joe-Clayton simetrizada (cópula-SJC)}

Patton (2006) utilizou uma cópula de Joe-Clayton Simetrizada para modelar taxas de câmbio. A função de distribuição da cópula de Joe-Clayton é dada por:

$$
C_{J C}\left(\mu, \nu \mid \lambda_{U}, \lambda_{L}\right)=1-\left(\left\{\left[1-(1-u)^{\kappa}\right]^{-\gamma}+\left[1-(1-\nu)^{\kappa}\right]^{-\gamma}-1\right\}^{-1 / \gamma}\right)^{1 / \kappa}
$$


com

$\kappa=1 / \log _{2}\left(2-\lambda_{U}\right) ; \gamma=-1 / \log _{2}\left(\lambda_{L}\right)$ e $\lambda_{U} \in(0,1), \lambda_{L} \in(0,1)$.

A cópula tem dois parâmetros, $\lambda_{U}$ e $\lambda_{L}$, que permitem a modelagem a dependência caudal superior e inferior, respectivamente. A copula de Joe-Clayton acima assume que $\lambda_{L}$ é igual a $\lambda_{U}$ em qualquer aplicação. Trata-se de um fato irreal no mercado acionário. Para superar tal limitação, a cópula de Joe-Clayton será modificada para a conhecida cópula de Joe-Clayton Simetrizada conforme Patton (2006):

$$
C_{J C S}\left(u, v \mid \lambda_{U}, \lambda_{L}\right)=0.5 C_{J C}\left(u, v \mid \lambda_{U}, \lambda_{L}\right)+0.5 C_{J C}\left(1-u, 1-v \mid \lambda_{U}, \lambda_{L}\right)+u+v-1
$$

Dessa forma, podemos retratar a dependência assimétrica dos retornos dos ativo, $\lambda_{L}>\lambda_{U}$. Nesta cópula os índices de cauda serão iguais aos parâmetros $u$ e $v$ estimados, $\lambda_{L}=$ $u$ e $\lambda_{U}=v$. Outras cópulas existentes na literatura também podem ser encontradas em Bergmann et al. (2011). Serão apresentadas algumas delas que são frequentemente utilizadas na prática como, por exemplo, a cópula-t, a cópula gaussiana e a cópula de Gumbel.

\subsubsection{A cópula gaussiana}

É cópula de uma distribuição normal bivariada com parâmetro de correlação $\delta$, dada por:

$C_{N}(u, v ; \delta)=\int_{-\propto}^{\Phi^{-1}(u)} d x \int_{-\propto}^{\Phi^{-1}(v)} d y \frac{1}{2 \pi \sqrt{1-\delta^{2}}} \exp \left\{-\frac{x^{2}-2 \delta x y+y^{2}}{2\left(1-\delta^{2}\right)}\right\}=\Phi_{\delta}\left(\Phi^{-1}(u), \Phi^{-1}(v)\right)$

onde $\Phi_{\delta}$ é a função de distribuição conjunta de uma normal padrão bivariada com coeficiente de correlação $\delta$. A cópula gaussiana gera distribuição normal bivariada se, e somente se, as marginais são normais padrões. É importante salientar que quando $\delta<1$, ou seja, há uma correlação não perfeita entre os ativos; $\lambda_{L}=\lambda_{U}=0$. Assim, esta cópula não capta a dependência assimétrica dos ativos. Abaixo encontra-se um exemplo de modelagem bivariada com cópula gaussiana entre os índices de ações da França (CAC 40) e da Alemanha (DAX 30) no período de 1999 a 2005 realizado no MATLAB R2009b. 


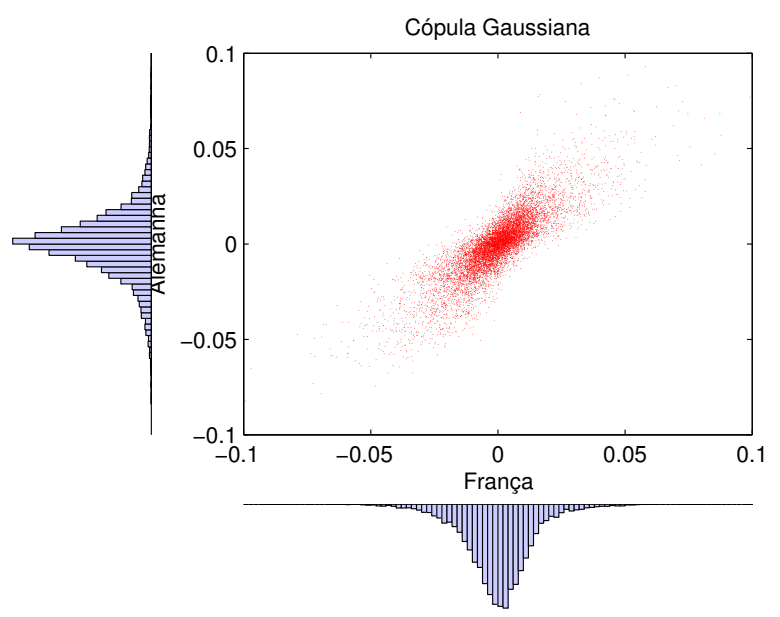

Figura 2.10 - Cópula Gaussiana estimada para os índices de ações da França e da Alemanha no período de 1999-2005

Percebe-se pela Figura acima que a cópula gaussiana não foi capaz de capturar eficientemente os relacionamentos entre os índices da França e da Alemanha nos momentos de alta volatilidade, pois há uma dispersão significativa dos pontos amostrais nas extremidades.

\subsubsection{Cópulas de valores extremos}

Estas apresentam a seguinte propriedade matemática:

$$
C\left(u^{t}, v^{t}\right)=(C(u, v))^{t}, \quad t>0
$$

e podem ser representadas na forma

$$
C(u, v)=\exp \left\{\log (u v) A\left(\frac{\log (u)}{\log (u v)}\right)\right\}
$$

onde $A:[0,1] \rightarrow[1 / 2,1]$ é uma função convexa, $\operatorname{com} \max (t, t-1) \leq A(t) \leq 1$, chamada de função de dependência. Quando $A(t)=\left(t^{\delta}+(1-t)^{\delta}\right)^{1 / \delta}$ encontramos a cópula de Gumbel com função de distribuição igual a:

$$
C_{G}(u, v ; \delta)=\exp \left\{-\left[\left(-\log (u)^{\delta}+\log (v)^{\delta}\right)^{1 / \delta}\right]\right\}, \delta>1
$$


Esta cópula de Gumbel apresenta $\lambda_{L}=0$ e $\lambda_{U}=2-2^{1 / \delta}$. Assim, esta cópula assume somente a presença de correlação em momentos de alta de mercado. Não é adequada, portanto, as nossas aplicações em otimização de carteiras.

\subsubsection{A cópula t-Student}

A cópula $t$ bivariada é definida pela expressão abaixo:

$$
C_{u, \nu, \Sigma}^{t}(u, v)=t_{\nu, 0, \Sigma}\left(t_{\nu}^{-1}(u), t_{\nu}^{-1}(u)\right)
$$

onde $t_{\nu, 0, \Sigma}$ é a função de distribuição $t$ bivariada de média 0 e matriz de covariâncias $\Sigma$, e $t_{\nu}$ é a $t$ univariada clássica, com $\nu$ graus de liberdade. Temos, pois, que $\delta=(\nu, \Sigma)$. Para a cópula t-Student temos que: $\lambda_{L}=\lambda_{U}=2 H_{\nu}\left(-\sqrt{\frac{(\nu+1)(1-\rho)}{1+\rho}}\right)$, com $\nu$ graus de liberdade, coeficiente de correlação $\rho$ e função de distribuição da t de Student dada expressa por $H_{\nu}$.

A cópula-t apresenta $\lambda_{L}=\lambda_{U}$, que não é um fato empírico constatado nos mercados acionários. Por tal fato, optamos pelo uso no nosso trabalho da cópula de Joe-Clayton Simetrizada, pois $\lambda_{L}$ pode ser superior a $\lambda_{U}$.

Abaixo encontra-se um exemplo de modelagem bivariada da cópula-t entre os índices de ações da França e da Alemanha no período de 1999 a 2005.

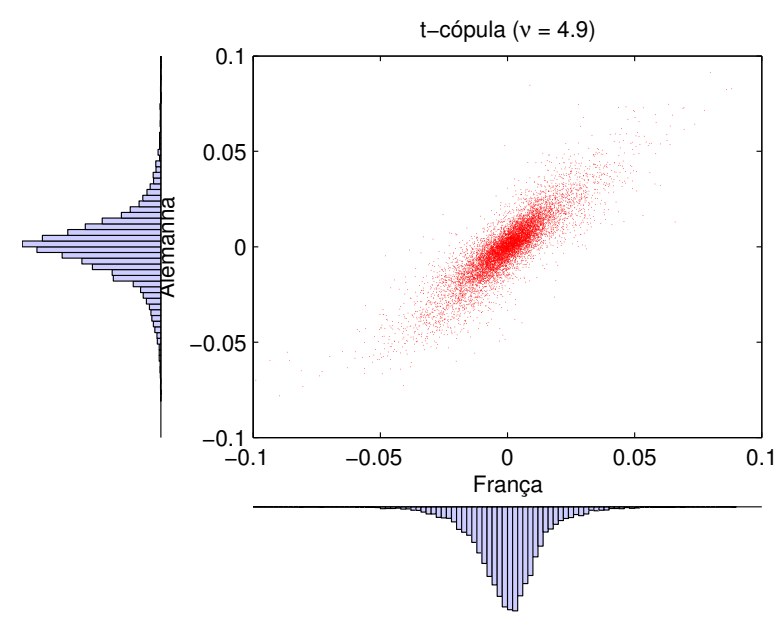

\section{Figura 2.11 - Cópula-t estimada para os índices de ações da França e da Alemanha no período de 1999-2005}

Pela comparação da Figura (2.10) com a Figura (2.11), verifica-se que existe uma maior 
habilidade da cópula-t em capturar a dependência em momentos extremos do que a cópula gaussiana, pois há uma maior concentração dos pontos nas extremidades na cópula-t. Percebe-se também pela Figura acima que a cópula-t não foi capaz de evidenciar se o relacionamento entre os ativos em momentos de alta é diferente do relacionamento dos ativos em momentos de baixa, pois sa concentração dos pontos nos extremos é simétrica.

\subsubsection{Medidas de dependência}

Existe certo número de conceitos sobre associação, nesta seção apresentaremos alguns destes conceitos. Entre as medidas de associação mais utilizadas podemos destacar a concordância (como sendo distinta de dependência), correlação linear, dependência de cauda e dependência de quadrante positivo. E algumas medidas associadas com estas, como: $\tau$ de Kendall, correlação de Spearman, coeficiente de correlação linear e os índices de dependência de cauda. Todas estas medidas estão relacionadas às propriedades das cópulas, desde que, acoplando uma função de distribuição com suas marginais, a cópula "captura certos aspectos do relacionamento entre as variáveis, de modo que os conceitos de dependência são propriedades das cópulas" (NELSEN, 1999).

Suponha que temos duas v.a.'s $X$ e $Y$ e $\delta(X, Y)$ seja uma medida de dependência entre elas. As seguintes propriedades são desejáveis para $\delta$ (EMBRECHTS, MCNEIL e STRAUSSMANN, 2003):

1. $\delta(X, Y)=\delta(Y, X)$;

2. $-1 \leq \delta(X, Y) \leq 1$

3. $\delta(X, Y)=1$ se $X$ e $Y$ são comonotônicas e $\delta(X, Y)=-1$ se $X$ e $Y$ são contramonotônicas.

4. Se $T$ for uma transformação monótona,

$$
\delta(T(X), Y)=\left\{\begin{aligned}
\delta(X, Y), & \text { se } T \text { crescente } \\
-\delta(X, Y), & \text { se } T \text { decrescente }
\end{aligned}\right.
$$

5. $\delta(X, Y)=0$ se e somente se $X$ e $Y$ são independentes.

Dizemos que $X$ e $Y$ são comonotônicas se $Y$ (ou $X$ ) for uma função estritamente crescente de $X$ (ou $Y$ ) em quase toda parte e são contramonotônicas se a função for estritamente decrescente. 
O coeficiente de correlação de Pearson, $\rho_{P}$, satifaz (1)-(2). Além disso, $\rho_{P}$ requer que as variâncias de $X$ e de $Y$ sejam finitas, $\rho=0$ não implica independência entre $X$ e $Y$, a não ser que $(X, Y)$ tenha uma distribuição normal bivariada. Também, $\rho_{P}$ não é invariante sob transformações não lineares estritamente crescentes. Outras medidas de dependência global entre duas variáveis $X$ e $Y$, largamente usadas, são os coeficientes $\tau_{K}$ de Kendall e o coeficiente $\rho_{S}$ de Spearman. Estas medidas sempre existem, são não paramétricas, baseadas em postos e não dependem das distribuições marginais de $X$ e de $Y$, mas somente da cópula $C$ dessas duas variáveis. Diferente de $\rho_{P}$, essas medidas são invariantes por escala. Uma outra propriedade interessante é que, como dependem da cópula das duas variáveis, $\tau_{K}$ e $\rho_{S}$ podem ser usadas para ajustar uma cópula a dados, pois frequentemente os parâmetros de uma cópula são funções desses coeficientes.

s medidas de dependência nas caudas são utilizadas para capturar a dependência na cauda da distribuição bivariada. Serve para descrever o quanto grandes (ou pequenos) valores de uma variável aleatória acompanham valores grandes (ou pequenos) de outra variável aleatória. Conforme Morettin (2011, p. 324), as principais medidas de dependência existentes na teoria estatística são:

\subsubsection{Coeficiente de correlação linear}

Também chamado coeficiente de correlação linear de Pearson, é definido por:

$$
\rho_{P}(X, Y)=\frac{\operatorname{Cov}(X, Y)}{\sigma_{X} \sigma_{Y}}
$$

onde $\operatorname{Cov}(X, Y)=E(X Y)-E(X)-E(Y)$ é a covariância entre $X$ e $Y$ e $\sigma_{X}, \sigma_{Y}$ indicam os desvios padrões de $X$ e $Y$, respectivamente. Notamos que:

1. $-1 \leq \rho_{P} \leq 1$

2. $\rho_{P}=0$ quando $X$ e $Y$ são independentes;

3. $\rho_{P}= \pm 1$ quando $Y$ é uma função linear de $X$.

Um estimador de momentos de $\rho_{P}$ é obtido estimando-se a covariância por:

$$
\widehat{\operatorname{Cov}(X, Y)}=\frac{1}{n} \sum_{t=1}^{n}\left(x_{t}-\bar{x}\right)\left(y_{t}-\bar{y}\right)=\frac{1}{n} \sum_{t=1}^{n} x_{t} y_{t}-n \overline{x y}
$$


dada a amostra $\left(x_{1}, y_{1}\right), \ldots,\left(x_{n}, y_{n}\right)$ de $(X, Y)$, e onde $\bar{x}, \bar{y}$ denotam as médias amostrais de $X$ e $Y$, respectivamente. O desvio padrão de $X$ é estimado por $\widehat{\sigma}_{X}$, onde:

$$
\widehat{\sigma}_{X}=\frac{1}{n} \sum_{t=1}^{n}\left(x_{t}-\bar{x}\right)^{2}=\frac{1}{n} \sum_{t=1}^{n} x_{t}^{2}-\bar{x}^{2}
$$

é o estimador da variância de $X$, expressão análoga para $\hat{\sigma}_{Y}$. Segue-se que um estimador para $\rho_{P}$ é dado por:

$$
\hat{\rho}_{P}=\frac{\sum_{t=1}^{n} x_{t} y_{t}-n \overline{x y}}{\left[\left(\sum_{t=1}^{n} x_{t}^{2}-n \bar{x}^{2}\right)\left(\sum_{t=1}^{n} y_{t}^{2}-\overline{n y}^{2}\right)\right]^{1 / 2}}
$$

É um fato que $-1 \leq \rho_{P} \leq 1$ e, na prática, se o valor estimado estiver próximo de +1 ou -1, as variáveis são fortemente associadas ou correlacionadas linearmente e se estiver próximo de zero, as variáveis são não correlacionadas. Se $(X, Y)$ for normal bivariada, podemos falar em dependentes e independentes, respectivamente.

Convém reafirmar que $\rho_{P}$ mede dependência linear entre $X$ e $Y$, e não outro tipo de dependência. De fato, suponha que uma das variáveis possa ser expressa linearmente em termos da outra, por exemplo $X=a Y+b$, e seja $d=E\left(|X-a Y-b|^{2}\right)$. Então, pode-se provar que o mínimo de $d$ ocorre quando

$$
a=\frac{\sigma_{X}}{\sigma_{Y}} \rho_{P}, \quad b=E(X)-a E(Y)
$$

e o mínimo é dado por

$$
\min d=\sigma_{X}^{2}\left(1-\rho_{P}^{2}\right)
$$

Nota-se, portanto, que quanto maior o valor absoluto do coeficiente de correlação entre $X$ e $Y$, melhor a acurácia com que uma das variáveis pode ser representada como uma combinação linear da outra. Obviamente, este mínimo anula-se se e somente se $\rho_{P}=1$ ou $\rho_{P}=-1$. Segue-se imediatamente de (2.73) que: 


$$
\rho_{P}(X, Y)=\frac{\sigma_{X}^{2}-\min _{a, b} E\left(|X-a Y-b|^{2}\right)}{\sigma_{X}^{2}}
$$

ou seja, $\rho_{P}$ mede a redução relativa na variância de $X$ por meio de uma regressão linear de $X$ sobre $Y$. Mendes, Leal e Carvalhal-da-Silva (2007) afirmaram que o coeficiente de correlação $\rho_{P}$ entre duas variáveis pode ser bem maior do que a verdadeira associação entre as variáveis em períodos de alta volatilidade, deteriorando os benefícios da diversificação dos ativos.

\subsubsection{Coeficiente de correlação tau de Kendall}

Suponha que a v.a. $(X, Y)$ tenha distribuição $F$, contínua. As v.a.'s $X$ e $Y$ são concordantes se pequenos valores de uma estão associadas a pequenos da outra, o mesmo ocorrendo com os valores grandes. Formalmente, sejam $\left(X_{1}, Y_{1}\right)$ e $\left(X_{2}, Y_{2}\right)$ dois pares independentes obtidos de $F$. Dizemos que estes pares são concordantes se $X_{1}>X_{2}$ sempre que $Y_{1}>Y_{2}$ e $X_{1}<X_{2}$ sempre que $Y_{1}<Y_{2}$, isto é, se $\left(X_{1}-X_{2}\right)\left(Y_{1}-Y_{2}\right)>0$. Os pares são discordantes se ocorre $X_{1}>X_{2}$ sempre que $Y_{1}<Y_{2}$ e $X_{1}<X_{2}$ sempre que $Y_{1}>Y_{2}$, ou seja, se $\left(X_{1}-X_{2}\right)-\left(Y_{1}-Y_{2}\right)<0$. Geometricamente, dois pontos distintos $\left(X_{1}, Y_{1}\right),\left(X_{2}, Y_{2}\right)$ no plano são concordantes se o segmento de reta que os une tem inclinação positiva, e discordantes se o segmento tem inclinação negativa. O coeficiente $\tau_{K}$ de Kendall é dado por:

$$
\tau_{K}=P\left\{\left(X_{1}-X_{2}\right)\left(Y_{1}-Y_{2}\right)>0\right\}-P\left\{\left(X_{1}-X_{2}\right)\left(Y_{1}-Y_{2}\right)<0\right\}
$$

Uma estimativa de $\tau_{K}$, baseada numa amostra de tamanho $n$ de $(X, Y)$, é dada por:

$$
\widehat{\tau}_{K}=\left(\begin{array}{c}
n \\
2
\end{array}\right)^{-1} \sum_{1 \leq i \leq j \leq n} \operatorname{sinal}\left(\left(x_{i}-x_{j}\right)\left(y_{i}-y_{j}\right)\right)
$$

ou seja, o quociente entre o número de pares concordantes menos o número de pares discordantes e o número total de pares. Nesta fórmula, sinal $(x)=1$, se $x>0,0$ se $x=0$, $\mathrm{e}-1$, se $x<0$.

Seja $R_{i}$ o posto de $X_{i}$ dentre $X_{1}, \ldots, X_{n}$ e $S_{i}$ o posto de $Y_{i}$ dentre $Y_{1}, \ldots, Y_{n}$. Então, $\left(X_{i}-X_{j}\right)\left(Y_{i}-Y_{j}\right)>0$ se e somente se $\left(R_{i}-R_{j}\right)\left(S_{i}-S_{j}\right)>0$, ou seja, $\widehat{\tau}_{K}$ é uma função somente dos postos das observações. 
Em aplicações financeiras, em que $X$ e $Y$ representam por exemplo retornos financeiros, o interesse está nos casos em que $X$ e $Y$ tomam valores muito grandes ou muito pequenos ao mesmo tempo. Nestes casos, $\widehat{\tau}_{K}$ fornece uma medida de concordância entre $X$ e $Y$. Outra medida de concordância é o coeficiente de Spearman.

\subsubsection{Coeficiente de correlação de Spearman}

Suponha que $(X, Y)$ tenha distribuição conjunta $F$ e que as distribuições marginais de $X$ e $Y$ sejam $F_{1}$ e $F_{2}$, respectivamente. O coeficiente $\rho_{S}$ de Spearman é também baseado em concordância e discordância. Suponha que $\left(X_{1}, Y_{1}\right),\left(X_{2}, Y_{2}\right)$ e $\left(X_{3}, Y_{3}\right)$ sejam três cópias independentes de $(X, Y)$, ou seja, amostras aleatórias das variáveis originais escolhidas ao acaso. Então:

$$
\rho_{S}=3\left(P\left[\left(X_{1}-X_{2}\right)\left(Y_{1}-Y_{3}\right)>0\right]-P\left[\left(X_{1}-X_{2}\right)\left(Y_{1}-Y_{3}\right)<0\right]\right)
$$

Ou seja, $\rho_{S}$ é definido como sendo proporcional à probabilidade de concordância menos a probabilidade de discordância dos dois vetores $\left(X_{1}, Y_{1}\right)$ e $\left(X_{2}, Y_{3}\right)$. Nota-se também que a função de distribuição de $\left(X_{1}, Y_{1}\right)$ é $F$, enquanto que a função de distribuição de $\left(X_{2}, Y_{3}\right)$ é $F_{1}(x) F_{2}(y)$, pois $X_{2}$ e $Y_{3}$ são independentes. Pode-se provar que:

$$
\rho_{S}=\rho_{P}\left(F_{1}(X), F_{2}(Y)\right)
$$

onde o coeficiente $\rho_{S}$ é uma medida de correlação de postos. Uma estimativa de $\rho_{S}$, baseada numa amostra de tamanho $n$ de $(X, Y)$ é dada por:

$$
\widehat{\rho}_{S}=\frac{\sum_{i=1}^{n}\left(R_{i}-\bar{R}\right)\left(S_{i}-\bar{S}\right)}{\sqrt{\sum_{i=1}^{n}\left(R_{i}-\bar{R}\right)^{2} \sum_{i=1}^{n}\left(S_{i}-\bar{S}\right)^{2}}}
$$

\subsubsection{Medidas de dependência de caudas}

Cherubini, Luciano e Vecchiato (2004, p. 42) afirmaram que a falta de normalidade numa variável aleatória está associada com a presença de assimetria e/ou curtose nas respectivas distribuições marginais. No contexto mutivariado, o problema da curtose pode surgir pelo comportamento individual dos retornos ou pela influência dos grandes movimentos de mercado. Este conceito é conhecido como dependência caudal. Intuitivamente, ativos que não se associam fortemente em dias usuais podem apresentar forte associação em 
momentos extremos de mercado e vice-versa. A utilização da cópula habilita capturar como os ativos se relacionam entre si nos momentos com maior volatilidade.

Sejam $X$ e $Y$ variáveis aleatórias contínuas com funções de distribuição $F$ e $G$, respectivamente. O parâmetro de dependência na cauda superior $\lambda_{U}$ é o limite (se existir) da probabilidade condicional de $Y$ ser maior que o 100t-ésimo percentil de $G$ dado que $X$ é maior que o 100t-ésimo percentil de $F$ quando t se aproxima de 1 pela esquerda, ou seja:

$$
\lambda_{U}=\lim _{t \rightarrow 1^{-}} P\left[Y>G^{(-1)}(t) \mid X>F^{(-1)}(t)\right]
$$

De forma similar, o parâmetro de dependência na cauda inferior $\lambda_{L}$ é o limite (se existir) da probabilidade condicional de $Y$ ser menor ou igual que o 100t-ésimo percentil de $G$ dado que $X$ é menor ou igual que o 100t-ésimo percentil de $F$ quando t se aproxima de 0 pela direita, ou seja:

$$
\lambda_{L}=\lim _{t \rightarrow 0^{+}} P\left[Y \leq G^{(-1)}(t) \mid X \leq F^{(-1)}(t)\right]
$$

Estes parâmetros são não-paramétricos e dependem apenas da cópula formada por X e Y. De modo geral, $0<\lambda_{U} \leq 1,0<\lambda_{L} \leq 1$, sendo que $\lambda_{U}=0$ implica em independência (assintótica) na cauda superior e $\lambda_{L}=0$ implica em independência assintótica na cauda inferior.

O índice de dependência caudal é um número entre zero e um, e será zero quando as variáveis forem assintoticamente independentes nos momentos extremos. Entretanto, dependência caudal não significa independência. Mendes, Leal e Carvalhal-da-Silva (2007) evidenciaram que dois ativos podem possuir um coeficiente de correlação $\rho$ igual a zero (ou mesmo negativo) e um $\lambda_{L}$ positivo (digamos, $\lambda_{L}=0.12$ ) ao mesmo tempo. Assim, $\rho=0.00$ não garante que não haverá co-movimentos dos ativos em períodos de alta volatilidade. Por outro lado, duas carteiras podem possuir $\rho=0.90$ e $\lambda_{L}=0.00$ (seria o caso da cópula gaussiana), o que exibe forte correlação durante os dias usuais e total disassociação nos eventos extremos de mercado. Além disso, dois ativos podem possuir diferentes índices $\lambda_{L}$ e $\lambda_{U}$, significando que os ganhos extremos são diferentes das perdas extremas. Mendes, Leal e Carvalhal-da-Silva (2007) evidenciaram que os ativos financeiros tipicamente possuem $\lambda_{U}<\lambda_{L}$, que é um tipo de assimetria comumente reportado na literatura acadêmica (PATTON, 2004; LONGIN e SOLNIK, 2001).

Mendes e Leal (2010) investigaram empiricamente a dependência entre alguns índices da América Latina. Os coeficientes de correlação $\rho_{P}$ são mostrados a seguir: 
Tabela 2.4 - Coeficientes de correlação de Pearson entre os log-retornos diários dos índices de ações dos países da America Latina no período de 1994-2006.

\begin{tabular}{cccccc}
\hline Países & Argentina & Brasil & Chile & México & EUA \\
\hline Argentina & 1 & 0,4595 & 0,3258 & 0,3896 & 0,3088 \\
Brasil & 0,4595 & 1 & 0,4241 & 0,4723 & 0,4045 \\
Chile & 0,3258 & 0,4241 & 1 & 0,3308 & 0,2803 \\
México & 0,3896 & 0,4723 & 0,3308 & 1 & 0,4526 \\
EUA & 0,3088 & 0,4045 & 0,2803 & 0,4526 & 1 \\
\hline
\end{tabular}

Fonte: Elaborado por Mendes e Leal (2010).

Tabela 2.5 - Coeficientes de índices de dependência caudal $\lambda_{U}$ e $\lambda_{L}$ entre os logretornos diários dos índices de ações dos países da América Latina no período de 1994-2006

\begin{tabular}{cccccc}
\hline Países & Argentina & Brasil & Chile & México & EUA \\
\hline Argentina & 1 & 0,2988 & 0,2404 & 0,2330 & 0,1757 \\
Brasil & 0,3809 & 1 & 0,1977 & 0,2407 & 0,2373 \\
Chile & 0,2746 & 0,3463 & 1 & 0,2177 & 0,0271 \\
México & 0,2765 & 0,3490 & 0,2794 & 1 & 0,2629 \\
EUA & 0,1837 & 0,2103 & 0,0829 & 0,2387 & 1 \\
\hline
\end{tabular}

Fonte: Elaborado por Mendes e Leal (2010).

As tabelas acima mostram que os índices caudais são menores do que os coeficientes de correlação linear de Pearson, evidenciando que $\rho_{P}$ tende a superestimar a associação entre os ativos quando da presença de períodos extremos, implicando que os benefícios da diversifcação podem ser mais pronunciados pelo uso da dependência caudal. Como já mencionado, é crucial que o índice de cauda inferior $\lambda_{L}$ seja incorporado no modelo de otimização.

Mendes, Leal e Carvalhal-da-Silva (2007) mostraram que de um total de 91 pares de países emergentes no período de 1994 a 2005, 29 são dependentes sob cenários negativos extremos (23 no mercado asiático e 6 na América Latina) e 19 durante o período de grandes ganhos (14 no mercado asiático e 5 na América Latina). Pode-se notar que os EUA e Japão são assintoticamente independentes durante os declínios extremos do mercado, pois um par de países com $\lambda_{L}=0$ não será evidenciado na figura abaixo. Verifica-se também que Hong Kong, Malásia, Singapura e Tailândia apresentam uma forte dependência nos momentos de alta volatilidade (seu pares são evidenciados abaixo) e que a América Latina não se move conjuntamente com o mercado da Ásia. Assim, carterias diversificadas com ações do Japão e dos EUA podem ser adequadas para se proteger de grandes perdas em períodos de alta volatilidade. Os autores agruparam 32 países com mesma dependência caudal cujos resultados se mostram na figura abaixo: 


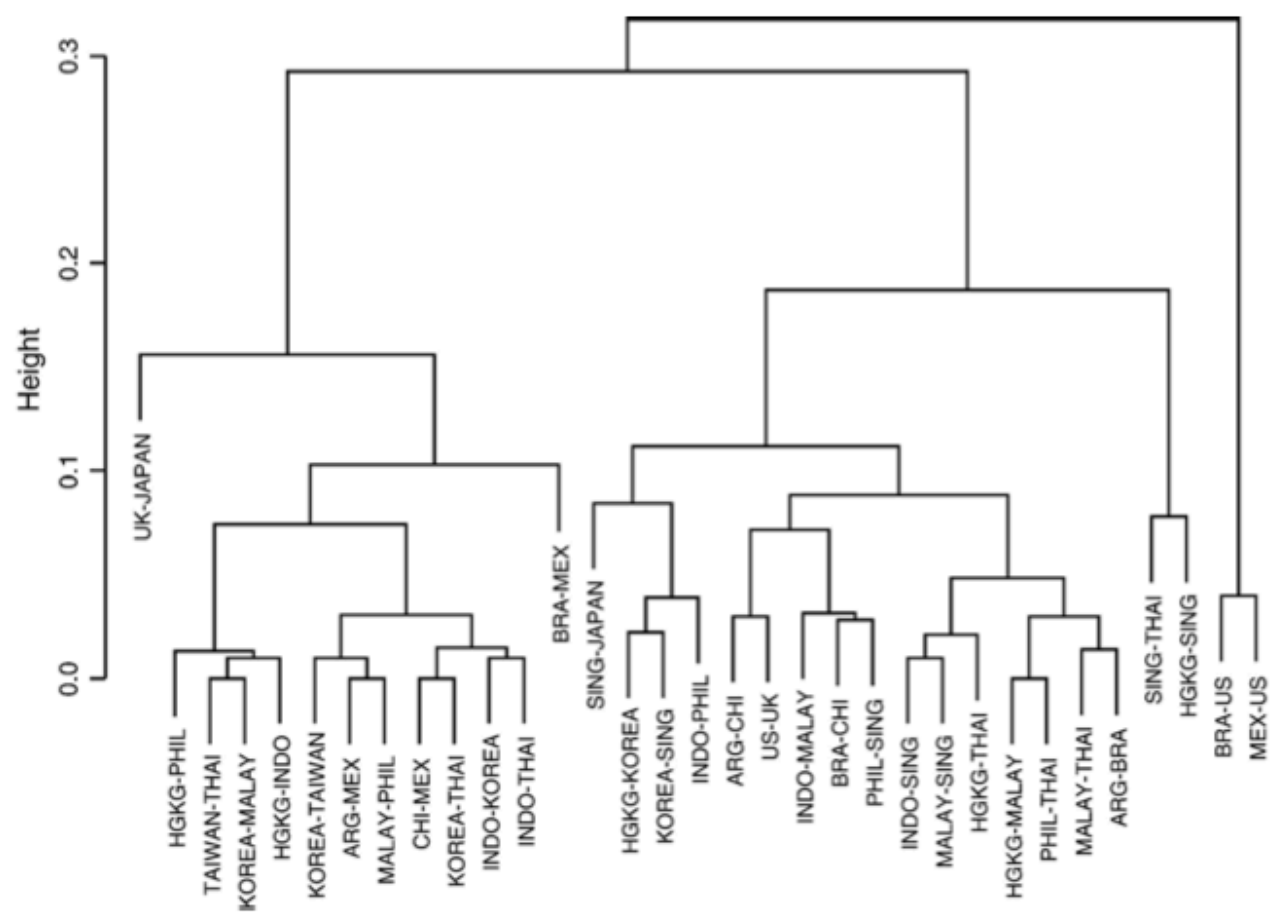

Figura 2.12 - Dendograma dos 32 pares de países conforme os índices de dependência caudal inferior $\lambda_{L}$ dos pares dos países.

Fonte: Mendes, Leal e Carvalhal-da-Silva (2007).

Vale lembrar que os índices de cauda inferior $\lambda_{L}$ da Figura acima foram calculados por meio de cópulas-t entre os pares dos países. Percebe-se que os mercados da Malásia, Filipinas, Argentina e México se relacionam da mesma forma em momentos de alta volatilidade. Assim, trocar os ativos da Malásia e da Filipinas pelos ativos da Argentina e do México numa carteiras de ativos não proporcionará beneficíos significativos de diversificação. 


\section{Capítulo 3}

\section{METODOLOGIA}

Segundo Martins (2002) este trabalho poderá ser classificado conforme às seguintes modalidades de pesquisa:

- Empírico-analíticas: são abordagens que apresentam em comum a utilização técnicas de coleta, tratamento e análise de dados marcadamente quantitativas. Privilegiam estudos práticos. Suas propostas têm caráter técnico, restaurador e incrementalista. Tem forte preocupação com a relação causal entre variáveis. A validação da prova cientifica é realizada através de testes de significância e sistematização das definições operacionais.

- Ex post facto: tipo de investigação empírica em que o investigador não tem controle direto sobre a(s) variável (is) independente (s) porque suas manifestações já ocorreram, ou porque é (são) por sua natureza, não manipulável (is).

\subsection{Hipóteses de Pesquisa}

A nossa situação-problema pode ser enunciada como:

\section{A existência da dependência assimétrica dos ativos pode proporcionar carteiras com maior desempenho em comparação ao modelo $1 / \mathrm{N}$ (regra de Talmud) no mercado norte-americano?}

Faz-se necessário a verificação das seguinte hipóteses de pesquisa:

Hipótese 1:

$\mathrm{H}_{0}$ : As carteiras formadas por estratégias com dependência assimétrica possuem mesmo desempenho médio do que àquelas determinadas pela regra de Talmud.

$\mathrm{H}_{1}$ : As carteiras formadas por estratégias de dependência assimétrica possuem maior desempenho médio do que àquelas determinadas pela regra de Talmud. 
Por outro lado, Silvapulle e Granger (2001), Long e Solnik (2001), Ramchand e Susmel (1998), Ang e Bekaert (2002) e Patton (2004) mostraram que os retornos de ações tendem a estar mais correlacionados nos mercados em declínio (bear markets) do que durante os mercados em alta (bull markets). Assim, Patton (2006) e Silvapulle e Granger (2001) afirmam que este relacionamento assimétrico entre os ativos deve ser levado em conta na avaliação da relação risco/retorno, pois o aumento da correlação entre os ativos em períodos de bear markets tende a diminuir significativamente os benefícios da diversificação. Mendes, Leal e Silva (2007, p.195) declararam que dois ativos que forem independentes em condições normais de mercado podem ser significativamente dependentes em períodos de alta volatilidade. Da mesma forma, ativos independentes nos períodos de alta volatilidade podem ser significativamente dependentes em condições normais de mercado. Logo, a dependência entre os ativos em condições extremas é uma informação muito valiosa a ser considerada num modelo de otimização de carteiras.

Campbell, Koedijk e Koofman (2002) mostraram que os benefícios advindos da diversificação podem ser relevantes quando a dependência assimétrica entre os ativos (medida pela correlação quantílica) for considerada na matriz de covariâncias do MMV, pois houve um deslocamento para a esquerda da respectiva fronteira eficiente. Leal e Mendes (2009) incorporaram a dependência assimétrica no modelo MMV por meio dos índices de dependência caudal da teoria de cópulas. Esta metodologia sobressai-se a outras abordagens alternativas, e.g. valores extremos, por modelar toda a distribuição conjunta dos ativos em questão, fornecendo além de medida de locação e dispersão como, por exemplo, média e variância, outras medidas de dependência como dependências de cauda e correlações de postos. Assim, faz-se necessário inserir a matriz de índices de dependência caudal no MMV para que consideremos os períodos de alta volatilidade na composição de carteiras de ações. Este procedimento será denominado de MMV caudal, pois leva em consideração a dependência assimétrica dos ativos.

\subsubsection{Variáveis operacionais}

As variáveis operacionais necessárias para o estudo acima são relatadas nos itens a seguir:

1. O retorno esperado será dado pela média e o risco pelo desvio-padrão conforme as equações $E\left(R_{i}\right)=\bar{R}_{i}=\sum_{j=1}^{M} P_{i j} R_{i j}$ e $\sigma^{2}\left(R_{i}\right)=\sigma_{i}^{2}=\sum_{j=1}^{M}\left(P_{i j}\left(R_{i j}-E\left(R_{1}\right)\right)^{2}\right)$ do intervalo de 120 meses que compõe o período de 03/1990 até 12/2012 a fim de se obter o vetor ótimo de pesos para carteiras com 3, 5, 10 e 20 ativos escolhidos ao acaso da DJIA (Dow Jones Industrial Average).

2. O coeficiente de correlação de Pearson é incapaz de medir o relacionamento dos ativos em períodos de alta volatilidade no modelo MMV clássico. Para tanto, utilizaremos os índices de cauda inferior da cópula de Joe-Clayton Simetrizada 
(BERGMANN et al., 2011 e PATTON, 2006). Assim, construímos a matriz dos índices de dependência caudal inferior para ser usada no modelo MMV. O índice dependência caudal inferior para cada par de ações será determinado pelo parâmetro estimado $v$ da equação (2.61). Estas rotinas de estimação pelo MATLAB se encontram no anexo deste trabalho.

3. Determinação da matriz robusta de covariâncias pelo algoritmo de Ledoit e Wolf (2004) conforme a equação $\Sigma=\delta F+(1-\delta) S$ encontrada no referencial teórico de matriz robusta de covariâncias;

4. Determinação do parâmetro $\delta$ e $\gamma$ para combinar as estratégias de diversificação $1 / \mathrm{N}, \mathrm{MMV}$ robusto e o MMV caudal conforme as equações $\bar{w}_{\text {Talmud-MMV }}=\delta w_{e}+$ $\left\{\frac{(1-\delta)}{2} \bar{w}_{M M V}\right\}$ e $\bar{w}_{\text {Talmud-MMVCaudal }}=\gamma w_{e}+\left\{\frac{(1-\gamma)}{2} \bar{w}_{M M V C a u d a l}\right\}$, com $\delta$ e $\gamma$ entre 0 $\mathrm{e}+1$.

5. Determinação da utilidade para comparação do desempenho das carteiras conforme Tu e Zhou (2011).

\subsubsection{Amostra}

A amostra dos 30 ativos do DJIA foi obtida pelo servidor da Bloomberg via software Mathematica 9.0 no dia 3/01/2013. Obteve-se o preço mensal de fechamento no período de 03/1990 até 12/2012. Escolheu-se 03/1990 como ponto de partida para que tenhamos todos os 30 ativos do DJIA. Os tickers das 30 ações pertencentes ao DJIA que compõem nossa amostra são: AA, AXP, BA, BAC, CAT, CSCO, CVX, DD, DIS, GE, HD, HPQ, IBM, INTC, JNJ, JPM, KO, MCD, MMM, MRK, MSFT, PFE, PG, T, TRV, UNH, UTX, VZ, WMT e XOM. Os comandos utilizados no software Mathematica 9.0 para obtenção da amostra foi :

mem = FinancialData["^DJI","Members];

FinancialData[\#,"Price",\{\{1990,3\},\{2012,12\},"Month" $\}][[$ All,2]]\&/@mem

Dow Jones Industrial Average (DJIA) é um índice criado em 1896 pelo editor do The Wall Street Journal e fundador do Dow Jones $\&$ Company Charles Dow. É o segundo mais antigo índice dos Estados Unidos, também conhecido como DJIA, INDP, Dow 30 ou Dow Jones. O índice Dow Jones Industrial Average (DJIA) é ao lado do Nasdaq Composite e do Standard \& Poor's 500 um dos principais indicadores dos movimentos do mercado americano. O cálculo deste índice é baseado na cotação das ações de 30 das maiores e mais importantes empresas industriais dos Estados Unidos. Como o índice não é calculado pela Bolsa de Valores de Nova Iorque (New York Stock Exchange), seus componentes são escolhidos pelos editores do jornal financeiro norte-americano The Wall Street Journal. Não existe nenhum critério pré-determinado, a não ser que os componentes sejam companhias norte-americanas líderes em seus segmentos de mercado. 
No cálculo do índice DJIA, a soma dos preços das ações das 30 empresas é dividida por um divisor, conhecido como Dow. Esse divisor é ajustado no caso de splits, spinoffs ou outras mudanças estruturais para assegurar que essas mudanças não vão alterar sobremaneira o valor do índice. O divisor inicialmente usado foi o número de empresas, de forma que o índice DJIA era a simples média aritmética dos preços das ações. Hoje, após muitos ajustes, o divisor tem um valor menor que um, ou seja, o valor do índice hoje é maior que a soma dos preços das ações das empresas componentes. Isto é: $D J I A=\frac{\sum p}{d}$, onde os valores de $p$ são os preços das ações das empresas que compõe o índice e $d$ é o divisor Dow. O método de cálculo do DJIA não reflete o fato de que uma mudança de um dólar para uma ação de valor $\$ 10$ é muito mais significativa que uma mudança de um dólar para uma ação de valor $\$ 100$. Além desse fato, a composição do índice usando apenas 30 empresas leva alguns críticos a dizer que o índice DJIA não representa de forma precisa o comportamento geral do mercado. Apesar de todas essas imperfeições, o índice DJIA tem historicamente representado a performance da economia americana de forma bastante precisa e o continua sendo um dos mais observados indicadores do desempenho do mercado de ações.

Os gráficos dos preços de fechamento para 4 ações escolhidas ao acaso (BAC, CSCO, CVX e DD) que compõem o DJIA no período de 03/1990 a 12/2012 estão localizados logo abaixo:

As carteiras serão formadas por 3, 5, 10 ou 20 ativos escolhidos ao acaso sem reposição. A janela de estimação conterá 120 retornos mensais para determinar o vetor de médias, covariâncias e os índices de dependência caudal inferior. Este período foi escolhido, pois Tu e Zhou (2011) e DeMiguel, Garlappi e Uppal (2009) usaram 120 meses para suas estimações na metodologia conhecida como "rolling window" (média-móvel). A priori, há uma desvantagem em trabalhar com retornos mensais, pois estes tendem para a normalidade e, assim, não haveria a presença de dependência caudal nos retornos de ações. Mas, Patton (2004) identificou, com base em retornos mensais de ativos da bolsa norte-americana, que a estratégia de alocação de ativos com base no coeficiente $\rho$ foi superada pela estratégia com dependência assimétrica. Houve um benefício significativo da utilização da dependência assimétrica em favor do modelo clássico nas séries de retornos mensais da bolsa norte-americana. Diante do exposto, as estratégias com dependência caudal se mostram mais adequadas quando os retornos não seguirem uma distribuição normal de probabilidades.

Para cada período de 120 meses determinaremos o vetor ótimo de pesos a fim de encontrar o retorno em excesso ao T-Bond de 10 anos da carteira no mês subsequente. Este processo é continuado para todas os 272 meses que compreendem o período de 03/1990 a 12/2012 

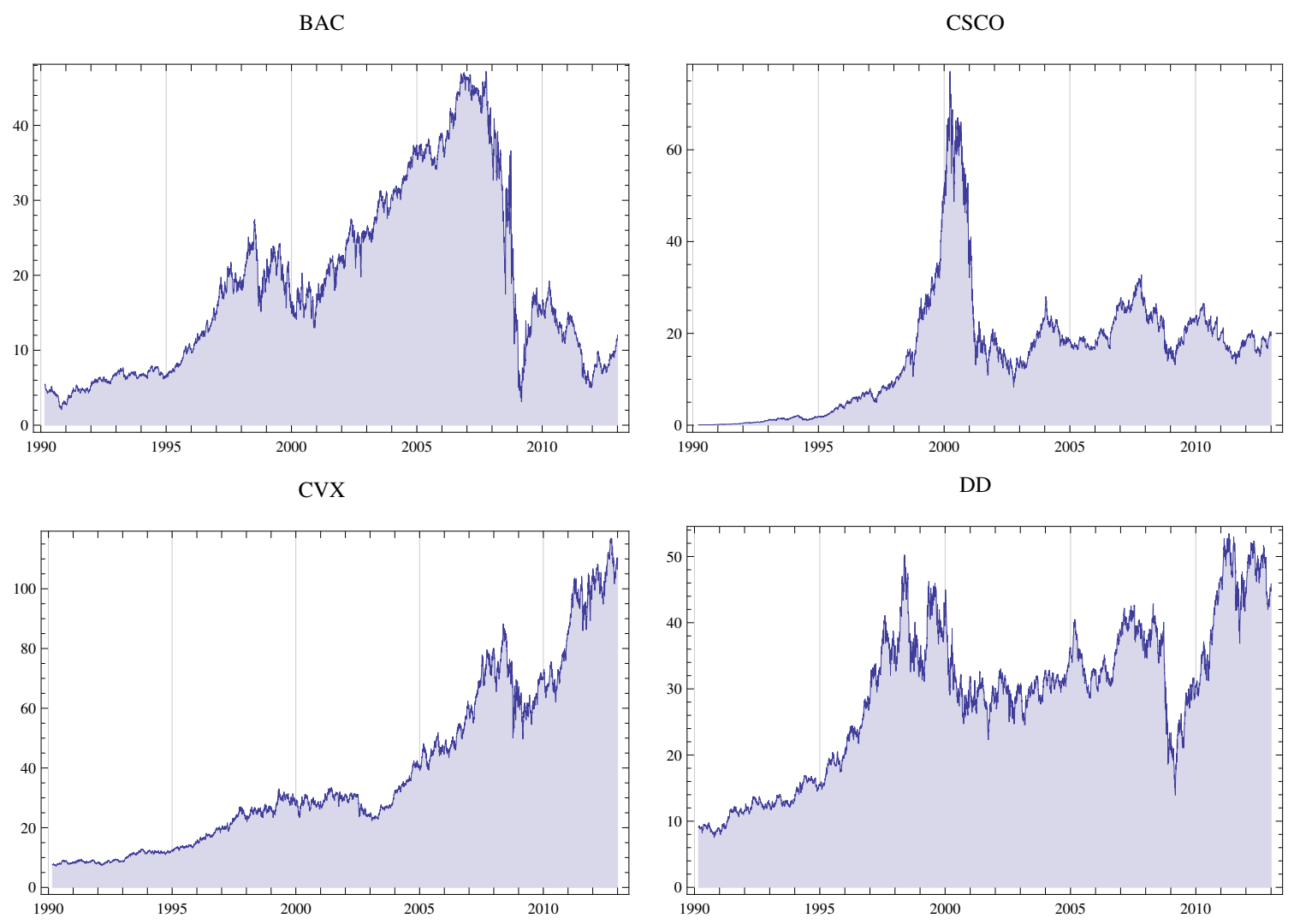

Figura 3.1 - Evolução dos preços de fechamento das ações BAC, CSCO, CVX e DD no período de 03/1990 a 12/2012.

a fim de encontrar uma série de retornos ex-ante com 272 - $120=152$ observações mensais. Estimaremos o vetor de pesos da carteira de mínima variância com 120 observações mensais na abordagem "rolling window" por MMV Caudal, denominado de $\bar{w}_{\text {Cópula }}$. Optaremos por determinar a carteira de mínima variância, pois vários trabalhos acadêmicos reportaram seus resultados nesta abordagem e pela facilidade de estimação dos parâmetros (LEAL e MENDES, 2010). Os procedimentos para verificar a veracidade das hipóteses declaradas serão:

1. Escolhe-se aleatoriamente as 1.000 carteiras com 3, 5, 10, 15 e 20 ativos do DJIA no período de 03/1990 até 12/2012 (sem reposição);

2. Para cada período de 120 meses determina-se o vetor ótimo dos pesos conforme os passos declarados acima para determinar o retorno em excesso ao T-Bond de 10 anos da carteira no mês posterior. Este processo é continuado para todas os 120 meses que compreendem o período de análise a fim de encontrar uma série com 152 observações de retornos em excesso mensais (TU e ZHOU, 2011; PATTON, 2004);

3. MMV robusto: Calcular a matriz de correlação conforme Ledoit e Wolf (2004) para 
estimar o vetor de pesos da carteira de mínima variância na abordagem "rolling window". Assim, por exemplo, para 1.000 carteiras com três ativos teremosuma matriz de pesos de 1.000 linhas com 3 colunas;

4. Calcular o peso ótimo da combinação de estratégias de Markowitz com a regra de Talmud. Neste caso, considera-se a combinação de $\bar{w}_{M M V}$ com a regra de Talmud, $w_{e}$, por meio somente do peso $\delta$ de acordo com a equação (2.48);

5. Dependência caudal: (i) Determinar as distribuições marginais de todos os pares dos ativos envolvidos na carteira conforme uma distribuição estável de Pareto encontrada em Rachev, Menn e Fabozzi (2005). Conforme Rachev, Menn e Fabozzi (2005, p. 81), as distribuições estáveis de Pareto apresentam propriedades extremamente desejáveis na modelagem de retornos de ações, pois captam adequadamente os seguintes fatos estilizados em finanças: assimetria, caudas gordas e os eventos extremos da amostra. (ii) Determinar os parâmetros $u$ e $v$ da cópula de JCS a partir das marginais estimadas anteriormente. (iii) O índice de dependência caudal será dado pelo parâmetro estimado $u$ da cópula de Joe-Clayton Simetrizada encontrada em (2.61); (iv) Determinar a matriz dos índices de dependência de cauda inferior para todos os pares de ativos selecionados nas respectivas carteiras selecionadas aleatoriamente. (v) Determinar o vetor de pesos da carteira de mínima variância, $\bar{w}_{C o ́ p u l a}$, com a incorporação da matriz de dependência caudal no modelo de Markowitz;

6. Haverá a obtenção de 152 vetores de pesos conforme a amostra de ações escolhidas ao acaso. Assim, esse processo será relaizado para as 1.000 carteiras sob análise;

7. Dependência caudal em modelos combinados: Calcular o peso ótimo da combinação de estratégias sob a consideração da dependência caudal. Neste caso, considera-se a combinação de $\bar{w}_{M M V}$, de $w_{e}$ e $\bar{w}_{C o ́ p u l a ~}$ por meio da estimação de $\delta$ e de $\gamma$;

8. Determinar os retornos em excesso fora da amostra (ex-post) do MMV robusto;

9. Determinar os retornos em excesso do MMV caudal (dependência caudal);

10. Determinar os retornos em excesso do modelo de Tu e Zhou;

11. Determinar os retornos em excesso da combinação entre a regra de Talmud, o MMV caudal e o MMV robusto (dependência caudal em modelos combinados);

12. Calcular a utilidade fora da amostra para os itens de 7 a 10 . Calcular a utilidade para a regra de Talmud sob a consideração que os pesos são sempre iguais a $1 / N$;

13. Por fim, aplica-se o teste não-paramétrico de Wilcoxon a fim de verificar se há diferenças significativas entre a performance da estratégia com dependência 
assimétrica com a da regra de Talmud. Utilizamos o teste de Wilcoxon, pois as amostras são emparelhadas e as carteiras são independentes umas das outras, pois as ações foram escolhidas ao acaso. Analogamente, comparamos o item 10 (dependência assimétrica em modelos combinados) com a regra de Talmud;

14. Se os valores-P do testes acima forem menores do que $5 \%$, rejeitamos o fato de que as utilidades para os modelos acima sejam estatisticamente iguais;

15. Obteremos a média dos retornos acumulados das 1.000 carteiras selecionadas ao acaso para para verificar se os modelos com dependência caudal apresentaram maiores ganhos do que a regra de Talmud no período considerado.

A Hipótese 2 pode ser expressa por:

$\mathrm{H}_{0}$ : As carteiras formadas por estratégias de dependência assimétrica possuem mesmo desempenho médio do que àquelas determinadas pelo MMV robusto.

$\mathrm{H}_{1}$ : As carteiras formadas por estratégias de dependência assimétrica possuem maior desempenho médio do que àquelas determinadas pelo MMV robusto.

Espera-se rejeitar $H_{o}$ conforme Hatherley e Alcock (2007) e Patton(2004). Os procedimentos para verificar a veracidade da hipótese nula acima ao nível de $5 \%$ são:

1. Reaiza-se os passos de 1 a 6 mencionados logo acima;

2. Determinar os retornos em excesso fora da amostra do MMV robusto;

3. Determinar os retornos em excesso fora da amostra do MMV caudal (dependência caudal);

4. Determinar os retornos em excesso fora da amostra do modelo de Tu e Zhou;

5. Determinar os retornos em excesso fora da amostra da combinação entre a regra de Talmud, o MMV caudal e o MMV robusto (dependência caudal em modelos combinados);

6. Calcular a utilidade fora da amostra para os iten 2,3 , e 5;

7. Por fim, aplica-se o teste não-paramétrico de Wilcoxon a fim de verificar se há diferenças significativas entre a performance da estratégia com dependência assimétrica com o modelo de Markowitz. Utilizamos o teste de Wilcoxon, pois as amostras são emparelhadas e as carteiras são independentes umas das outras, pois as 
ações foram escolhidas ao acaso. Analogamente, comparamos o item 5 (dependência assimétrica em modelos combinados) com o modelo de Markowitz;

8. Se os valores-P do testes acima forem menores do que $5 \%$, rejeitamos o fato de que as utilidades para os modelos acima sejam estatisticamente iguais;

9. Calculamos o retorno em excesso acumulado nos 152 meses de análise para verificar se os modelos com dependência caudal apresentaram superam o modelo de Markowitz em termos de retorno realizado;

A Hipótese 3 pode ser expressa por:

$\mathrm{H}_{0}$ : As carteiras formadas por estratégias de dependência assimétrica possuem mesmo desempenho médio do que àquelas determinadas pela estratégia de Tu e Zhou

$\mathrm{H}_{1}$ : As carteiras formadas por estratégias de dependência assimétrica possuem maior desempenho médio do que àquelas determinadas pela estratégia de Tu e Zhou

Nesse caso, espera-se que a dependência assimétrica possa proporcionar benefícios adicionais na diversificação das carteiras pelos trabalhos acadêmicos já citados. Os procedimentos para verificar a veracidade da hipótese nula acima ao nível de $5 \%$ são:

1. Reaiza-se os passos de 1 a 6 mencionados logo acima;

2. Determinar os retornos em excesso fora da amostra do MMV robusto;

3. Determinar os retornos em excesso fora da amostra do MMV caudal (dependência caudal);

4. Determinar os retornos em excesso fora da amostra do modelo de Tu e Zhou;

5. Determinar os retornos em excesso fora da amostra da combinação entre a regra de Talmud, o MMV caudal e o MMV robusto (dependência caudal em modelos combinados);

6. Calcular a utilidade fora da amostra para os itens de 3 a 5;

7. Por fim, aplica-se o teste não-paramétrico de Wilcoxon a fim de verificar se há diferenças significativas entre a performance da estratégia com dependência assimétrica com o modelo de $\mathrm{Tu}$ e Zhou. Utilizamos o teste de Wilcoxon, pois as amostras são emparelhadas e as carteiras são independentes umas das outras, pois as ações foram escolhidas ao acaso. Analogamente, comparamos o item 5 (dependência assimétrica em modelos combinados) com o modelo de Tu e Zhou; 
8. Se os valores-P do testes acima forem menores do que $5 \%$, rejeitamos o fato de que as utilidades para os modelos acima sejam estatisticamente iguais;

9. Calculamos o retorno em excesso acumulado nos 152 meses de análise para verificar se os modelos com dependência caudal apresentaram superam o modelo de Tu e Zhou em termos de retorno realizado; 


\section{Capítulo 4}

\section{RESULTADOS OBTIDOS}

Escolhemos as 30 ações integrantes do índice Dow Jones Industrial Average através do software Mathematica 9 no período de 03/1990 até 12/2012. Geralmente, as ações do DJIA correspondem a companhias industriais líderes dos seus segmentos de mercado. São elas com seus respectivos setores de atuação: Alcoa - AA - (Metalurgia); American Express - AXP - (Serviços Financeiros); Boeing - BA - (Aeronaútica); Bank of America - BAC - (Serviços Financeiros); Caterpillar - CAT - (Maquinaria); Cisco - CSCO - (Tecnologia de Informática); Chevron - CVX - (Petroquímico); DuPont - DD - (Indústria Química); The Walt Disney Company - DIS - (Entretenimento), General Electric - GE - (Eletrônica e Serviços Financeiros), Home Depot - HD - (Material de Construção), Hewlett-Packard - HPQ - (Informática), International Business Machines - IBM - (Informática), Intel INTC - (Eletrônica), Johnson \& Johnson - JNJ - (Farmacêutico), JP Morgan Chase \& Co. - JPM - (Serviços Financeiros), Kraft Foods - KO - (Alimentos), McDonald's - MCD - (Alimentos), 3M - MMM - (Eletrônica, química e entretenimento), Merck \& Co - MRK - (Farmacêutica), Microsoft - MSFT - (Software), Pfizer Inc. - PFE - (Farmacêutica), Procter \& Gamble - PG - (Entretenimento, farmacêutico e alimentação), AT\&T - T (Telecomunicações), Travelers - TRV - (Seguros), United Health Group - UNH - (Saúde), United Technologies - UTX - (Aeroespacial), Verizon - VZ - (Telecomunicações), Wal Mart Stores Inc. - WMT (Distribuição e Varejo) e Exxon Mobil Corp. - XOM - (Petroquímico). As estatísticas descritvas para o banco de dados acima são: 
Tabela 4.1 - Estatísticas das 30 ações que compõem o DJIA e para o S\&P 500 no período de 03/1990 a 12/2012.

\begin{tabular}{|c|c|c|c|c|c|c|}
\hline Ativos & Média & Desvio-Padrão & Máximo & Mínimo & Beta & Normalidade \\
\hline $\mathbf{A A}$ & $-0,09 \%$ & $10,54 \%$ & $40,91 \%$ & $-67,55 \%$ & 1,65 & $0,0000^{* * *}$ \\
\hline AXP & $0,67 \%$ & $9,09 \%$ & $62,88 \%$ & $-35,14 \%$ & 1,41 & $0,0000^{* * *}$ \\
\hline BA & $0,31 \%$ & $8,27 \%$ & $17,93 \%$ & $-42,69 \%$ & 0,98 & $0,0000^{* * *}$ \\
\hline BAC & $0,01 \%$ & $12,06 \%$ & $54,91 \%$ & $-76,04 \%$ & 1,62 & $0,0000^{* * *}$ \\
\hline CAT & $0,80 \%$ & $9,42 \%$ & $33,84 \%$ & $-43,57 \%$ & 1,31 & $0,0011^{* * *}$ \\
\hline $\mathrm{CSCO}$ & $1,74 \%$ & $11,85 \%$ & $32,62 \%$ & $-46,16 \%$ & 1,62 & $0,0391^{* * *}$ \\
\hline CVX & $0,70 \%$ & $5,67 \%$ & $20,85 \%$ & $-16,68 \%$ & 0,67 & $0,0276^{* * *}$ \\
\hline DD & $0,31 \%$ & $7,29 \%$ & $22,25 \%$ & $-23,14 \%$ & 1,09 & $0,0010^{* * *}$ \\
\hline DIS & $0,42 \%$ & $7,65 \%$ & $21,19 \%$ & $-31,48 \%$ & 1,11 & $0,0000^{* * *}$ \\
\hline GE & $0,46 \%$ & $7,53 \%$ & $22,39 \%$ & $-32,63 \%$ & 1,28 & 0,3401 \\
\hline HD & $1,06 \%$ & $8,04 \%$ & $25,96 \%$ & $-23,24 \%$ & 1,03 & $0,0030^{* * *}$ \\
\hline HPQ & $0,22 \%$ & $10,55 \%$ & $30,16 \%$ & $-39,06 \%$ & 1,45 & $0,0000^{* * *}$ \\
\hline IBM & $0,59 \%$ & $8,11 \%$ & $30,16 \%$ & $-30,64 \%$ & 1,02 & $0,0000^{* * *}$ \\
\hline INTC & $0,81 \%$ & $11,44 \%$ & $28,96 \%$ & $-59,37 \%$ & 1,53 & $0,0020^{* * *}$ \\
\hline JNJ & $0,75 \%$ & $5,75 \%$ & $16,85 \%$ & $-17,91 \%$ & 0,60 & $0,0000^{* * *}$ \\
\hline JPM & $0,62 \%$ & $10,29 \%$ & $28,11 \%$ & $-43,01 \%$ & 1,49 & $0,0000^{* * *}$ \\
\hline KO & $0,66 \%$ & $6,20 \%$ & $19,70 \%$ & $-21,65 \%$ & 0,63 & $0,0047^{* * *}$ \\
\hline MCD & $0,74 \%$ & $6,47 \%$ & $16,72 \%$ & $-29,84 \%$ & 0,76 & $0,0037^{* * *}$ \\
\hline MMM & $0,52 \%$ & $5,87 \%$ & $22,58 \%$ & $-17,67 \%$ & 0,68 & $0,0000^{* * *}$ \\
\hline MRK & $0,49 \%$ & $7,63 \%$ & $20,11 \%$ & $-30,19 \%$ & 0,70 & $0,0000^{* * *}$ \\
\hline MSFT & $1,14 \%$ & $9,47 \%$ & $33,67 \%$ & $-42,57 \%$ & 1,28 & $0,0000^{* * *}$ \\
\hline PFE & $0,80 \%$ & $6,91 \%$ & $23,33 \%$ & $-19,42 \%$ & 0,80 & $0,0000^{* * *}$ \\
\hline PG & $0,69 \%$ & $6,08 \%$ & $22,10 \%$ & $-44,19 \%$ & 0,44 & $0,0000^{* * *}$ \\
\hline $\mathbf{T}$ & $0,40 \%$ & $6,73 \%$ & $25,58 \%$ & $-20,93 \%$ & 0,69 & $0,0060^{* * *}$ \\
\hline TRV & $0,69 \%$ & $7,31 \%$ & $42,66 \%$ & $-30,41 \%$ & 0,75 & $0,0070^{* * *}$ \\
\hline UNH & $1,65 \%$ & $9,96 \%$ & $33,41 \%$ & $-45,29 \%$ & 0,99 & $0,0000^{* * *}$ \\
\hline UTX & $0,80 \%$ & $7,02 \%$ & $21,68 \%$ & $-38,86 \%$ & 1,09 & $0,0000^{* * *}$ \\
\hline $\mathbf{V Z}$ & $0,34 \%$ & $6,61 \%$ & $32,97 \%$ & $-23,98 \%$ & 0,68 & $0,0000^{* * *}$ \\
\hline WMT & $0,74 \%$ & $6,63 \%$ & $23.11 \%$ & $-23.73 \%$ & 0.64 & $0,0176^{* * *}$ \\
\hline XOM & $0,72 \%$ & $4,66 \%$ & $20,79 \%$ & $-12,64 \%$ & 0,53 & $0,0034^{* * *}$ \\
\hline S\&P 500 & $0,525 \%$ & $4,38 \%$ & $10,58 \%$ & $-18,56 \%$ & 1,00 & $0,0022^{* * *}$ \\
\hline
\end{tabular}

Nota: Níveis de Significância: * : 10\%, ${ }^{* *}: 5 \%,{ }^{* * *}: 1 \%$. (1) O teste de Jarque-Bera foi realizado para avaliar se os retornos de ações podem ser representados por uma distribuição normal de probabilidades.

Calcularemos o beta do ativo com base no S\&P 500 como carteira de mercado e o TBond de 10 anos como ativo livre de risco durante o período analisado. Pela Tabela acima, verifica-se que somente os retornos da GE podem ser descritos por uma distribuição normal ao nível de 5\% conforme o tradicional teste de Jarque-Bera (valor-P $=0,3401>$ $0,05)$. Todos os outros ativos apresentaram valores-P inferiores a $5 \%$ e, portanto, podemos rejeitar a hipótese nula da existência de normalidade. Sabe-se que se os pares de ativos seguirem uma distribuição normal conjunta de probabilidades, a presença da dependência caudal entre os pares dos ativos fica severamente comprometida. Se dois ativos quaisquer não seguirem isoladamente uma distribuição normal de probabilidades, sua distribuição conjunta nunca poderá ser uma normal. Do exposto, a dependência caudal estará presente entre os pares de ativos quando pelo menos um deles não for normal. a dependência caudal 
pode ser previamente estudada na amostra em questão. Apenas um ativo (GE) pode ser descrito por uma normal e, assim, a dependência caudal pode ser previamente estudada na amostra em questão.

Conforme a Tabela acima, os 10 ativos que apresentam maior risco de mercado são: MSFT, GE, CAT, AXP, HPQ, JPM, INTC, BAC, CSCO e AA. O beta médio dos dez ativos destacados é de 1.46, demonstrando que se trata de uma carteira mais arriscada do que a carteira de mercado (S\&P 500). A volatilidade condicional é a principal fonte de dependência assimétrica segundo Mendes e Kolev (2008). Assim, quanto maior for o risco de mercado dos ativos, maior tende a ser os benefícios proporcionados pela matriz de dependência caudal na diversificação.

\subsection{Resultados obtidos para carteiras formadas com 3 ativos escolhidos aleatoriamente}

Escolhemos 1000 carteiras com 3 ações do DJIA ao acaso. Assim, teremos 1000 retornos acumulados e 1000 utilidades para cada estratégia contemplada neste trabalho. O teste não-paramétrico de Wilcoxon foi utilizado, pois as utilidades das estratégias não são normais e as carteiras são independentes, ou seja, as ações são escolhidas ao acaso. As utilidades foram anualizadas e calculadas com base num coeficiente de aversão ao risco $\gamma=1$. O retorno esperado contempla a média dos retornos das 1.000 carteiras em cada estratégia. Já o risco compreende o desvio-padrão da série que contempla o retorno médio das 1000 carteiras geradas em cada estratégias. Os principais resultados foram:

Tabela 4.2 - Resultados médios para 1.000 carteiras de 3 ações escolhidas ao acaso do DJIA no período de 03/1990 a 12/2012.

\begin{tabular}{ccccc}
\hline Estratégias & $\begin{array}{c}\text { Retorno } \\
\text { Esperado }\end{array}$ & Risco & $\begin{array}{c}\text { CER } \\
\text { Médio }^{(1)} \\
\text { Hipótese I }\end{array}$ & $\begin{array}{c}\text { Média dos } \\
\text { Retornos } \\
\text { Acumulados }\end{array}$ \\
\hline Painel A: Sem dependência caudal & & & & \\
Talmud & $0,063 \%$ & $5,978 \%$ & $-0,122 \%$ & $84,128 \%$ \\
Markowitz & $0,126 \%$ & $5,461 \%$ & $-0,275 \% * *$ & $93,678 \%$ \\
Tu e Zhou & $0,103 \%$ & $5,794 \%$ & $-0,056 \% * *$ & $84,722 \%$ \\
\hline Painel B: Com dependência caudal & & & & \\
Dependência Caudal & $0,136 \%$ & $5,432 \%$ & $-0,018 \% * *$ & $95,116 \%$ \\
$\begin{array}{c}\text { Combinação de Talmud, } \\
\text { Markowitz e Dependência Caudal }\end{array}$ & $0,102 \%$ & $7,493 \%$ & $-0,054 \% * *$ & $78,116 \%$ \\
\hline $\begin{array}{c}\text { S\&P 500 } \\
\text { T-Bond (10 anos) }\end{array}$ & $0,824 \%$ & $4,527 \%$ & $0,722 \%$ & $221,650 \%$ \\
\hline
\end{tabular}

Nota: Níveis de Significância: * : 10\%, ${ }^{* *}: 5 \%, * * *: 1 \%$. (1) O teste de Wilcoxon foi realizado para se avaliar $H_{0}: C E R_{\text {Médio }}$ da regra de Talmud $=C E R_{\text {Médio }}$ da respectiva estratégia. A média dos retornos acumulados está se referenciando aos 152 meses analisados. 
Pelos resultados acima, verificamos que as estratégias com dependência caudal superaram significativamente a regra de Talmud ao nível de 5\%. Todas as estratégias com 3 ativos se mostraram perdedoras devido as utilidades serem negativas. Podemos afirmar também que, em termos de utilidade média, todas estratégias tiveram melhor desempenho do que a regra de Talmud, com exceção do modelo de Markowitz. Nota-se que o modelo de Markowitz apresentou um desempenho inferior ao da regra de Talmud, com utilidade média igual a $-0,275 \%$ (valor-P $=0,0330<5 \%$ ).

A média dos retornos acumulados das 1000 carteiras geradas pela estratégia com dependência caudal foi maior do que todas as outras estratégias em destaque. Notamos que a média dos retornos acumulados da estratégia com dependência caudal $(95,116 \%$ a.p.). O modelo de Markowitz também apresentou um retorno acumulado de 93,678\% a.p. que se encontra muito próximo (diferença de 1,438\% a.p.) ao da estratégia com dependência caudal. O retorno médio acumulado da estratégia com dependência caudal supera em torno de $58 \%$ dos meses o do modelo de Markowitz. Isso mostra que, em termos de retorno acumulado, a estratégia com dependência caudal foi vencedora na maioria dos meses perante outras estratégias e Markowitz. Vale ressaltar que Rachev (2004) compara o desempenho de diversas métricas de desempenho a partir do retorno acumulado gerado pela abordagem rolling-window numa carteira com 5 ações de empresas alemãs.

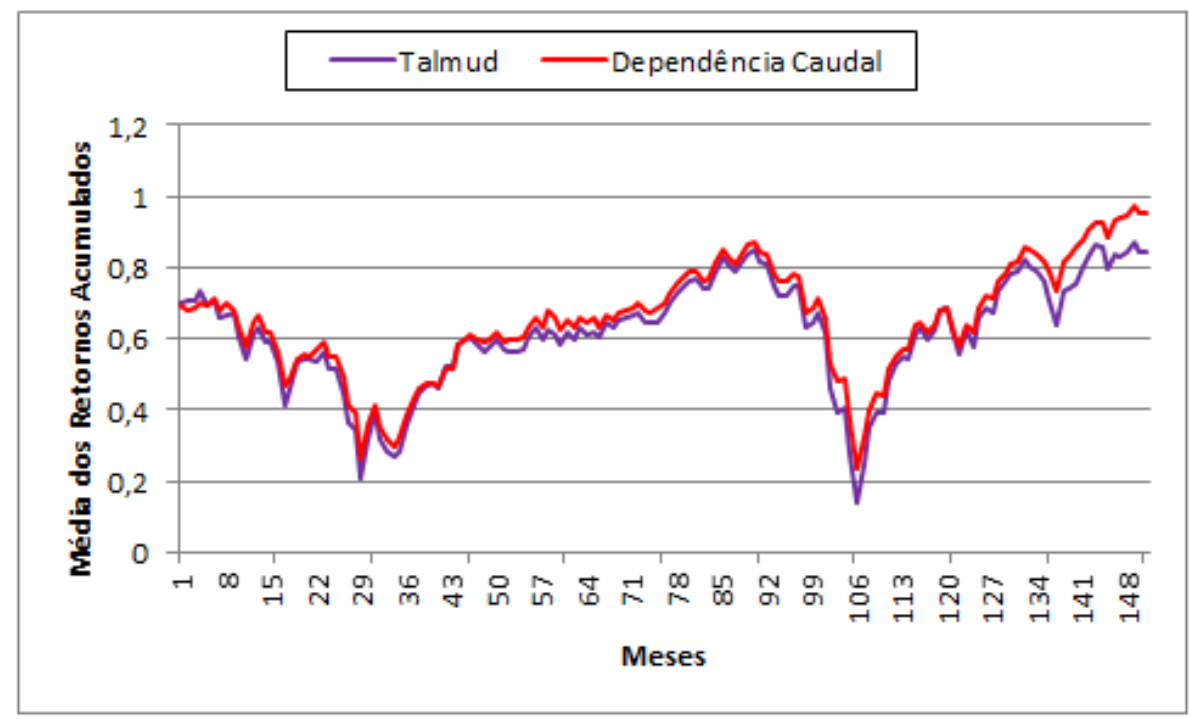

Figura 4.1 - Média dos retornos acumulados para 1.000 carteiras com 3 ações do DJIA escolhidas aleatoriamente nos 152 meses.

O gráfico acima representa a evolução da média dos retornos acumulados para as 1.000 carteiras escolhidas ao acaso do DJIA no período de 03/1990 até 12/2012. O retorno acumulado da estratégia com dependência caudal foi superior ao da regra de Talmud em 93\% dos meses analisados. Optou-se por retratar somente a estratégia com dependência 
caudal, pois esta obteve um retorno acumulado superior àquela que contempla os modelos combinados.Observamos que nos dois maiores momentos de queda, situados em torno do $30^{0}$ mês e do $110^{0}$ mês (crise norte-americana do subprime), a estratégia com dependência caudal superou a regra de Talmud. Isto está em conformidade com os resultados encontrados por Hatherley e Alcock (2007), pois a estratégia caudal tende a formar carteiras com menores perdas potenciais em momentos de alta volatilidade. A Tabela abaixo contém os resultados necessários para avaliarmos as hipóteses II e III. O teste de Wilcoxon foi realizado para se avaliar a Hipótese II: $H_{0}: C E R_{\text {Médio }}$ da estratégia

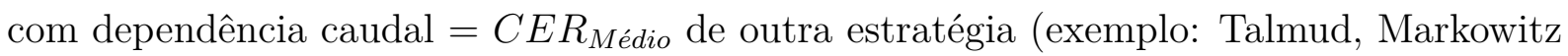
ou Tu e Zhou). Avaliamos também a Hipótese III: $H_{0}: C E R_{\text {Médio }}$ da estratégia com dependência caudal em modelos combinados $=C E R_{\text {Médio }}$ de outra estratégia avaliada.

Tabela 4.3 - Comparação entre o CER médio das estratégias com dependência caudal e o CER médio das outras estratégias ao nível de $5 \%$ para as 1.000 carteiras com 3 ações do DJIA escolhidas ao acaso.

\begin{tabular}{ccc}
\hline Estratégias & $\begin{array}{c}\text { CER Médio } \\
\text { Hipótese II }\end{array}$ & $\begin{array}{c}\text { CER Médio } \\
\text { Hipótese III }\end{array}$ \\
\hline Painel A: Sem dependência caudal & & \\
Talmud & $-0,122 \%^{* *}$ & $-0,122 \%^{* *}$ \\
Markowitz & $-0,275 \%^{* *}$ & $-0,275 \% * *$ \\
Tu e Zhou & $-0,056 \%$ & $-0,056 \%$ \\
\hline Painel B: Com dependência caudal & & \\
Dependência Caudal & $\mathrm{X}$ & $-0,018 \%$ \\
Combinação de Talmud, & $-0,054 \%$ & $\mathrm{X}$ \\
Markowitz e Dependência Caudal & & \\
\hline
\end{tabular}

Nota: Níveis de Significância: * : 10\%, ** : 5\%,*** : $1 \%$.

Podemos afirmar que as estratégias com dependência caudal superaram Markowitz e Talmud ao nível de 5\% para carteiras formadas com 3 ativos. Já DeMiguel, Garlappi e Uppal (2009) encontraram que, para o caso de 3 ativos, a regra de Talmud superou tanto Markowitz como as outras regras de alocação de ativos. Os principais motivos seriam: (i) erro de estimação do vetor de médias e da matriz de covariâncias e (ii) diminuição do risco idiossincrático advindo da utilização de carteiras formadas por outras carteiras já constituídas por certos critérios financeiros encontrados no website do Prof. Kenneth French (size, book-to-market etc).

O erro de estimação sempre estará presente nos modelos de otimização. Assim, assumese, por hipótese, que o erro de estimação não diferencia os resultados encontrados nesta tese com os trabalhos divulgados anteriormente. Como nossa amostra é baseada em carteiras formadas por ações do índice DJIA, concluímos que a diminuição do risco idiossincrático na constituição das amostras pode explicar a superioridade da regra de Talmud em DeMiguel, Garlappi e Uppal (2009) e do modelo combinado em Tu e Zhou 
(2011). Na prática os gestores de investimentos formam carteiras a partir da seleção de ações, reforçando a importância dos resultados aqui encontrados.

\subsection{Resultados obtidos para carteiras formadas com 5 ativos escolhidos aleatoriamente}

Escolhemos 1000 carteiras com 5 ações do DJIA ao acaso. Assim, teremos 1000 retornos acumulados e 1000 utilidades para cada estratégia contemplada neste trabalho. O teste não-paramétrico de Wilcoxon foi utilizado, pois as utilidades das estratégias não são normais e as carteiras são independentes, ou seja, as ações são escolhidas ao acaso. As utilidades foram anualizadas e calculadas com base num coeficiente de aversão ao risco $\gamma=1$. Os principais resultados foram:

Tabela 4.4 - Resultados encontrados para 1.000 carteiras com 5 ações escolhidas ao acaso do DJIA no período de 03/1990 a 12/2012.

\begin{tabular}{ccccc}
\hline Estratégias & $\begin{array}{c}\text { Retorno } \\
\text { Esperado }\end{array}$ & Risco & $\begin{array}{c}\text { CER } \\
\text { Médio }^{(1)} \\
\text { Hipótese I }\end{array}$ & $\begin{array}{c}\text { Média dos } \\
\text { Retornos } \\
\text { Acumulados }\end{array}$ \\
\hline Painel A: Sem dependência caudal & & & & \\
Talmud & $0,072 \%$ & $4,746 \%$ & $-1,015 \%$ & $85,500 \%$ \\
Markowitz & $0,161 \%$ & $4,128 \%$ & $0,449 \%^{* * *}$ & $99,034 \%$ \\
Tu e Zhou & $0,038 \%$ & $4,894 \%$ & $-1,648 \% * * *$ & $80,212 \%$ \\
\hline Painel B: Com dependência caudal & & & & \\
Dependência Caudal & $0,176 \%$ & $3,943 \%$ & $0,678 \% * * *$ & $101,201 \%$ \\
$\begin{array}{c}\text { Combinação de Talmud, } \\
\text { Markowitz e Dependência Caudal }\end{array}$ & $0,116 \%$ & $4,297 \%$ & $-0,267 \%^{* * *}$ & $92,531 \%$ \\
\hline $\begin{array}{c}\text { S\&P 500 } \\
\text { T-Bond (10 anos) }\end{array}$ & $0,824 \%$ & $4,527 \%$ & $0,722 \%$ & $221,650 \%$ \\
\hline
\end{tabular}

Nota: Níveis de Significância: * : 10\%, ** : 5\%, *** : 1\%. (1) O teste de Wilcoxon foi realizado para se avaliar $H_{0}: C E R_{M e ́ d i o}$ da regra de Talmud $=C E R_{M e ́ d i o ~}$ da respectiva estratégia.

Pela Tabela (4.4) verifica-se que as estratégias com dependência caudal superaram significativamente a regra de Talmud ao nível de 5\%. Vale ressaltar que a utilidade da estratégia com dependência caudal $(0,678 \%)$ foi positiva e maior do que aquela obtida pela estratégia com dependência caudal em modelos combinados (-0,267\%). Nota-se que o modelo de Tu e Zhou apresentou um desempenho inferior ao da regra de Talmud, com utilidade média igual a $-1,648 \%$ (valor-P $=0,000$ ). Portanto, conclui-se que em termos de utilidade média, todas as estratégias tiveram maior utilidade do que a regra de Talmud, com exceção do modelo de combinação de estratégias de Tu e Zhou.

A média dos retornos acumulados das 1000 carteiras geradas pela estratégia com 
dependência caudal foi maior do que todas as outras estratégias em destaque. Notamos que a média dos retornos acumulados da estratégia com dependência caudal (101,201\% a.p.) foi superior a todas as estratégias analisadas. O modelo de Markowitz foi o que apresentou retorno acumulado mais próximo ao obtido pela estratégia de dependência caudal (99,304\% a.p.). Entretanto, o retorno médio acumulado da estratégia com dependência caudal superou em $72 \%$ dos meses o do modelo de Markowitz. Isso mostra que, em termos de retorno acumulado, a estratégia com dependência caudal foi vencedora perante todas as estratégias analisadas

O gráfico abaixo representa a evolução da média dos retornos acumulados para as 1.000 carteiras com 5 ações escolhidas ao acaso do DJIA no período de 03/1990 até 12/2012. O retorno acumulado da estratégia com dependência caudal foi superior ao da regra de Talmud em 100\% dos 152 meses analisados. Optou-se por retratar somente a estratégia com dependência caudal, pois esta obteve um retorno acumulado superior àquela que contempla os modelos combinados.

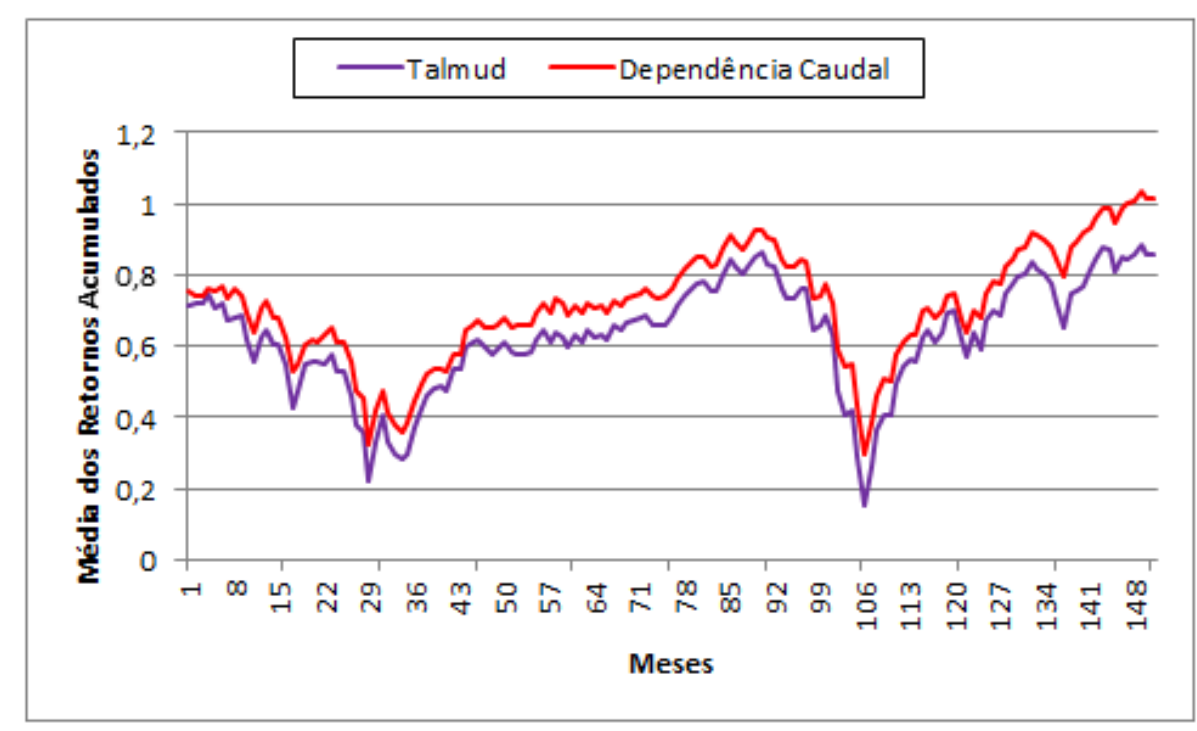

Figura 4.2 - Média dos retornos acumulados para 1.000 carteiras com 5 ações do DJIA escolhidas aleatoriamente nos 152 meses.

Pelo gráfico acima, observamos que nos dois maiores momentos de queda, situados em torno do $30^{0}$ mês e do $107^{0}$ mês (crise norte-americana do subprime), a estratégia com dependência caudal superou a regra de Talmud. Isto está em conformidade com os resultados encontrados por Hatherley e Alcock (2007), pois a estratégia caudal tende a formar carteiras com menores perdas potenciais em momentos de alta volatilidade. A Tabela abaixo contém os resultados necessários para avaliarmos as hipóteses II e III. O teste de Wilcoxon foi realizado para se avaliar a Hipótese II: $H_{0}: C E R_{\text {Médio }}$ da estratégia

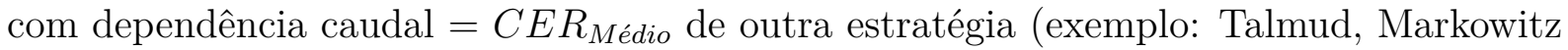


ou Tu e Zhou). Avaliamos também a Hipótese III: $H_{0}: C E R_{\text {Médio }}$ da estratégia com dependência caudal em modelos combinados $=C E R_{M e ́ d i o ~}$ de outra estratégia avaliada.

Tabela 4.5 - Comparação entre o CER médio das estratégias com dependência caudal e o CER médio das outras estratégias ao nível de $5 \%$ para as 1.000 carteiras com 5 ações do DJIA escolhidas ao acaso.

\begin{tabular}{ccc}
\hline Estratégias & $\begin{array}{c}\text { CER Médio } \\
\text { Hipótese II }\end{array}$ & $\begin{array}{c}\text { CER Médio } \\
\text { Hipótese III }\end{array}$ \\
\hline Painel A: Sem dependência caudal & & \\
Talmud & $-1,015 \%^{* * *}$ & $-1,015 \% * * *$ \\
Markowitz & $0,449 \%$ & $0,449 \%^{* * *}$ \\
Tu e Zhou & $-1,648 \%^{* * *}$ & $-1,648 \% * * *$ \\
\hline Painel B: Com dependência caudal & & \\
Dependência Caudal & $\mathrm{X}$ & $0,678 \% * * *$ \\
Combinação de Talmud, & $-0,267 \%^{* * *}$ & $\mathrm{X}$ \\
Markowitz e Dependência Caudal & & \\
\hline
\end{tabular}

Nota: Níveis de Significância: * $: 10 \%,{ }^{* *}: 5 \%,{ }^{* * *}: 1 \%$.

Podemos afirmar que as estratégias com dependência caudal superaram tanto Talmud como o modelo Tu e Zhou ao nível de 5\%. Já o modelo de Markowitz superou o modelo que combina a dependência caudal com outras estratégias ao nível de 5\%. Não podemos concluir que exista diferença significativa de performance ex-ante entre Markowitz e o modelo com dependência caudal ao nível de 5\%, embora o retorno acumulado da dependência caudal seja superior (101,201\%). Já DeMiguel, Garlappi e Uppal (2009) encontraram que, para o caso de 5 ativos com uma janela de estimação de 120 meses, a regra de Talmud superou Markowitz. Notamos que a eliminação do risco idiossincrático advindo da amostra de carteiras empregada foi o principal motivo que conduziu aos resultados devastadores para Markowitz. Dessa forma, concluímos que os modelos de dependência caudal e o de Markowitz tiveram um desempenho superior aos demais modelos.

\subsection{Resultados obtidos para carteiras formadas com 10 ativos escolhidos aleatoriamente}

Escolhemos 1000 carteiras com 10 ações do DJIA ao acaso. Assim, teremos 1000 retornos acumulados e 1000 utilidades para cada estratégia contemplada neste trabalho. O teste não-paramétrico de Wilcoxon foi utilizado, pois as utilidades das estratégias não são normais e as carteiras são independentes, ou seja, as ações são escolhidas ao acaso. As utilidades foram anualizadas e calculadas com base num coeficiente de aversão ao risco $\gamma=1$. Os principais resultados foram: 
Tabela 4.6 - Resultados encontrados para 1.000 carteiras com 10 ações escolhidas ao acaso do DJIA no período de 03/1990 a 12/2012.

\begin{tabular}{ccccc}
\hline Estratégias & $\begin{array}{c}\text { Retorno } \\
\text { Esperado }\end{array}$ & Risco & $\begin{array}{c}\text { CER } \\
\text { Médio }^{(1)} \\
\text { Hipótese I }\end{array}$ & $\begin{array}{c}\text { Média dos } \\
\text { Retornos } \\
\text { Acumulados }\end{array}$ \\
\hline Painel A: Sem dependência caudal & & & & \\
Talmud & $0,034 \%$ & $4,830 \%$ & $-0,103 \%$ & $79,743 \%$ \\
Markowitz & $0,137 \%$ & $4,016 \%$ & $0,043 \% * *$ & $95,303 \%$ \\
Tu e Zhou & $0,029 \%$ & $4,841 \%$ & $-0,109 \%$ & $78,669 \%$ \\
\hline Painel B: Com dependência caudal & & & & \\
Dependência caudal & $0,141 \%$ & $3,762 \%$ & $0,044 \%^{* * *}$ & $96,989 \%$ \\
$\begin{array}{c}\text { Combinação de Talmud, } \\
\text { Markowitz e Dependência Caudal }\end{array}$ & $0,104 \%$ & $4,151 \%$ & $0,001 \% * * *$ & $90,291 \%$ \\
\hline $\begin{array}{c}\text { S\&P 500 } \\
\text { T-Bond (10 anos) }\end{array}$ & $0,824 \%$ & $4,527 \%$ & $0,722 \%$ & $221,650 \%$ \\
\hline
\end{tabular}

Nota: Níveis de Significância: * : 10\%, ${ }^{* *}: 5 \%,{ }^{* * *}: 1 \%$. (1) O teste de Wilcoxon foi realizado para se

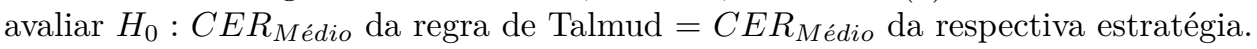

Pelos resultados acima, verificamos que as estratégias com dependência caudal e o modelo de Markowitz superaram significativamente a regra de Talmud ao nível de $5 \%$. As estratégias de Talmud e Tu e Zhou se mostraram perdedoras para o investidor devido às respectivas utilidades negativas. O modelo de Tu e Zhou apresentou um desempenho ex-ante similar ao da regra de Talmud ao nível de 5\%. Portanto, conclui-se que em termos de utilidade média, todas estratégias tiveram maior utilidade do que a regra de Talmud, com exceção do modelo de Tu e Zhou.

A média dos retornos acumulados das 1000 carteiras geradas pela estratégia com dependência caudal foi maior do que todas as outras estratégias em destaque. Notamos que a média dos retornos acumulados da estratégia com dependência caudal (96,989\% a.p.) para 10 ativos foi bem próxima da média do modelo de Markowitz (95,303\% a.p.). Observa-se que para 10 ativos a regra de Talmud e o modelo de Tu e Zhou evidenciaram retornos acumulados inferiores às simulações com 3 e 5 ativos. O retorno médio acumulado da estratégia com dependência caudal supera em torno de $60 \%$ dos meses o do modelo de Markowitz. Isso mostra que, em termos de retorno acumulado, a estratégia com dependência caudal foi vencedora na maioria dos meses perante Markowitz e as outras estratégias.

O gráfico abaixo representa a evolução da média dos retornos acumulados para as 1.000 carteiras com 10 ações escolhidas ao acaso do DJIA no período de 03/1990 até 12/2012. O retorno acumulado da estratégia com dependência caudal foi superior ao da regra de Talmud em 100\% dos 152 meses analisados. 


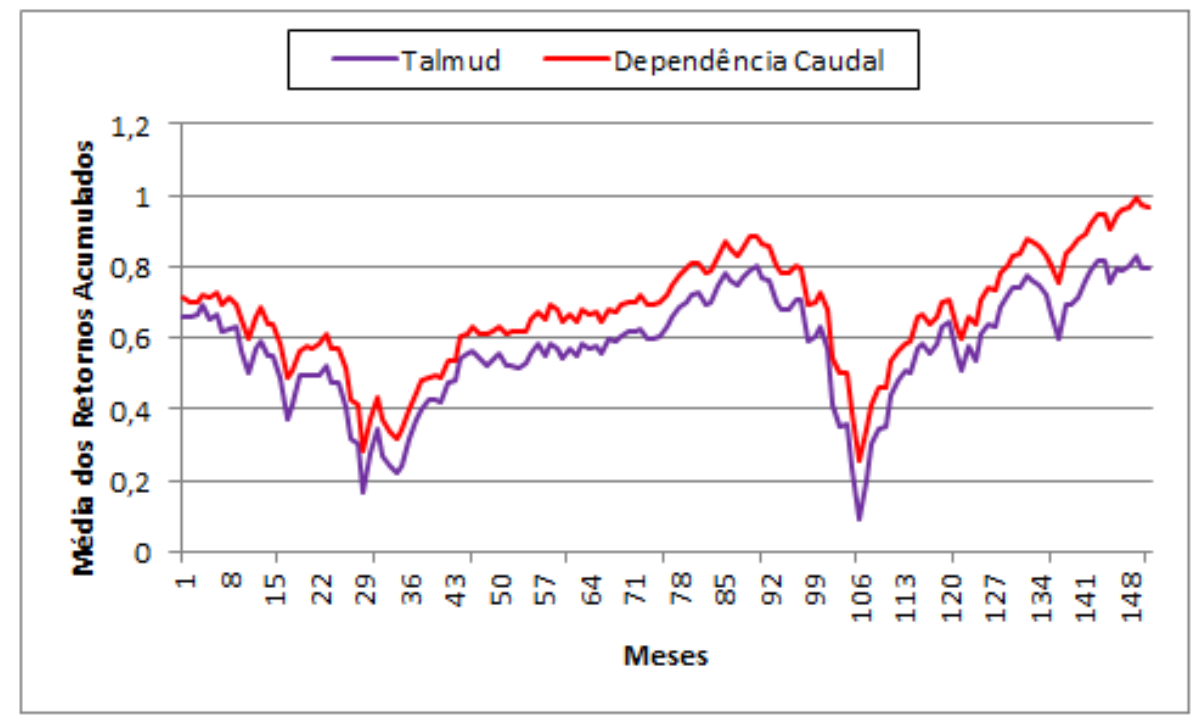

Figura 4.3 - Média dos retornos acumulados para 1.000 carteiras com 10 ações do DJIA escolhidas aleatoriamente nos 152 meses.

Pelo gráfico acima, observamos que nos dois maiores momentos de queda, situados em torno do $30^{0}$ mês e do $110^{0}$ mês (crise norte-americana do subprime), a estratégia com dependência caudal superou a regra de Talmud. Isto está em conformidade com os resultados encontrados por Hatherley e Alcock (2007), pois a estratégia caudal tende a formar carteiras com menores perdas potenciais em momentos de alta volatilidade. A Tabela abaixo contém os resultados necessários para avaliarmos as hipóteses II e III. O teste de Wilcoxon foi realizado para se avaliar a Hipótese II: $H_{0}: C E R_{\text {Médio }}$ da estratégia com dependência caudal $=C E R_{\text {Médio }}$ de outra estratégia (exemplo: Talmud, Markowitz ou Tu e Zhou). Avaliamos também a Hipótese III: $H_{0}: C E R_{\text {Médio }}$ da estratégia com

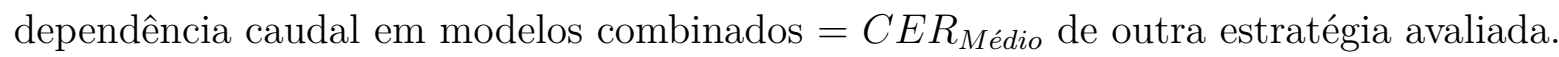


Tabela 4.7 - Comparação entre o CER médio das estratégias com dependência caudal e o CER médio das outras estratégias ao nível de $5 \%$ para as 1.000 carteiras com 10 ações do DJIA escolhidas ao acaso.

\begin{tabular}{ccc}
\hline Estratégias & $\begin{array}{c}\text { CER Médio } \\
\text { Hipótese II }\end{array}$ & $\begin{array}{c}\text { CER Médio } \\
\text { Hipótese III }\end{array}$ \\
\hline Painel A: Sem dependência caudal & & \\
Talmud & $-0,1031 \%^{* * *}$ & $-0,103 \%^{* * *}$ \\
Markowitz & $0,043 \%$ & $0,043 \%^{* *}$ \\
Tu e Zhou & $-0,109 \%^{* * *}$ & $-0,109 \%^{* * *}$ \\
\hline Painel B: Com dependência caudal & & \\
Dependência Caudal & - & $0,044 \%^{*}$ \\
Combinação de Talmud, & $0,001 \%^{*}$ & - \\
Markowitz e Dependência Caudal & & - \\
\hline
\end{tabular}

Nota: Níveis de Significância: * : 10\%, ** : 5\%, *** : $1 \%$.

Podemos afirmar que as estratégias com dependência caudal superaram tanto Talmud como o modelo Tu e Zhou ao nível de $5 \%$ para carteiras com 10 ativos. Já o modelo de Markowitz superou o modelo que combina a dependência caudal com outras estratégias ao nível de 5\%. Não podemos concluir que exista diferença significativa de utilidade entre Markowitz e o modelo com dependência caudal ao nível de 5\%. Já DeMiguel, Garlappi e Uppal (2009) encontraram que, para o caso de 10 ativos com uma janela de estimação de 120 meses, a regra de Talmud superou também Markowitz. Notamos que a eliminação do risco idiossincrático advindo da amostra de carteiras empregada foi o principal motivo que conduziu aos resultados negativos para Markowitz. Dessa forma, concluímos que os modelos de dependência caudal e o de Markowitz tiveram uma performance superior aos demais modelos.

\subsubsection{Resultados obtidos para carteiras formadas com 20 ativos escolhidos aleatoriamente}

Escolhemos 1000 carteiras com 20 ações do DJIA ao acaso. Assim, teremos 1000 retornos acumulados e 1000 utilidades para cada estratégia contemplada neste trabalho. O teste não-paramétrico de Wilcoxon foi utilizado, pois as utilidades das estratégias não são normais e as carteiras são independentes, ou seja, as ações são escolhidas ao acaso. As utilidades foram anualizadas e calculadas com base num coeficiente de aversão ao risco $\gamma=1$. Os índices de Sharpe para Talmud e Tu e Zhou foram negativos e, portanto, o conceito de utilidade anualizada será escolhido para comparar a performance ex-ante das estratégias. Os principais resultados foram: 
Tabela 4.8 - Resultados encontrados para 1.000 carteiras com 20 ações escolhidas ao acaso do DJIA no período de 03/1990 a 12/2012.

\begin{tabular}{ccccc}
\hline Estratégias & $\begin{array}{c}\text { Retorno } \\
\text { Esperado }\end{array}$ & Risco & $\begin{array}{c}\text { CER } \\
\text { Médio }^{(1)} \\
\text { Hipótese I }\end{array}$ & $\begin{array}{c}\text { Média dos } \\
\text { Retornos } \\
\text { Acumulados }\end{array}$ \\
\hline Painel A: Sem dependência caudal & & & & \\
Talmud & $0,158 \%$ & $4,357 \%$ & $-0,092 \%$ & $80,454 \%$ \\
Markowitz & $0,192 \%$ & $4,128 \%$ & $0,033 \% * *$ & $95,620 \%$ \\
Tu e Zhou & $0,156 \%$ & $4,841 \%$ & $-0,101 \%$ & $78,842 \%$ \\
\hline Painel B: Com dependência caudal & & & & \\
Dependência Caudal & $0,218 \%$ & $3,991 \%$ & $0,035 \% * *$ & $96,132 \%$ \\
$\begin{array}{c}\text { Combinação de Talmud, } \\
\text { Markowitz e Dependência Caudal }\end{array}$ & $0,157 \%$ & $4,151 \%$ & $0,021 \% * *$ & $90,142 \%$ \\
\hline $\begin{array}{c}\text { S\&P 500 } \\
\text { T-Bond (10 anos) }\end{array}$ & $0,824 \%$ & $4,527 \%$ & $0,722 \%$ & $221,650 \%$ \\
\hline
\end{tabular}

Nota: Níveis de Significância: * : 10\%, ${ }^{* *}: 5 \%,{ }^{* * *}: 1 \%$. (1) O teste de Wilcoxon foi realizado para se

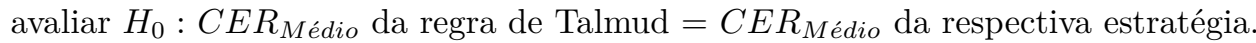

Pelos resultados acima, verificamos que as estratégias com dependência caudal e o modelo de Markowitz superaram significativamente a regra de Talmud ao nível de $5 \%$. As estratégias de Talmud e Tu e Zhou se mostraram perdedoras para o investidor devido às respectivas utilidades serem negativas. $\mathrm{O}$ modelo de $\mathrm{Tu}$ e Zhou apresentou um desempenho similar ao da regra de Talmud ao nível de 5\%. Portanto, conclui-se que em termos de utilidade média, todas estratégias tiveram maior utilidade do que a regra de Talmud, com exceção do modelo de Tu e Zhou.

A média dos retornos acumulados das 1000 carteiras geradas pela estratégia com dependência caudal foi maior do que todas as outras estratégias em destaque $(96,132 \%$ a.p.) O modelo de Markowitz apresentou um retorno acumulado de 95,620\% a.p. que se encontra próximo ao da estratégia com dependência caudal (diferença de 0,512\% a.p.). O retorno médio acumulado da estratégia com dependência caudal supera em torno de $60 \%$ dos meses o do modelo de Markowitz. Isso mostra que, em termos de retorno acumulado, a estratégia com dependência caudal foi vencedora na maioria dos meses perante Markowitz e as outras estratégias.

O gráfico abaixo representa a evolução da média dos retornos acumulados para as 1.000 carteiras com 10 ações escolhidas ao acaso do DJIA no período de 03/1990 até 12/2012. O retorno acumulado da estratégia com dependência caudal foi superior ao da regra de Talmud em 100\% dos 152 meses analisados.

Pelo gráfico acima, observamos que nos dois maiores momentos de queda, situados em 


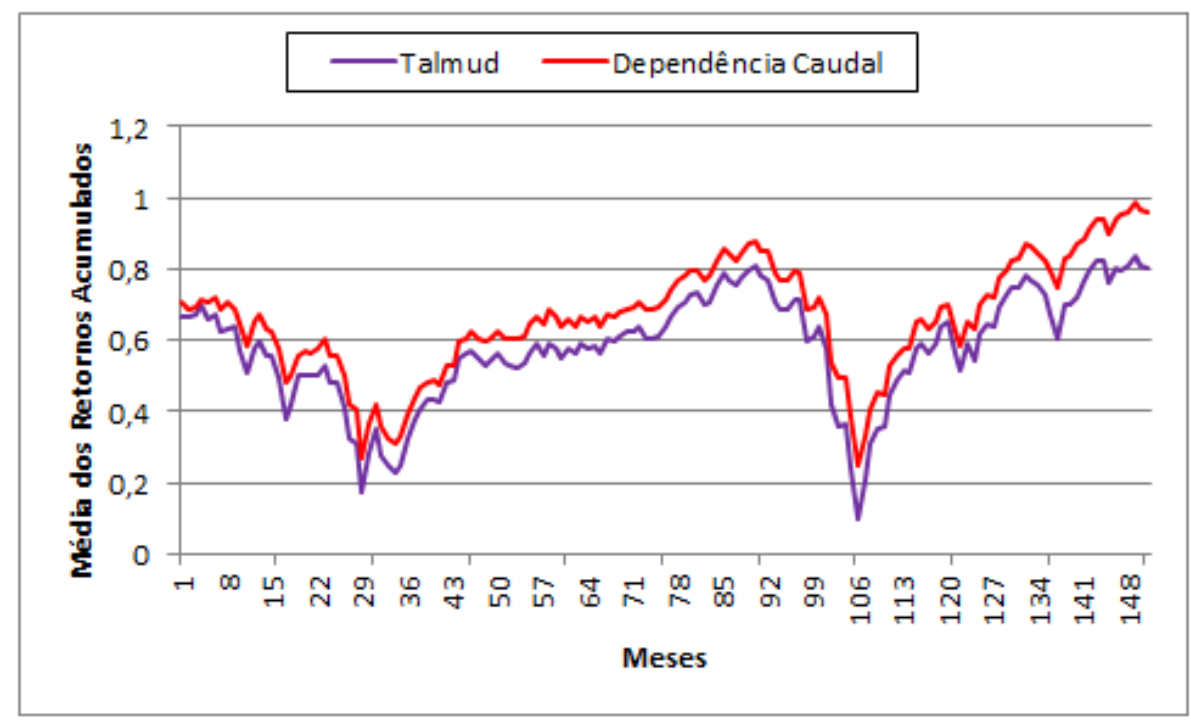

Figura 4.4 - Média dos retornos acumulados para 1.000 carteiras com 20 ações do DJIA escolhidas aleatoriamente nos 152 meses.

torno do $30^{0}$ mês e do $110^{0}$ mês (crise norte-americana do subprime), a estratégia com dependência caudal superou a regra de Talmud. Isto está em conformidade com os resultados encontrados por Hatherley e Alcock (2007), pois a estratégia caudal tende a formar carteiras com menores perdas potenciais em momentos de alta volatilidade. A Tabela abaixo contém os resultados necessários para avaliarmos as hipóteses II e III. O teste de Wilcoxon foi realizado para se avaliar a Hipótese II: $H_{0}: C E R_{\text {Médio }}$ da estratégia com dependência caudal $=C E R_{\text {Médio }}$ de outra estratégia (exemplo: Talmud, Markowitz ou Tu e Zhou). Avaliamos também a Hipótese III: $H_{0}: C E R_{\text {Médio }}$ da estratégia com dependência caudal em modelos combinados $=C E R_{M e ́ d i o ~}$ de outra estratégia avaliada.

Tabela 4.9 - Comparação entre o CER médio das estratégias com dependência caudal e o CER médio das outras estratégias ao nível de $5 \%$ para as 1.000 carteiras com 20 ações do DJIA escolhidas ao acaso.

\begin{tabular}{ccc}
\hline Estratégias & $\begin{array}{c}\text { CER Médio } \\
\text { Hipótese II }\end{array}$ & $\begin{array}{c}\text { CER Médio } \\
\text { Hipótese III }\end{array}$ \\
\hline Painel A: Sem dependência caudal & & \\
Talmud & $-0,092 \%^{* *}$ & $-0,092 \%^{* *}$ \\
Markowitz & $0,033 \%$ & $0,033 \%$ \\
Tu e Zhou & $-0,101 \% * *$ & $-0,101 \% * *$ \\
\hline Painel B: Com dependência caudal & & \\
Dependência Caudal & $\mathrm{X}$ & $0,035 \%$ \\
Combinação de Talmud, & $0,021 \%$ & $\mathrm{X}$ \\
Markowitz e Dependência Caudal & & \\
\hline
\end{tabular}

Nota: Níveis de Significância: $*: 10 \%,{ }^{* *}: 5 \%,{ }^{* *}: 1 \%$.

Podemos afirmar que as estratégias com dependência caudal superaram tanto Talmud como o modelo Tu e Zhou ao nível de 5\% para carteiras com 20 ativos ao nível de 
5\%. . Não podemos concluir que exista diferença significativa de performance ex-ante entre Markowitz e o modelo com dependência caudal ao nível de 5\%. Vale ressaltar que Markowitz supera Talmud ao nível de 5\% para 20 ativos. Já DeMiguel, Garlappi e Uppal (2009) encontraram que, para o caso de 20 ativos com uma janela de estimação de 120 meses, a regra de Talmud superou também Markowitz. Notamos que a eliminação do risco idiossincrático advindo da amostra de carteiras empregada foi o principal motivo que conduziu aos resultados devastadores para Markowitz. Dessa forma, concluímos que os modelos de dependência caudal e o de Markowitz tiveram uma performance ex-ante superior aos demais modelos. O gráfico abaixo compara as utilidades esperadas da regra de Talmud com as do modelo com dependência caudal para carteiras com 3, 5, 10 e 20 ativos.

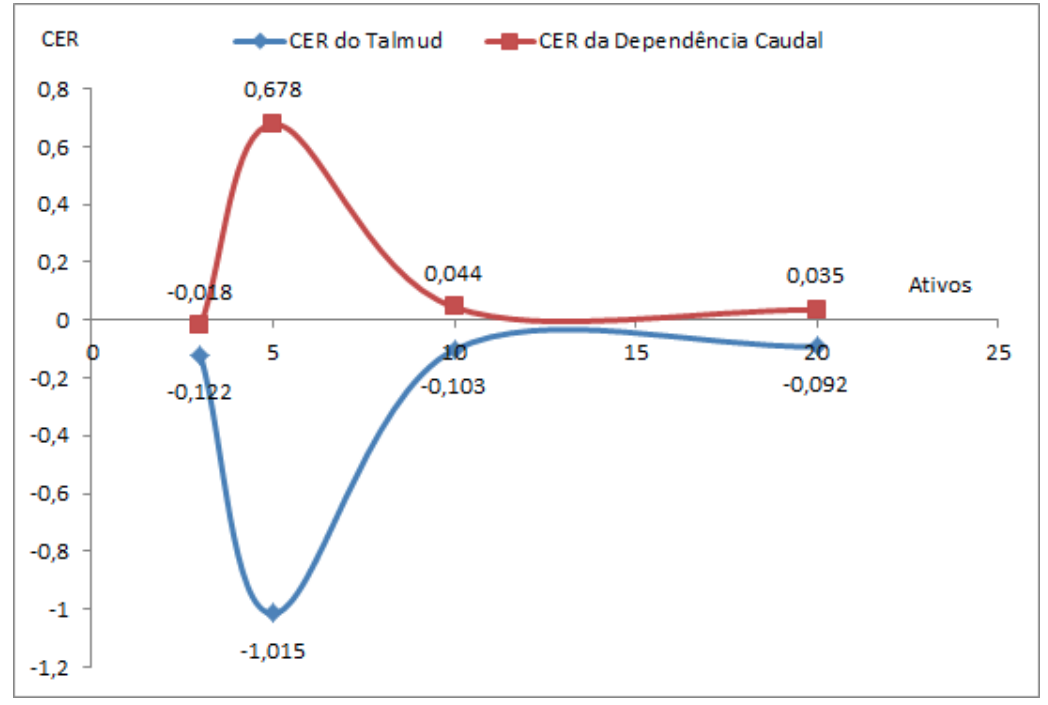

\section{Figura 4.5 - Comparação entre o CER do Talmud e o CER da Dependência Caudal para carteiras com $3,5,10$ e 20 ativos}

Pelo gráfico abaixo, percebemos que o modelo com dependência caudal superou a regra de Talmud ao nível de 5\% para 3, 5, 10 e 20 ativos numa janela de estimação de 120 meses. Para carteiras que contém 5 até 10 ativos, notamos que há um ganho substancial na utilidade esperada do modelo com dependência caudal frente ao Talmud. Verifica-se que, para carteiras com mais de 10 ativos, as diferenças entre as utilidades dos modelos são menores do que com 5 ativos, tendendo a se concentrar num mesmo patamar devido a diminuição do risco idiossincrático.

O gráfico abaixo compara as utilidades esperadas do modelo de Tu e Zhou com as do modelo com dependência caudal para carteiras com 3, 5, 10 e 20 ativos.

Pelo gráfico abaixo, percebemos que o modelo com dependência caudal superou o modelo de Tu e Zhou ao nível de 5\% para carteiras com 3, 5, 10 e 20 ativos escolhidos ao acaso 


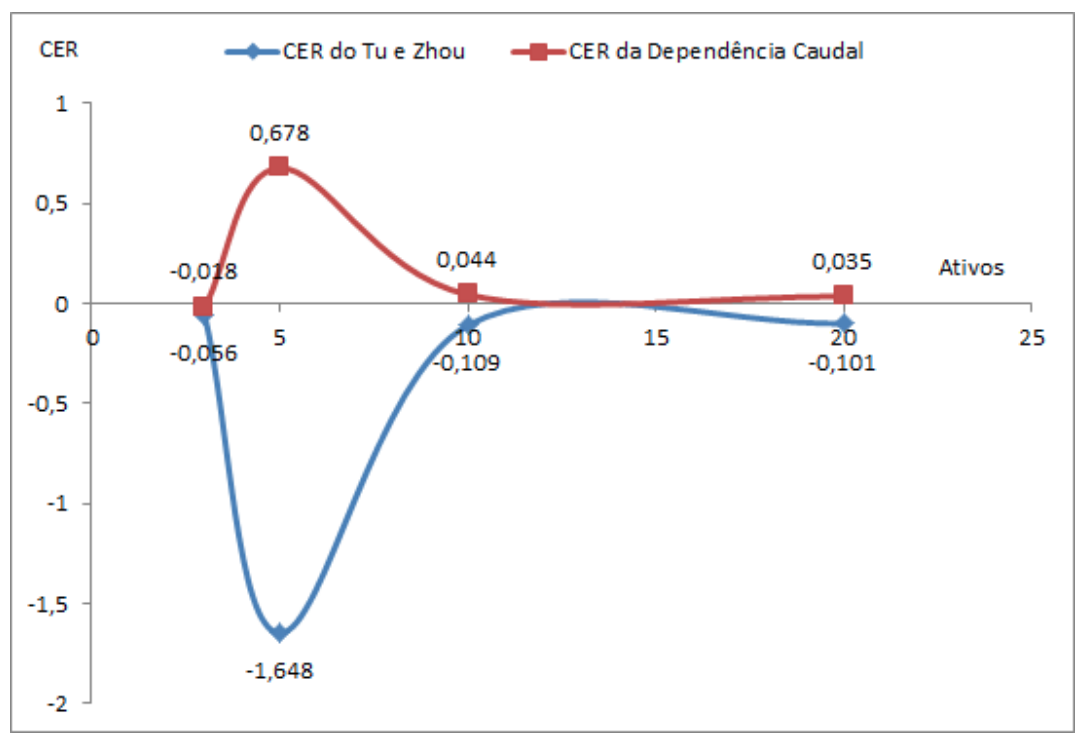

Figura 4.6 - Comparação entre o CER do Tu e Zhou e o CER da Dependência Caudal para carteiras com 3, 5, 10 e 20 ativos

numa janela de estimação de 120 meses. Para carteiras que contém 5 até 10 ativos, notamos que há um ganho substancial na utilidade esperada do modelo com dependência caudal frente ao Talmud. Verifica-se que, para carteiras com mais de 10 ativos, as diferenças entre as utilidades dos modelos são menores do que com 5 ativos, tendendo a se concentrar num mesmo patamar devido a diminuição do risco idiossincrático. Vale ressaltar que estes resultados valem também para Markowitz. São resultados opostos daqueles obtidos em Tu e Zhou (2011) no contexto de carteiras formadas por 3, 5, 10 e 20 ativos. Pelo gráfico abaixo, observamos que a regra de Talmud superou Tu e Zhou para carteiras com 5 ativos.

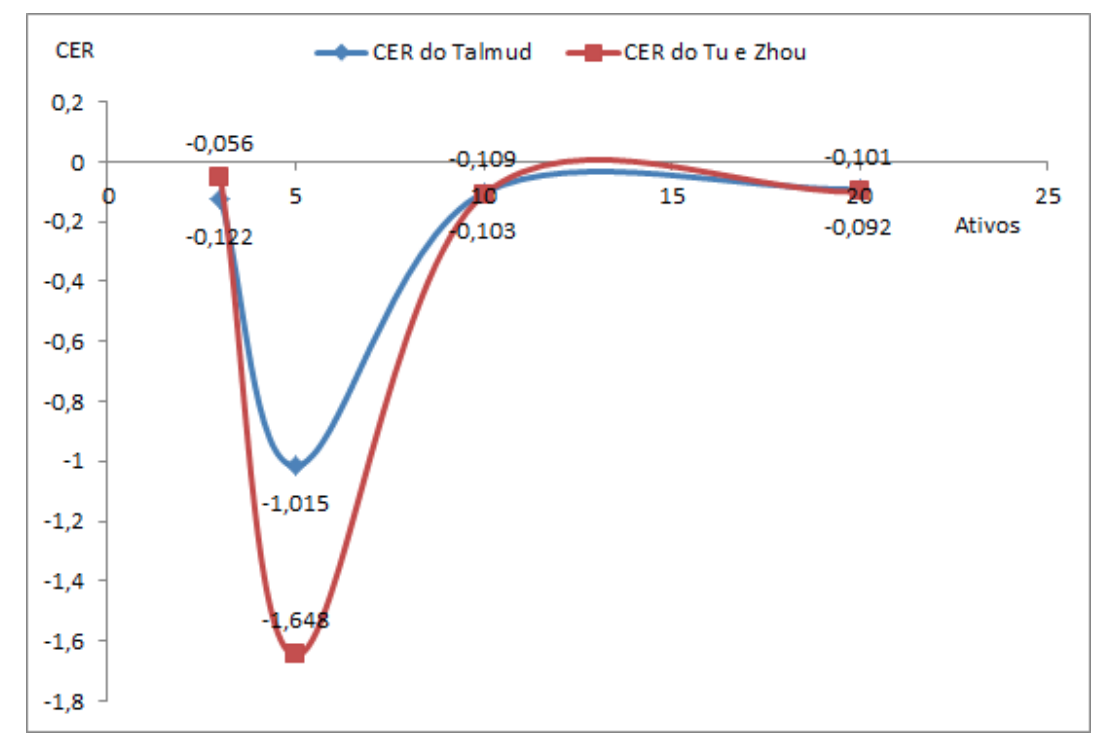

Figura 4.7 - Comparação entre o CER do Tu e Zhou e o CER da regra de Talmud para carteiras com 3, 5, 10 e 20 ativos 
Pela Figura acima, observamos que a regra de Talmud superou Tu e Zhou para carteiras com 5 ativos. As diferenças entre os modelos de Tu e Zhou e Talmud para carteiras com 10 e 20 ativos não são significativas ao nível de 5\%. Diante dos resultados obtidos, a dependência caudal e o modelo de Markowitz superaram Talmud e Tu e Zhou ao nível de $5 \%$. 


\section{Capítulo 5}

\section{CONCLUSÃO}

A desconsideração da dependência caudal inferior durante o processo de construção de carteiras poderá diminuir a habilidades dos gestores de fundos de ativos em reduzir o risco através da diversificação. Como resultado, há um grande número de trabalhos que procuraram avaliar a interdependência dos ativos usando modelos de eventos extremos, incluindo a teoria de cópulas (EMBRECHTS e DIAS, 2003; McNEIL, 1999). A modelagem de cópulas sobre os retornos dos ativos nos permite calcular uma alternativa para medir a dependência não-linear dos ativos através do índice de dependência caudal, $\lambda$. Este coeficiente de dependência caudal, $\lambda$, mede como duas variáveis aleatórias se relacionam nos quantis extremos da distribuição de probabilidades. Esta nova medida de interdependência pode ser calculada para ganhos conjuntos, pelo índice de dependência caudal superior $\lambda_{U}$, e para perdas conjuntas, pelo índice de dependência caudal inferior $\lambda_{L}$. Longin e Solnik (2001) relataram que há um efeito expressivo de aumento da correlação dos ativos somente quando os mercados estão em declínio e, portanto, utilizaremos somente a medida $\lambda_{L}$ nos modelos de alocação de carteiras de ações. Por tal resultado, não haveria mudanças significativas em se utilizar $\lambda_{U}$ ao invés do coeficiente de correlação $\rho$.

Embretchs, McNeil e Straumann (2001) e Longin e Solnik (2001) identificaram que o relacionamento entre os ativos em dias usuais de mercado pode ser bem diferente do que em períodos extremos. Durante as crises econômico-financeiras, os mercados se tornam muito mais integrados devido ao contágio, e a correlação linear $\rho$ é insuficiente para capturar integralmente como os ativos se relacionam. Patton (2004) e Silvapulle e Granger (2001) afirmaram que a dependência em períodos de alta volatilidade entre os ativos deve ser considerada na avaliação do retorno ajustado ao risco, pois o aumento da correlação entre os ativos em períodos de bear markets tende a diminuir significativamente os benefícios da diversificação.

$\mathrm{Na}$ presença de fatores extremos, o coeficiente $\rho$ tende a crescer em módulo, tornando espúrios os resultados de uma diversificação baseadas apenas neste coeficiente. Nestas circunstâncias, a superioridade do índice caudal como fator de diversificação torna-se evidente produzindo melhores resultados no estudo em tela. A desconsideração da dependência caudal inferior durante o processo de construção de carteiras poderá diminuir a habilidades dos gestores de fundos de ativos em reduzir o risco através da diversificação. 
A modelagem de cópulas sobre os retornos dos ativos nos permite calcular uma alternativa para medir a dependência não-linear dos ativos através do índice de dependência caudal, $\lambda$. Este coeficiente de dependência caudal, $\lambda$, mede como duas variáveis aleatórias se relacionam nos quantis extremos da distribuição de probabilidades. Esta nova medida de interdependência pode ser calculada para ganhos conjuntos, pelo índice de dependência caudal superior $\lambda_{U}$, e para perdas conjuntas, pelo índice de dependência caudal inferior $\lambda_{L}$. Longin e Solnik (2001) relataram que há um efeito expressivo de aumento da correlação dos ativos somente quando os mercados estão em declínio e, portanto, utilizaremos somente a medida $\lambda_{L}$ nos modelos de alocação de carteiras de ações. Por tal resultado, não haveria mudanças significativas em se utilizar $\lambda_{U}$ ao invés do coeficiente de correlação $\rho$.

Tu e Zhou (2011), DeMiguel, Garlappi e Uppal (2009) e Disatnik e Benninga (2007) não consideraram os efeitos deletérios dos eventos extremos na diversificação dos ativos. Leal e Mendes (2010), Alcock e Hatherley (2009) e Hatherley e Alcock (2007) construiram fronteiras eficientes sob o efeito da dependência assimétrica numa abordagem ex-post. $\mathrm{O}$ modelo clássico de Markowitz tende a subestimar as perdas potenciais que venham a ocorrer na presença de eventos extremos de mercado (crashes), pois a fronteira eficiente da estratégia com dependência assimétrica se deslocou para a direita em relação a do modelo clássico. Portanto, a escolha de uma metodologia (teoria de cópulas) que permita mensurar como os ativos se relacionam em momentos extremos pretende produzir carteiras com maior utilidade do que a regra de Talmud e o próprio MMV numa abordagem fora da amostra.

Para carteiras formadas com 3 ativos escolhidos ao acaso do DJIA no período de 03/1990 até $12 / 2012$, as estratégias com dependência caudal superaram significativamente a regra de Talmud e Markowitz ao nível de 5\%. Todas as estratégias com 3 ativos se mostraram perdedoras devido as utilidades serem negativas. Nota-se que o modelo de Markowitz apresentou uma utilidade inferior a da regra de Talmud ao nível de 5\%. O retorno médio acumulado da estratégia com dependência caudal supera $58 \%$ dos meses o do modelo de Markowitz e em 93\% dos meses a regra de Talmud. Isso mostra que, em termos de retorno acumulado, a estratégia com dependência caudal foi vencedora na maioria dos meses perante Markowitz e as outras estratégias.

Para carteiras formadas com 5 ativos escolhidos ao acaso do DJIA, as estratégias com dependência caudal superaram significativamente a regra de Talmud ao nível de 5\%. Observamos que todas estratégias tiveram maior utilidade do que a da regra de Talmud, com exceção do modelo combinado de Tu e Zhou. O retorno médio acumulado da estratégia com dependência caudal supera em $72 \%$ das meses o do modelo de Markowitz e em $99 \%$ dos meses a regra de Talmud. Isso mostra que, em termos de retorno acumulado, a 
estratégia com dependência caudal foi vencedora na maioria dos meses perante Markowitz e as outras estratégias.

Para carteiras formadas com 10 e 20 ativos escolhidos ao acaso do DJIA, as estratégias com dependência caudal e o modelo de Markowitz superaram significativamente a regra de Talmud ao nível de 5\%. As estratégias de Talmud e Tu e Zhou se mostraram perdedoras para o investidor devido as suas respectivas utilidades negativas. O modelo de $\mathrm{Tu}$ e Zhou apresentou utilidade similar a da regra de Talmud ao nível de 5\%. Portanto, conclui-se que todas estratégias tiveram maior utilidade do que a da regra de Talmud, com exceção do modelo de Tu e Zhou. O retorno médio acumulado da estratégia com dependência caudal supera em $60 \%$ dos meses o do modelo de Markowitz e em 100\% a regra de Talmud. Logo, a estratégia com dependência caudal foi vencedora na maioria dos meses perante Markowitz e as outras estratégias.

Portanto, em todos os casos com 3, 5, 10 e 20 ativos, conclui-se que todas estratégias tiveram maior utilidade do que a da regra de Talmud, com exceção do modelo de Tu e Zhou. Este foi até inferior a regra de Talmud com 5 ativos. Isso contraria os resultados apontados no trabalho de Tu e Zhou (2011) e DeMiguel, Galarppi e Uppal (2009). Estes autores declararam que os principais motivos seriam: (i) erro de estimação do vetor de médias e da matriz de covariâncias e (ii) diminuição do risco idiossincrático advindo da utilização de carteiras formadas por outras carteiras já constituídas por certos critérios financeiros encontrados no website do Prof. Kenneth French (e.g. size, book-to-market etc).

O erro de estimação sempre estará presente nos modelos de otimização. Assim, assumese, por hipótese, que o erro de estimação não diferencia os resultados encontrados nesta tese com os trabalhos divulgados anteriormente. Como nossa amostra é baseada em carteiras formadas por ativos do índice DJIA, concluímos que a diminuição do risco idiossincrático na constituição das amostras pode explicar a superioridade da regra de Talmud em DeMiguel, Garlappi e Uppal (2009) e do modelo combinado em Tu e Zhou (2011). Na prática os gestores de investimentos formam carteiras a partir da seleção de ações, reforçando a importância dos resultados aqui encontrados.

Dessa forma, concluímos que os modelos de dependência caudal e o de Markowitz tiveram uma performance superior aos demais modelos para 3, 5, 10 e 20 ativos escolhidos ao acaso do índice DJIA no período de 03/1990 até 2012/12. 


\section{Referências Bibliográficas}

ALCOCK, J.; HATHERLEY, A. Asymmetric Dependence Between Domestic Equity Indices and its Effect on Portfolio Construction. The Australian Actuarial Journal, v. 15, n. 1, p. 143-180, 2009.

ALLAIS, M. F. C.; HAGEN, O. Expected Utility Hypotheses and the Allais Paradox. Dordretch, Holanda: Reidel, 1979.

ANDERSEN, T.G.; BOLlERSLEV, T.; DIEBOLD, F. X.; EBENS, H. The distribution of realized stock return volatility. Journal of Financial Economics, v.61, p.43-76, 2001.

ANÉ, T.; KHAROUBI, C. Dependence structure and risk measure. Journal of Business, v. 76, p. 411-438, 2003.

ANG, A.; BEKAERT, G. International Asset Allocation With Regime Shifts. Review of Financial Studies, v. 15, p. 1137-1187, 2002.

ANG, ; CHEN, J. Asymetric Correlations of Equity Portfolios. Journal of Financial Economics, vol. 63(3), p. 443-494, 2002.

ASSIS, R. M.; LAURINI, M. P. Funções de Cópula na Precificação de Opções. Working Paper 148 - Ibmec São Paulo, 2008.

BAE, K.; KAROLYI, G.; STULZ, R. A new approach to measuring financial contagion. Review of Financial Studies, vol. 16(3), p. 716-763, 2003.

BOROVKOVA, S. Risk Management with Tail Copulas for Emerging Market Portfolios. International Journal of Economics and Finance Studies, v. 3, n. 1, p. 219-228, 2011.

BOYER, B.; GIBSON, M.; MULDER, C. Pitfalls in tests for changes in correlations. International Finance Discussion Paper, 597, Board of Governors of the Federal Reserve System, 1999.

BEKMAN, O. R.; COSTA NETO, P. L. Análise estatística da decisão. Ed. Blucher. São Paulo, 124p., 2002. 
BENGTSSON, C.; HOLST, J. On portfolio selection: Improved Covariance Matrix Estimation for Swedish Asset Returns. Working paper, Lund University and Lund Institute of Technology, 2002.

BERGMANN, D. R.; SAVOIA, J. R. F.; MENDES-DA-SILVA, W.; OLIVEIRA, M. A.; NAKAMURA, W. T. Análise dos co-movimentos dos mercados de capitais do Brasil e dos EUA. Brazilian Business Review, v.4, n.8, 2011.

BERNOULLI, D. Exposition of a New Theory of the Measurement of Risk. Econometrica, v. 22, n. 1, p. 23-36. Tradução do Latim para o Inglês do Original: Specimen Theoriae Novae de Mensura Sortis (1738), 1954.

BORCH, K. H. The Economics of Uncertainty. Princeton, NJ: Princeton, 1968.

BRANDT, M. Portfolio choice problems. In: Äıt-Sahalia, Y.; Hansen, L., Handbook of Financial Econometrics. Elsevier, North-Holland, Amsterdam, pp. 269-336, 2009.

BREYMANN, W.; DIAS, A.; EMBRECHTS, P. Dependence Structures for Multivariate High-Frequency Data in Finance. Quantitative Finance, v.3, p.1-14, 2003.

CAMPBELL, R.; KOEDIJK, K.; KOFMAN, P. Increased correlation in bear markets. Financial Analysts Journal, Charlottesville, United States, Charlottesville, v. 58, n. 1, p. 87-94, 2002.

CAMPBELL, J. Y.; LO, A. W.; MACKINLAY, A. C. The Econometrics of Financial Markets. New Jersey: Princeton, 1997.

CASTRO JUNIOR, F. H. Apreçamento de ativos com assimetria e curtose. Um teste de co-momentos com dados em painel. Tese defendida para a obtenção do título de Doutor em Administração no Departamento de Administração da Faculdade de Administração, Economia e Contabilidade da Universidade de São Paulo, 2008.

CHAN, L. K. C.; KARCESKI, J.; LAKONISHOK, J. On Portfolio Optimization: Forecasting Covariances and Choosing the Risk Model. Review of Financial Studies, v. 12, p. 937-974, 1999.

CHERUBini, U.; LUCIANO, E.; VECCHIATO, W. Copula Methods in Finance. London: John Wiley \& Sons Inc., 2004. 
Clemente, A. D.; ROMANO, C. Measuring and Optimizing Portfolio Credit Risk: A Copula-based Approach. Banca Monte dei Paschi di Siena SpA, v. 33, n. 3, p. 325-357, 2004.

COCHRAnE, John H. Asset Pricing. New Jersey: Princeton, 2001.

CONT, R. Empirical properties of asset returns: stylized facts and statistical issues. Quantitative Finance, v. 1, n. 2, p. 223-36, 2001.

DEMIGUEL, V.; GARLAPPI, L.; UPPAL, R. Optimal versus naive diversification: how inefficient is the $1 / \mathrm{N}$ portfolio strategy? The Review of Financial Studies, v. 22, p. 1915-1953, 2009.

DISATNIK, D. J.; BENNINGA, S. Shrinking the covariance matrix optimal versus naive diversification: how inefficient is the $1 / \mathrm{N}$ portfolio strategy? The Journal of Portfolio Management, v. 33, n. 4, p. 56-63, 2007.

DUCHIN, R.; LEVY, H. Markowitz versus the Talmudic portfolio diversification strategies. Journal of Portfolio Management, v. 35, p. 71-74, 2009.

EMBRECHTS, P.; MCNEIL, A. J.; STRAUSMANN, D. Correlation: Pitfalls and alternatives. Risk Magazine, v. 12, n. 5, p. 69-71, 1999.

EMBRECHTS, P.; MCNEIL, A.; STRAUSMAnN, D. Correlation and Dependency in Risk Management: Properties and Pitfals. Working paper, Risklab ETH Zurich, 2001.

FAJARDO, J.; FARIAS, A. Generalized Hyperbolic Distributions and Brazilian Data. Working Paper, IBMEC/RJ, 2003.

FORBES, K.; RIGOBON, R. No Contagion, Only Interdependence: Measuring Stock Markets Co-movements, Journal of Finance, v.57, p. 2223-2261, 2002.

FROST, P.A.; SAVARINO, J.E. An empirical Bayes approach to efficient portfolio selection. Journal of Financial and Quantitative Analysis, v. 21, v. 293-305, 1986.

GENEST, C.; GENDRON, M.; BORDEAU-BRIEN, M. The Advent of Copulas in Finance. The European Journal of Finance, v.00, p. 1-10, 2009. 
GENEST C., RÉMILlaRD, B.; BEAUDOIN, D. Goodnest-of-fit tests for copulas: A review and a power study. Insurance: Mathematics and Economics, v. 44, p. 199-213, 2009.

GOORAH, A. Real Estate Risk Management with Copulas. Journal of Property Research, v. 24, n. 4, p. 289-311, dez./2007.

HATHERLEY, A.; ALCOCK, J. Portfolio construction incorporating asymmetric dependence structures: A users guide. Accounting and Finance, v. 47, n. 3, p. 447-472, 2007

HOEFFDING, W. Masstabinvariante korrelationstheorie, Schr. Math. Inst. Univ. Berlin, v. 5, p. 179-233, 1940.

HON, M. T.; STRAUSS, J.K.; YONG, S.K. Deconstructing the NASDAQ bubble: a look at contagion across international stock markets. Journal of International Financial Markets, Institutions and Money, v.17, p. 213-230, 2007.

HU, L. 'Dependence patterns across financial markets: a mixed copula approach', Applied Financial Economics, v.16, n. 10, p. 717-729, 2006.

HULL, J.; WHITE, A. Valuation of a CDO and an nth to Default CDS Without Monte Carlo Simulation. Journal of Derivatives, v. 12, n. 2, inverno/2004.

INGERSOLL JR., J. E. Theory of Financial Decision Making. Savage, MD: Rowman \& Littlefield, 1987.

JAGANNATHAN, R.; MA, T. Risk Reduction in Large Portfolios: Why Imposing the Wrong Constraints Helps. Journal of Finance, v. 54, n. 4, p. 1651-1683, 2003.

JOBSON, D.J.; KORKIE, B.M. Estimation for Markowitz efficient portfolios. Journal of the American Statistical Association, v. 75, p. 544-554, 1981.

JORION, P. Bayes-Stein estimation for portfolio analysis. Journal of Financial and Quantitative Analysis, v. 21, p. 279-292, 1986.

KAN, R.; ZHOU, G. Optimal portfolio choice with parameter uncertainty. Journal of Financial and Quantitative Analysis, v.42, p. 621-656, 2007. 
KENORGIOS, D; SAMITAS, A.; PALTALIDIS, N. Financial crises and stock market contagion in a multivariate time-varying asymmetric framework. Journal of International Financial Markets, Institutions and Money, v. 21, p. 92-106, 2011.

KING, M.; WADHWANI, S. Transmission of volatility between stock markets. Review of Financial Studies, v.3, p. 5-33, 1990.

LEAL, R. P. C.; MENDES, B. V. M. Incorporating tail dependence into Markowitz model. Working Paper, COPPEAD/UFRJ, 2010

LEDOIT, O.; WOLF, M. Improved estimation of the covariance matrix of stock returns with an application to portfolio selection. Journal of Empirical Finance, v. 10, p. 603-621, 2003.

LEDOIT, O.; WOLF, M. Honey, I Shrunk the Sample Covariance Matrix. Journal of Portfolio Management, v. 30, n. 4, p. 110-119, 2004.

LEDOIT, O.; WOLF, M. Robust Performance hypothesis testing with the Sharpe ratio. Journal of Empirical Finance, v. 15, p. 850-859, 2008.

LI, D. X. On default correlation: A copula function approach. Journal of Fixed Income, v.9, p. 43-54, 2000.

LITTERMAN, B. Modern Investment Management: An Equilibrium Approach. New Jersey: John Wiley \& Sons Inc., 2003.

LONGIN, F.; SOLNIK, B. Extreme correlation of international equity markets. Journal of Finance, v. 56, n. 2, p. 649-676, 2001.

LUENBERGER, D. G. Investment Science. New York: Oxford, 1998.

MACHINA, M. J. "Expected Utility" Analysis without the Independence Axiom. Econometrica, v. 50, n. 2, p. 277-324, 1982.

MACKINLAY A.C.; Pastor, L. Asset pricing models: implications for expected returns and portfolio selection. Review of Financial Studies, v. 13, p. 883-916, 2000.

MARKOWITZ, H. Portfolio Selection. The Journal of Finance, v.7, n. 1, p. 77-91, 1952. 
MARTINS, G. A. Manual para Elaboração de Monografias e Dissertações. São Paulo: Edtora Atlas, 3. ed, 2002.

MARTELlinI, L.; MEYFREDI, J. C. A Copula Approach to Value-at-Risk Estimation for Fixed-Income Portfolios. The Journal of Fixed Income, p. 5-15, verão/2007.

MEMMEL, C. Performance hypothesis testing with the Sharpe ratio. Finance Letters, v. 1, p. 21-23, 2003.

MENDES, B. V. M. Asymmetric extreme interdependence in Latin equity markets. Applied Stochastic Models Bussiness, 2004.

MENDES, B. V. M.; LEAL, R. P. C.; CARVALHAL-DA-SILVA, A. Clustering in emerging equity markets, Journal of Empirical Finance, v.8, 2007.

MENDES, B.V. M.; KOLEV, N. How Long Memory in Volatility Increase Interdependence? International Review of Financial Analysis, v. 17, p. 1070-1086, 2008 .

MEUCCI, A., Risk and Asset Allocation. New York: Springer-Verlag, 2005.

MICHAUD, R. O. The Markowitz optimization enigma: is optimized or optimal?. Financial Analysts Journal, v.45, 1989

MICHAUD, R. O. Efficient asset management: a practical guide to stock portfolio optimization and asset allocation. Harvard Business School Publishing, 1998.

MORETTIN, P. A. Econometria Financeira. São Paulo: Blucher Editora, 2011.

MORETTIN, P. A.; TOLOI, C. M. Análise de Séries Temporais. Editora LTC, 2004.

NETO, C. T.; LEAL, R. P. C.; ALMEIDA, V. S. Índice de mínima variância de ações brasileiras. Revista de Economia Aplicada, v.15, n.4, p. 535-557, 2011.

NELSEN, R. B. An introduction to copulas. New York: Springer-Verlag, 1999.

NING, C. Dependence structure between the equity market and the foreign exchange market-A copula approach. Journal of International Money and Finance, v. 29, p. 743-759, 2010. 
PAGAN, A. The econometrics of financial markets. Journal of Empirical Finance, v. 3, n. 1, p. 15-102, 1996. ISSN 0927-5398.

PATTON, A. On the Out-of-Sample Importance of Skewness and Asymmetric Dependence for Asset Allocation. Journal of Financial Econometrics, v. 2, n. 1, p. 130-168, 2004.

PATTON, A. Modelling Asymmetric Exchange Rate Dependence. International Economic Review, v.47, n.2, p.527-556, 2006.

PARK, C. S.; SHARP-BETTE, G. P. Advanced Engineering Economics. New York: Wiley, 1990.

POON, S. H.; ROCKINGER, M.; TAWN, J. Extreme Value Dependence in Financial Markets: Diagnostics, Models and Financial Applications. The Review of Financial Studies, v. 17, n. 2, p. 581-610, 2004.

PRAUSE, K. The generalized hyperbolic models: Estimation, Financial Derivatives and Risk Management. PhD Thesis, Mathematics Faculty, University of Freiburg, Alemanha, 1999.

RACHEV, S.; MENN, C.; FABOZZI, F. J. Fat-Tailed and Skewed Asset Return Distributions. New Jersey: Wiley, 2005.

RAMCHAND, L.; SUSMEL, R. Volatility and cross correlation across major stock markets, Journal of Empirical Finance, v. 5, p. 397-416, 1998.

ROCKINGER, M.; JONDEAU, E. Conditional dependency of financial series: an application of copulas. Working paper NER \# 82, Banque de France. Paris, 2001.

RODRIGUEZ, J. Measuring Financial Contagion: A Copula Approach. Journal of Empirical Finance, vol. 14, 2007.

SANTOS, R. P. S.; PEREIRA, P. L. Modelando contágio financeiro através de cópulas. Working Paper, 2011.

SCHMIDT, R. Tail dependence for elliptically contoured distributions. Mathematical Methods of Operations Research, v. 55, 2002. 
SECURATO, J. R. Decisões Financeiras em Condições de Risco. São Paulo: Saint Paul Editora, 2009.

SHARPE, W. F. Capital Asset Market Prices: a Theory of Market Equilibrium under Conditions of Risk. The Journal of Finance, v. 19, n. 3, p. 425-442, 1964.

SILVAPULLE, P.; GRANGER, C. W. J. Large returns, conditional correlation and portfolio diversification: a value-at-risk approach. Quantitative Finance, v. 1, p. 542-551, 2001.

SKLAR, A. Fonctions de répartition á n dimensions et leurs marges. Publications de l'Institut de Statistique de l'Université de Paris, v. 8, p 229-2311959.

SOLNIK, B.; BOUCRELIE, C.; LE, Y. F. International Market Correlation and Volatility. Financial Analysts Journal, v.52, p.17-34, 1996.

STAMBAUGH, R.F. Analyzing investments whose histories differ in length. Journal of Financial Economics, v. 45, p. 285-331, 1997.

SUN, W.; RACHEV, S.; FABOZZI, F. Unconditional Copula-Based Simulation of Tail Dependence for Co-Movement of International Equity Markets. Germany: Technical Report, University of Karlsruhe, 2006.

SUN, W.; RACHEV, S., STOYANOV, S. V.; FABOZZI, F. J. 'Multivariate Skewed Student's t Copula in the Analysis of Nonlinear and Asymmetric Dependence in the German Equity Market'. Studies in Nonlinear Dynamics \& Econometrics, v. 12, n. 2, p. 1-35, 2008.

TU, J.; ZHOU, G. F. Markowitz meets Talmud: A combination of sophisticated and naive diversification strategies. Journal of Financial Economics, v. 99, n. 1, p. 204-215, Jan 2011. ISSN 0304-405X. Disponível em: < <Go to ISI >://000284679300012 >.

VON NEUMANN, J.; MORGENSTERN, O. Theory of Games and Economic Behavior. Princeton, NJ: Princeton, 1947. 


\section{Apêndice}

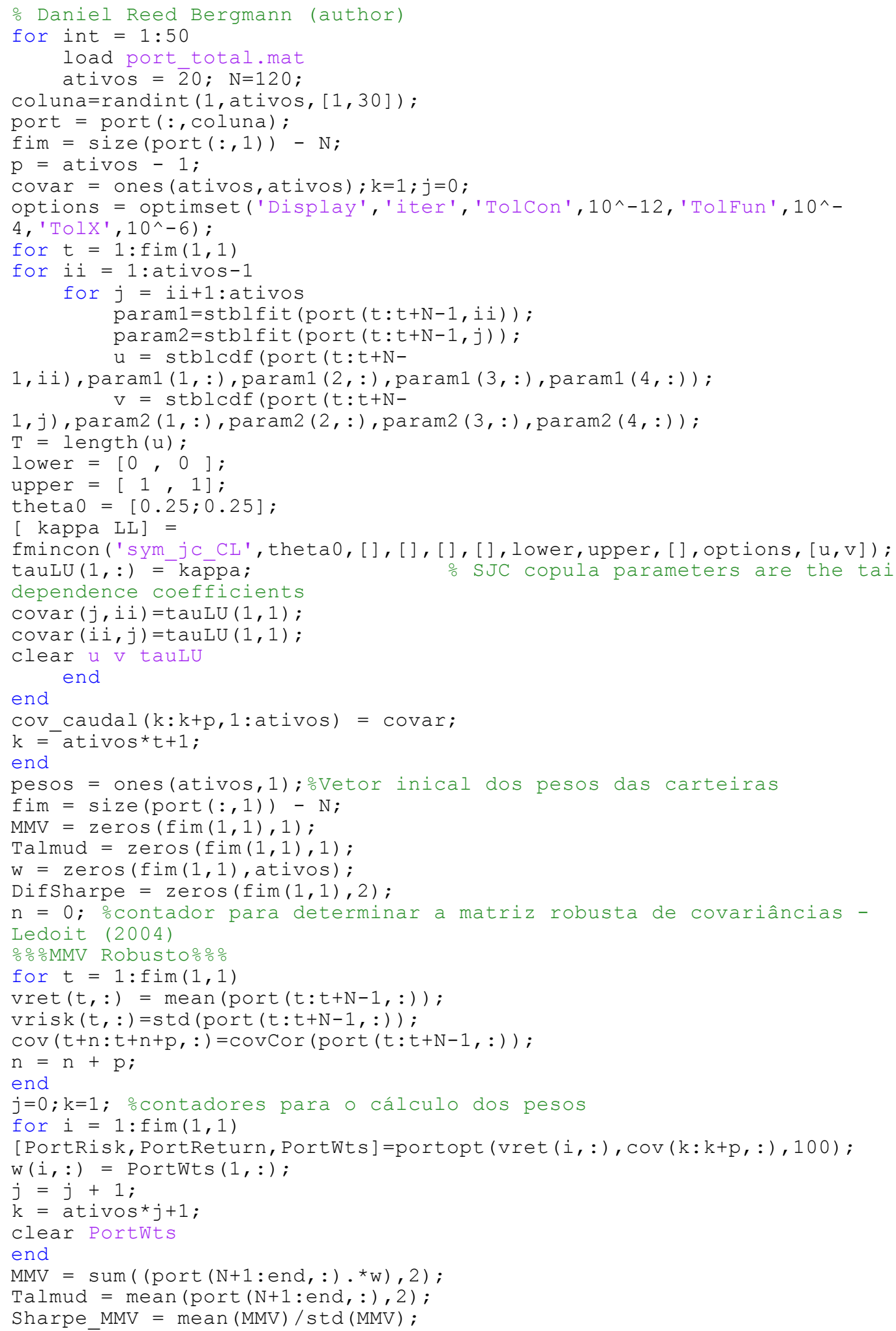




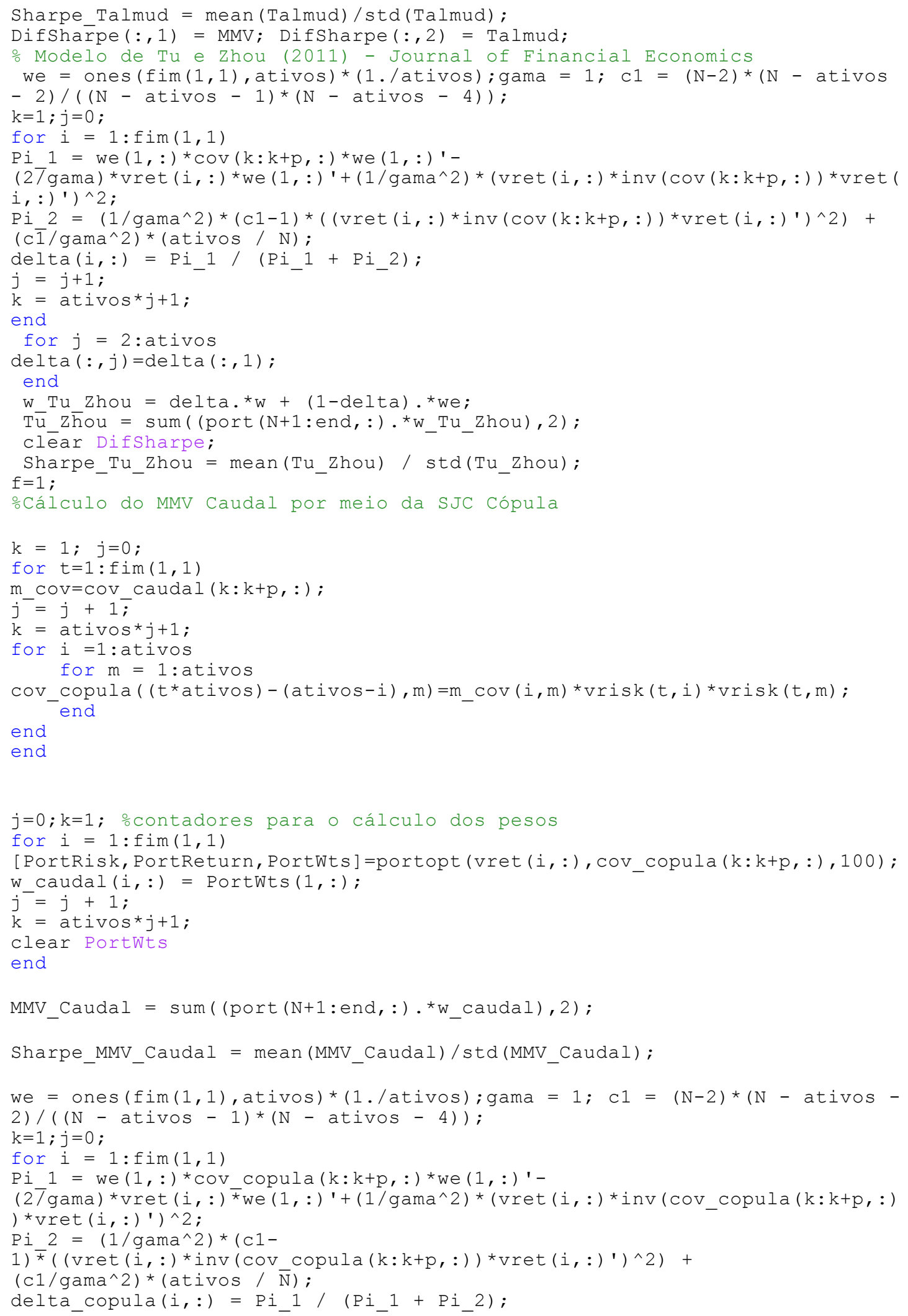




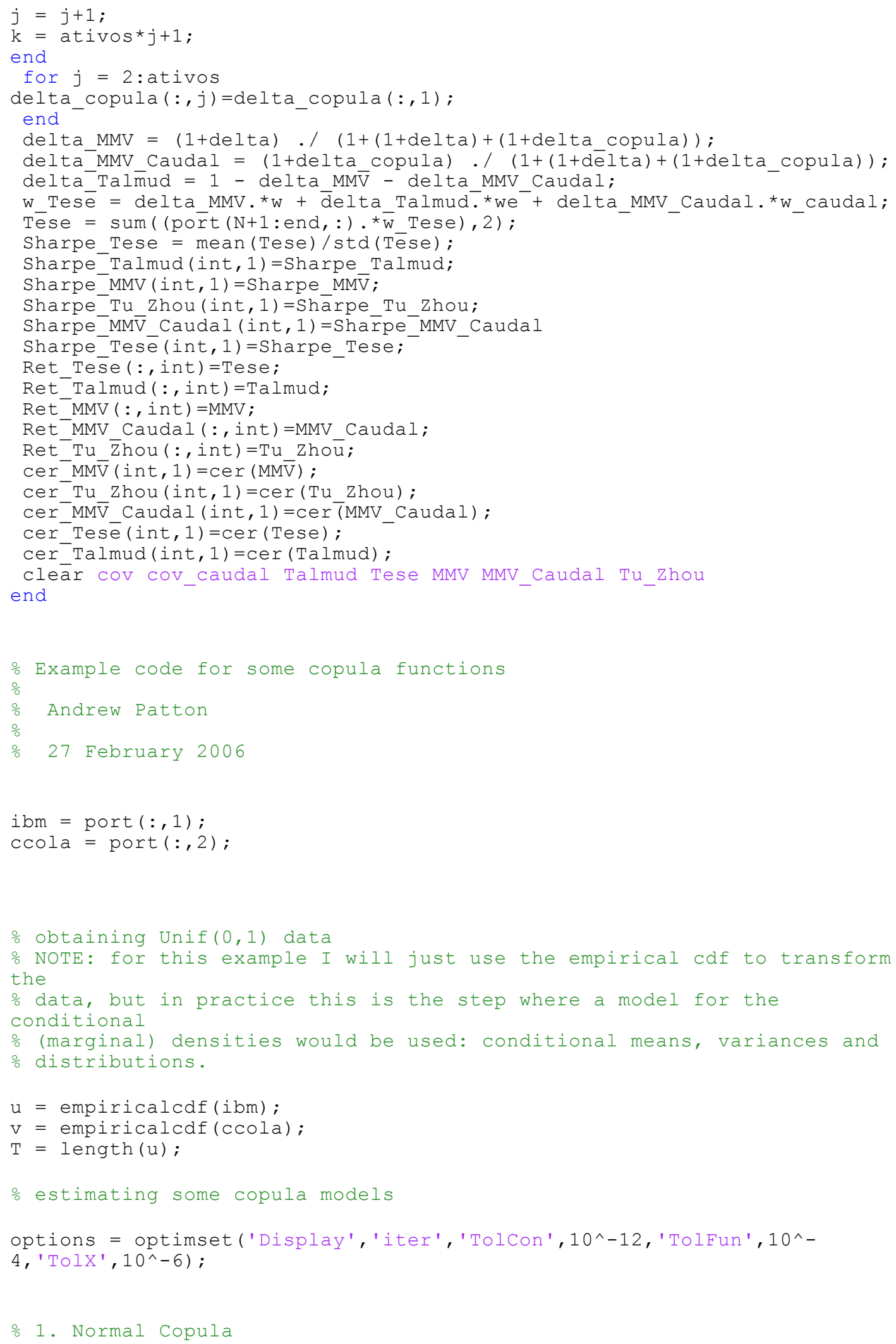


kappal = corrcoefl2 (norminv(u), norminv(v));

LL1 = NormalCopula_CL (kappa1, $[\mathrm{u}, \mathrm{v}])$;

․ 2. Clayton's copula

lower $=0.0001$;

theta 0 = 1

[ kappa2 LL2] =

fmincon ('claytonCL', theta0, [], [], [], [], lower, [], [], options, [u,v]);

\% 3. Rotated Clayton copula (with tail dep in upper tail instead of

lower)

lower $=0.0001$;

theta0 = 1 ;

[ $\operatorname{kappa} 3$ LL3] $=$

fmincon ('claytonCL', theta $0,[],[],[],[]$, lower, [ ], [ ], options, 1-[u, v] ) ;

\% 4. Plackett copula

lower $=0.0001$;

theta 0 =

$[$ kappa4 LL4] $=$

fmincon ('plackettCL', theta0, [], [], [], [], lower, [], [], options, [u,v] );

$\div \operatorname{LL} 5=-3.2721$

․ 5. Frank copula

theta0 = 1

$[\operatorname{kappa} 5$ LL5] $=$

fmincon ('frankCL', theta0, [], [], [], [], lower, [], [], options, [u, v]);

\% 6. Gumbel copula

lower $=1.1$;

theta $0=2$ i

$[$ kappa 6 LL6] $=$

fmincon ('gumbelCL', theta $0,[],[],[],[]$, lower, [ ], [ ], options, [u, v] );

\% 7. Rotated Gumbel copula

lower $=1.1$;

theta0 $=2$;

[ kappa7 LL7] $=$

fmincon ('gumbelCL', theta0, [ ], [ ], [ ], [ ], lower, [ ], [ ], options, 1-[u,v] );

\% 8. Student's t copula

lower $=[-0.9,2.1]$;

upper $=[0.9,100]$

theta $0=[$ kappal; 10$]$;

[ kappa8 LL8] $=$

fmincon ('tcopulaCL', theta0, [], [], [], [], lower, upper, [], options, [u, v] ) ;

ㅇ. 9. Symmetrised Joe-Clayton copula

lower $=[0,0]$;

upper $=[1,1]$;

thetao $=[0.25 ; 0.25]$;

[ kappa9 LL9] =

fmincon('sym_jc_CL', theta0, [], [], [], [], lower, upper, [], options, [u, v] ) ;

$\mathrm{LL}=[\mathrm{LL} 1 ; \mathrm{LL} 2 ; \mathrm{LL} 3 ; \mathrm{LL} 4 ; \mathrm{LL} 5 ; \mathrm{LL} 6 ; \mathrm{LL} 7 ; \mathrm{LL} 8 ; \mathrm{LL} 9] ;$

[ ( 1 : length (LL))', LL]

sortrows ([ (1: length $(\mathrm{LL}))$ ', LL ], 2)

\% optimal copula (in terms of log-likelihood) is one with lowest

likelihood

\% (since we minimise the *negative* LL, rather than maximise the positive

LI )

opt_copula $=$ find $(\mathrm{LL}==\min (\mathrm{LL}))$ 


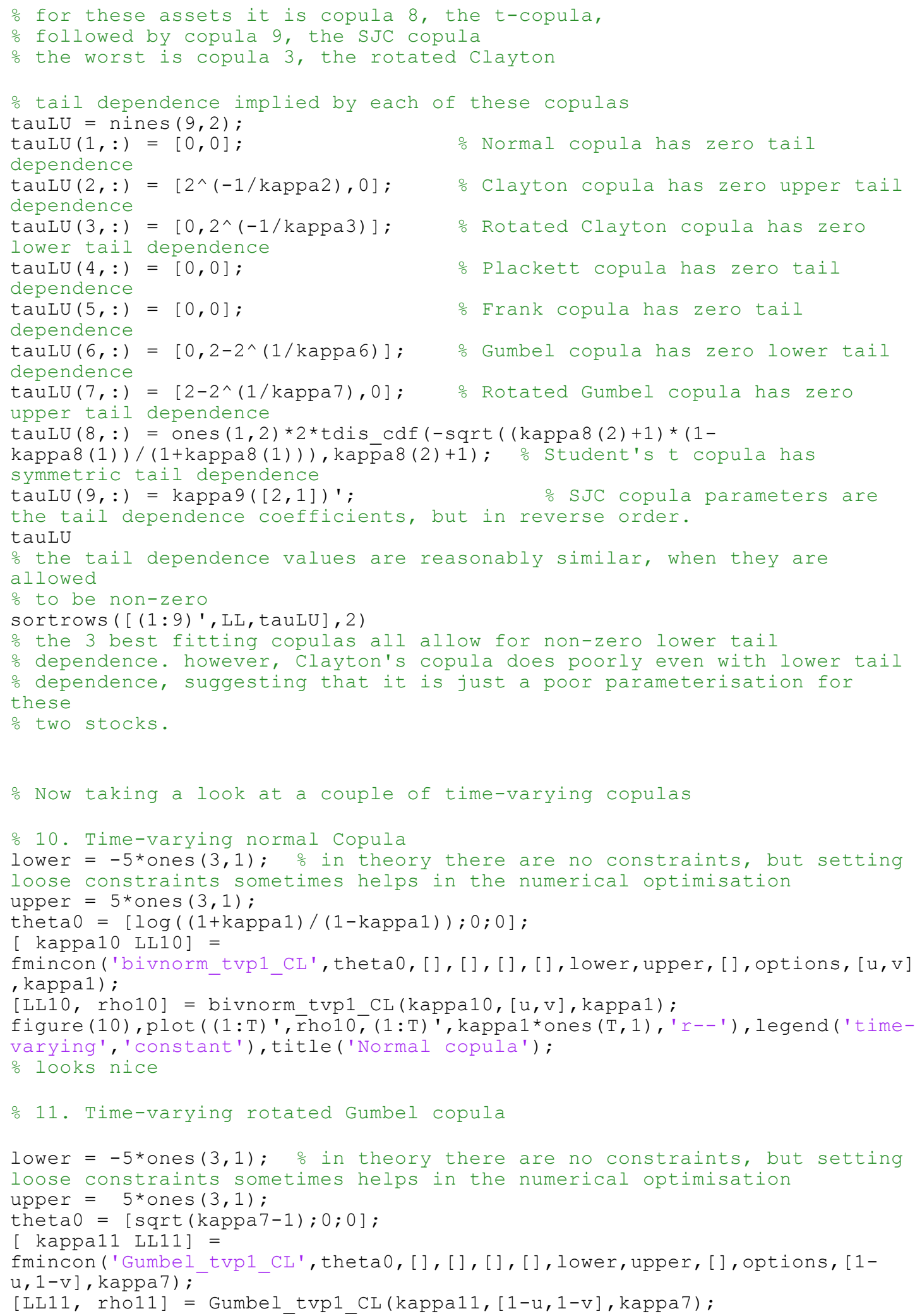


figure(11), plot( (1:T) ', rhol1, (1:T) ', kappa7*ones (T,1), 'r--'), legend('timevarying','constant'), title('Rotated Gumbel copula');

o not so nice: variation in this parameter looks like just noise.

\% 12. Time-varying SJC copula

lower $=-25$ *ones $(6,1)$; $\frac{\circ}{0}$ in theory there are no constraints, but setting loose constraints sometimes helps in the numerical optimisation

upper $=25 *$ ones $(6,1)$

theta $0=[\log (\operatorname{kappa} 9(1) /(1-\operatorname{kappa9}(1))) ; 0 ; 0 ; \log (\operatorname{kappa9}(2) /(1-$

kappa9(2)) );0;0];

[ kappa12 LL12] =

fmincon('sym_jC tvp_CL', theta0, [], [], [], [], lower, upper, [], options, [u, v], k appa9);

[ LL12 tauU12 tauL12] = sym jC tvp CL (kappa12, [u,v], kappa9);

figure (12), subplot $(2,1,1), \operatorname{p} \bar{l}$ ot $\left((1: \bar{T}) ', \operatorname{tauL12},(1: T) ', \operatorname{kappa} 9(2) *\right.$ ones $(T, 1),{ }^{\prime}$ r--'), legend('time-varying', 'constant'), title('SJC copula - lower

tail'), axis $([0, \mathrm{~T}, 0,0.8])$;

subplot $(2,1,2)$, plot $\left((1: T) ', \operatorname{tauU12},(1: T)^{\prime}\right.$ ', kappa9 $(1)$ *ones $(T, 1)$, 'r--

'), legend('time-varying', 'constant'), title('SJC copula - upper

tail'), axis $([0, \mathrm{~T}, 0,0.8])$;

o movement in upper tail dependence seems very noisy, whereas some of the movement in lower tail dependence appears informative.

$\mathrm{LL}=[\mathrm{LL} 1 ; \mathrm{LL} 2 ; \mathrm{LL} 3 ; \mathrm{LL} 4 ; \mathrm{LL} 5 ; \mathrm{LL} 6 ; \mathrm{LL} 7 ; \mathrm{LL} 8 ; \mathrm{LL} 9 ; \mathrm{LL} 10 ; \mathrm{LL} 11 ; \mathrm{LL} 12] ;$

$[(1:$ length $(\mathrm{LL}))$ ', LL]

sortrows ( [ ( 1 : length (LL)) ', LL], 2)

을 rankings:

\% 1 is time-varying SJC copula

\% 2 is time-varying rotated Gumbel

$\div 3$ is constant student's $t$

\% 4 is time-varying Normal

params $=[$ ones $(7,1) ; 2 ; 2 ; 3 ; 3 ; 6] ; \quad$ number of parameters in each model

$\mathrm{AIC}=2 * \mathrm{LL}+2 / \mathrm{T} *$ params;

$B I C=2 * L L+\log (T) / T *$ params;

$\left[(1: \text { length }(\mathrm{LL}))^{\prime}, \mathrm{LL}, \mathrm{AIC}, \mathrm{BIC}\right]$

sortrows ([ ( 1 : length (LL)) ', LL, AIC, BIC ], 2)

sortrows ( [ ( 1 : length (LL)) ', LL, AIC, BIC ] 3$)$

sortrows ( [ ( 1 : length (LL)) ', LL, AIC, BIC $], 4)$

o rankings by AIC and BIC are the same as by log-likelihood ( $T$ is so

large

\% that $\mathrm{k}=1$ vs $\mathrm{k}=6$ does not impose a very large penalty) 